JORGE ALEJANDRO ALVARADO MORA

\title{
MODELAGEM E SIMULAÇÃO DE PLANTA-PILOTO DE VAZÃo
}

Dissertação apresentada à Escola Politécnica da universidade de São Paulo para obtenção do título de Mestre em Ciências.

SÃO PAULO 
JORGE ALEJANDRO ALVARADO MORA

\section{MODELAGEM E SIMULAÇÃO DE PLANTA-PILOTO DE VAZÃO}

Dissertação apresentada à Escola Politécnica da universidade de São Paulo para obtenção do título de Mestre em Ciências.

Área de Concentração: Engenharia de Sistemas

Orientador: Prof. Dr. Claudio Garcia

SÃO PAULO 
Este exemplar foi revisado e alterado em relação à versão original, sob responsabilidade única do autor e com a anuência de seu orientador.

São Paulo, 08 de dezembro de 2014.

Assinatura do autor

Assinatura do orientador

Catalogação-na-publicação

Alvarado Mora, Jorge Alejandro

Modelagem e simulação de planta-piloto de vazão / J.A.

Alvarado Mora. -- versão corr. -- São Paulo, 2014. 116 p.

Dissertação (Mestrado) - Escola Politécnica da Universidade de São Paulo. Departamento de Engenharia de Telecomunicações e Controle.

1.Controle de procesos (Modelagem) 2.Válvulas de controle pneumático I.Universidade de São Paulo. Escola Politécnica. Departamento de Engenharia de Telecomunicações e Controle II.t. 


\section{RESUMO}

Este trabalho dedica-se ao desenvolvimento de um modelo matemático de uma planta piloto de vazão tendo em conta as não linearidades mais significativas no sistema como perdas de carga nos instrumentos e o efeito de atrito nas válvulas de controle. Este efeito foi modelado com procedimentos que foram estudados previamente em outras pesquisas e que neste documento vão ser brevemente descritos. Para realizar a modelagem se usaram valores fornecidos pelos fabricantes dos instrumentos para o modelo ser o mais próximo da realidade. Foram realizados testes comparativos em estado transitório e estacionário para avaliar e validar o desempenho do modelo e propor futuras melhorias que podem ser realizadas no modelo e na planta.

Palavras-chave: Modelagem de processos. Válvulas de controle. Modelos de Atrito. Controle de Processos. 


\begin{abstract}
This work will develop a mathematic model of a flow pilot plant taking into account the most significant non-linearities in the system as load loses in the instruments and the effect of friction in the control valves. This effect was modeled with procedures that were studied in other researches and they will be briefly described. The modeling work was done using the values supplied by the manufacturers for the model to be as close to reality. Comparative tests were performed, on transient and steady-state in order to evaluate and validate the performance of the model and propose future improvements that can be made in the model and the plant.
\end{abstract}

Keywords: Process vodeling. Control valves. Friction model. Process Control. 


\section{LISTA DE TABELAS}

Tabela 2-1 Quantidade de singularidades na Planta de Vazão

Tabela 2-2 Conexões do sistema ABB.

Tabela 2-3 Conexões do CLP Rockwell SLC 500. .33

Tabela 3-1 Equivalência das singularidades em metros de tubulação 35

Tabela 3-2 Valores de Cv para diferentes valores de abertura da válvula 40

Tabela 3-3 $C v$ para a válvula de perturbação 42

Tabela 3-4 Dados da Curva Manométrica da Bomba .47

Tabela 3-5 Erro na rotação da Bomba 49

Tabela 3-6 Resultados obtidos em (CASTRO, 2013). 59

Tabela 3-7 Resultados obtidos dos parâmetros de Karnopp. 60

Tabela 3-8 Resultados obtidos pelo método de identificação de Kano 63

Tabela 3-9 Refinamento dos parâmetros obtidos em (CASTRO, 2013).

Tabela 3-10 Melhores índices de desempenho para cada tipo de sinal. 69

Tabela 3-11 Índice de ajuste para cada um dos sinais testados. 69

Tabela 3-12 Sintonia dos controladores PI. 71

Tabela 4-1 Comportamento estático para diferentes valores de rotação da bomba. 77

Tabela 4-2 Comportamento estático da vazão para diferentes valores de abertura na válvula com gaxetas de Teflon. 79

Tabela 4-3 Comportamento da vazão aplicando diferentes valores de abertura na válvula com gaxetas de grafite 
Tabela 4-4 Resultados obtidos com o medidor de ultrassom.

Tabela 4-5 Comportamento dinâmico da vazão para um sinal em degrau na rotação da

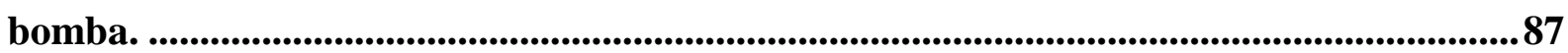

Tabela 4-6 Comportamento dinâmico da válvula com gaxetas de teflon aplicando um sinal degrau. 90

Tabela 4-7 Comportamento dinâmico da válvula com gaxetas de grafite aplicando sinais em degrau 


\section{LISTA DE FIGURAS}

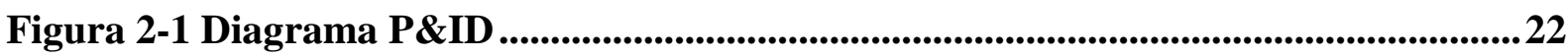

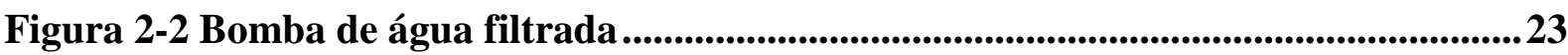

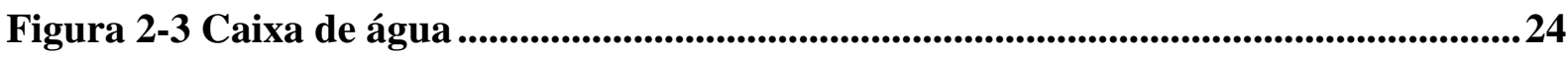

Figura 2-4 Tubulações de PVC ..................................................................................................................24

Figura 2-5 Placa de orifício......................................................................................................................25

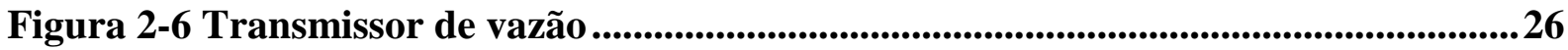

Figura 2-7 (a) Válvula com gaxetas de teflon. (b) Válvula com gaxetas de grafite .......27

Figura 2-8 Curva Cv da válvula de controle ..........................................................................28

Figura 2-9 Válvula de perturbaçãão......................................................................................................... 28

Figura 2-10 Cv Válvula de Perturbação................................................................................................29

Figura 2-11 Válvula solenoide...............................................................................................29

Figura 2-12 Características das Válvulas Solenoide. .....................................................30

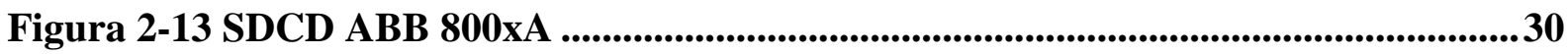

Figura 2-14 Tela de operação da Planta de vazão .....................................................................32

Figura 2-15 CLP Rockwell SLC 500...........................................................................................32

Figura 3-1 Bloco Lookup Table (DPtub x Qtub) ........................................................37

Figura 3-2 Modelo de perda de carga nas tubulações ..................................................................37

Figura 3-3 Perda de carga nas válvulas solenoide ..........................................................38

Figura 3-4 Lookup Table para as válvulas de controle..................................................41

Figura 3-5 Curva de Cv das válvulas de controle...................................................................41

Figura 3-6 Modelo de perda de carga para as válvulas de controle .................................42

Figura 3-7 Curva do Cv para a válvula de perturbação.........................................................43 
Figura 3-8 Modelo em MATLAB® para a válvula de perturbação 43

Figura 3-9 Placa de orifício desmontada 44

Figura 3-10 Modelo de perda de carga permanente na placa de orifício. .45

Figura 3-11 Curva Característica da Bomba 46

Figura 3-12 Curva Característica da bomba gerada em MATLAB® 47

Figura 3-13 Curva característica da bomba para $80 \%$ e $100 \%$ da rotação nominal .......49

Figura 3-14 Modelo para a Bomba 50

Figura 3-15 Modelo da perda de pressão gerada na placa de orifício. 51

Figura 3-16 Modelo do Medidor de Vazão. 52

Figura 3-17 Curva de Assinatura padrão de uma válvula de controle com efeito do stiction 53

Figura 3-18 Pressão da válvula com gaxetas de teflon. 55

Figura 3-19 Posição da haste da válvula com gaxetas de teflon.....................................56

Figura 3-20 Pressão na válvula com gaxeta de Grafite.........................................................56

Figura 3-21 Posição da haste da válvula com gaxeta de Grafite .............................................57

Figura 3-22 Assinatura da válvula com gaxetas de teflon. .............................................57

Figura 3-23 Assinatura da válvula com gaxetas de grafite..............................................58

Figura 3-24 Validação do modelo de Karnopp na válvula com gaxetas de teflon ...........60

Figura 3-25 Validação do modelo de Karnopp na válvula com gaxetas de grafite 61

Figura 3-26 Comparação da assinatura real e simulada da válvula com gaxetas de teflon

Figura 3-27 Comparação da assinatura real e simulada da válvula com gaxetas de grafite

Figura 3-28 Validação dos parâmetros de Kano na válvula com gaxetas de teflon. 64

Figura 3-29 Validação dos parâmetros de Kano na válvula de Grafite 64 
Figura 3-30 Assinatura da válvula com gaxetas de teflon com os parâmetros obtidos.... 65 Figura 3-31 Assinatura da válvula com gaxetas de grafite com os parâmetros obtidos..65 Figura 3-32 Estrutura do modelo OE. 66

Figura 3-33 Sinal GBN. 67

Figura 3-34 Sinal Random Number. 68

Figura 3-35 Trecho do sinal senoidal de entrada. 68

Figura 3-36 Índice de ajuste para o sinal senoidal. 70

Figura 3-37 Degrau aplicado no atuador .70

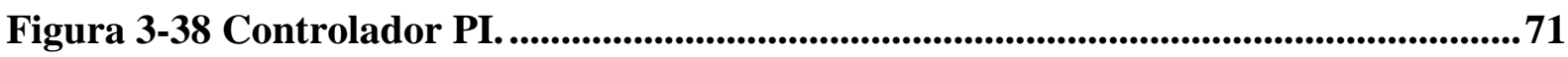

Figura 3-39 Modelo geral da perda de carga na Planta de Vazão ....................................72

Figura 3-40 Modelo da Bomba Centrífuga e do Medidor de Vazão................................. 73

Figura 3-41 Modelos de Atrito de Kano + Atuador. ....................................................................74

Figura 3-42 Modelo Geral da Planta de Vazão....................................................................... 75

Figura 4-1 (a) Inversor de frequência Siemens SINAMIC G110, (b) Tela de configurações do inversor/bomba. ............................................................................77

Figura 4-2 Peças internas da válvula com gaxetas de Grafite .........................................80

Figura 4-3 Esquema para validar o valor de $\mathrm{Cv}$ das válvulas...........................................81

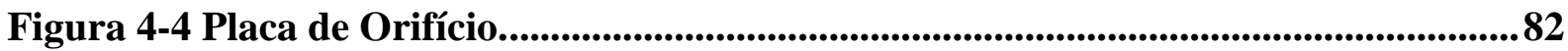

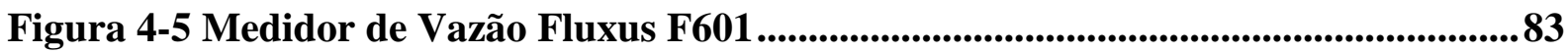

Figura 4-6 Funcionamento do Medidor de Vazão Fluxus F601 ..........................................83

Figura 4-7 Funcionamento do Medidor de Vazão Fluxus F601 ............................................84

Figura 4-8 Resposta dinâmica da vazão para um sinal degrau de $50 \%$ para $80 \%$...........86

Figura 4-9 Função de transferência para sistemas de primeira ordem.............................86 
Figura 4-10 Resultados da vazão aplicando-se um degrau de $80 \%$ para $90 \%$ na rotação da bomba.

Figura 4-11 Resultados da vazão aplicando-se um degrau de $80 \%$ para $70 \%$ na rotação da bomba.

Figura 4-12 Comportamento da vazão aplicando um degrau de 50\% para $0 \%$ na válvula com gaxetas de teflon...............................................................................................90

Figura 4-13 Comportamento da vazão aplicando um degrau de $0 \%$ para $50 \%$ na válvula

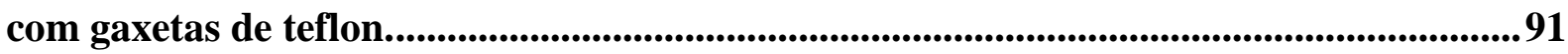

Figura 4-14 Comportamento da vazão aplicando um degrau de $0 \%$ para 50\% na válvula com gaxetas de grafite ....................................................................................................................93

Figura 4-15 Comportamento da vazão aplicando um degrau de 50\% para $0 \%$ na válvula com gaxetas de grafite .......................................................................................................................................93

Figura 4-16 Acompanhamento do set-point da válvula com gaxetas de teflon ...................95

Figura 4-17 Sinal de controle................................................................................................95

Figura 4-18 Acompanhamento do set-point da válvula com gaxetas de grafite................96

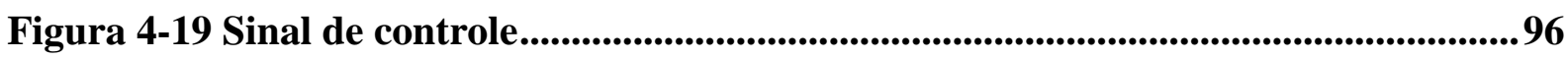

Figura 4-20 Acompanhamento do set-point da válvula com gaxetas de Teflon.................97

Figura 21 Sinal de Controle...........................................................................................................................97

Figura 4-22 Acompanhamento do set-point da válvula com gaxetas de Grafite................98

Figura 4-23 Sinal de Controle.....................................................................................................98 


\title{
LISTA DE SIMBOLOS E ABREVIAÇÕES
}

\author{
AI Analog Input \\ AO Analog Output \\ C Coeficiente de descarga que depende da geometria da placa de \\ orifício. \\ CLP Controlador Lógico Programável. \\ $C v \quad$ Coeficiente de vazão relacionado com a geometria da válvula. \\ Cvrel Coeficiente de vazão relacionado com a posição da haste. \\ d Diâmetro da placa de orifício. \\ D Diâmetro interno da tubulação. \\ DI Digital Input. \\ DO Digital Output. \\ DP Diferença de pressão gerada pelo atrito viscoso. \\ E $\quad$ Fator de velocidade de aproximação na placa de orifício. \\ $F_{\text {atrito }} \quad$ Força de atrito atuando na haste da válvula. \\ Fc Coeficiente de atrito de Coulomb. \\ $F_{\text {dinâmico }} \quad$ Força de atrito dinâmico. \\ $F_{\text {fluido }} \quad$ Força aplicada pelo fluido do processo sobre o obturador da haste. \\ $\mathrm{Fi} \quad$ Força de assentamento do obturador na sede da válvula. \\ FIT Flow Indicator Transmitter. \\ $F_{\text {mola }} \quad$ Força aplicada pela mola. \\ Fp Fator geométrico da tubulação que se considera quando as válvulas \\ são montadas entre redutores. \\ $F_{\text {pressão }} \quad$ Força aplicada pela pressão de ar no atuador da válvula. \\ Fs $\quad$ Coeficiente de atrito estático. \\ Fv $\quad$ Coeficiente de atrito viscoso. \\ FV Flow Valve. \\ $g \quad$ Aceleração da gravidade. \\ $G_{f} \quad$ Densidade relativa do fluido. \\ $h \quad$ Altura do ponto da tubulação.
}




\begin{tabular}{|c|c|}
\hline$H$ & Altura manométrica. \\
\hline$H S$ & Hand Switch. \\
\hline$J$ & Banda de agarramento Slip-jump. \\
\hline$K p$ & Ganho do processo. \\
\hline$K v$ & Coeficiente de vazão usado em países que utilizam sistema métrico. \\
\hline$L$ & Comprimento de tubulação. \\
\hline LSH & Level Sensor High. \\
\hline$L S L$ & Level Sensor Low. \\
\hline$N$ & Fator de ajuste de unidades. \\
\hline$N$ & Rotação da Bomba \\
\hline$P$ & Pressão. \\
\hline$P \& I D$ & Piping and Instrumentation Diagram. \\
\hline$P I D$ & Proporcional Integral Derivativo. \\
\hline$Q$ & Vazão volumétrica da planta. \\
\hline$S$ & Banda morta mais banda de agarramento. \\
\hline$S_{a}$ & Área do diafragma do atuador da válvula. \\
\hline$S D C D$ & Sistema Digital de Controle Distribuído. \\
\hline $\mathrm{Ti}$ & Tempo de integração do controlador. \\
\hline$v$ & Velocidade do fluido. \\
\hline$v_{s}$ & Velocidade de Stribeck. \\
\hline$\beta$ & Relação dos diâmetros $d / D$ entre o diâmetro interno da tubulação. \\
\hline$\Delta P$ & Pressão diferencial. \\
\hline$\rho$ & Massa específica do fluido. \\
\hline
\end{tabular}




\section{SUMARIO}

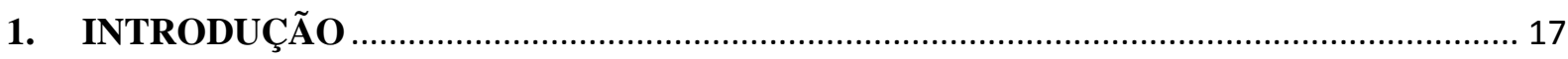

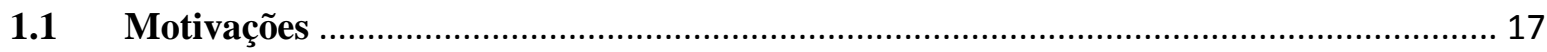

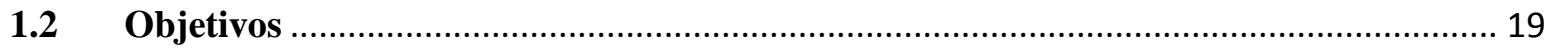

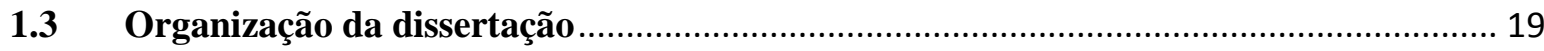

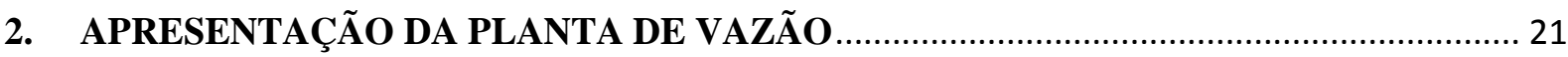

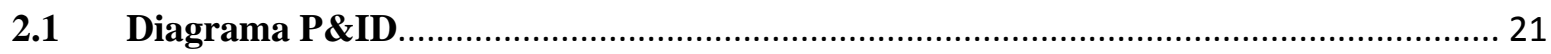

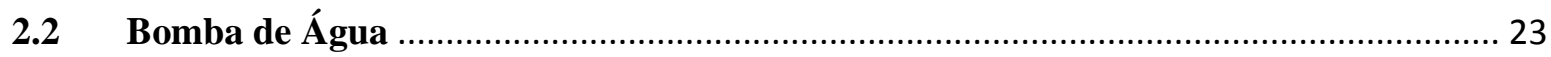

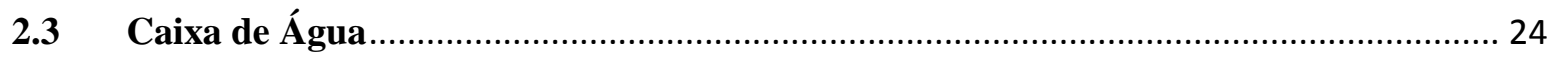

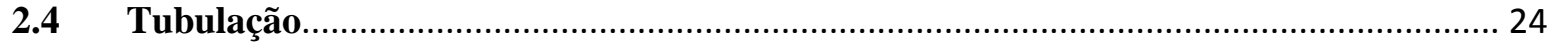

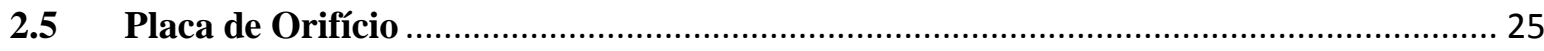

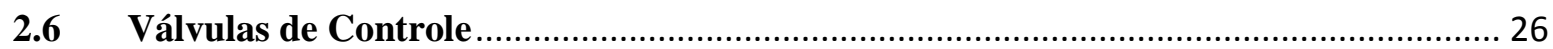

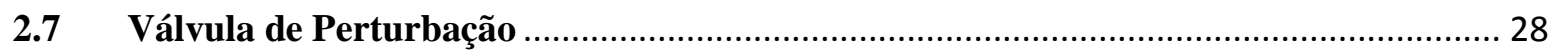

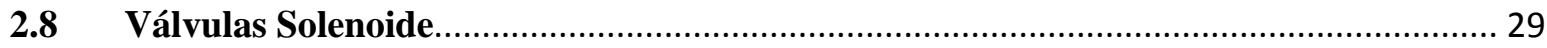

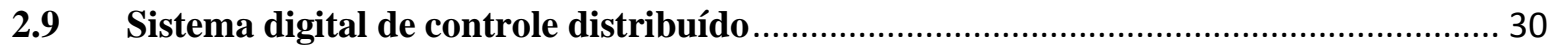

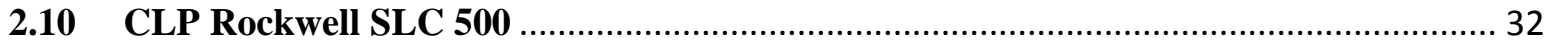

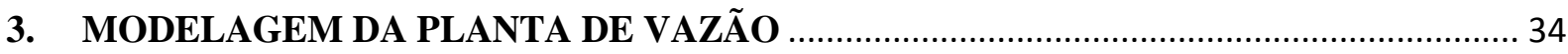

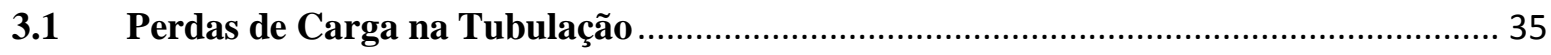

3.2 Perda de Carga nas Válvulas Solenoide ................................................................. 38

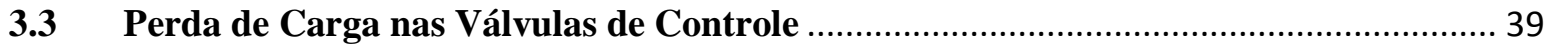

3.4 Perda de Carga na Válvula de Perturbação ….......................................................... 42

3.5 Perda de Carga Permanente na Placa de Orifício ....................................................... 44

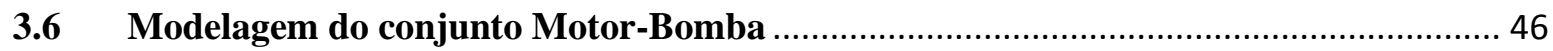

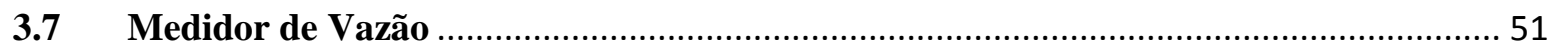




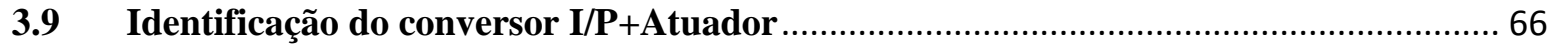

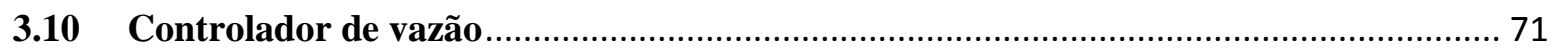

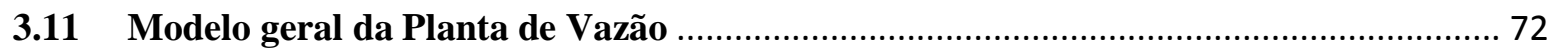

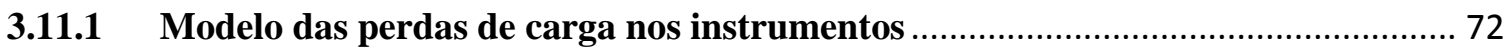

3.11.2 Modelo da bomba centrífuga e medidor de vazão............................................... 73

3.11.3 Modelos de atrito para as válvulas de controle ........................................................ 73

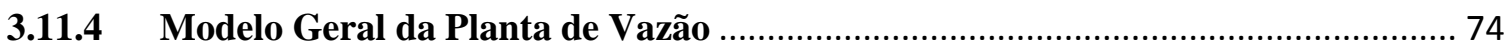

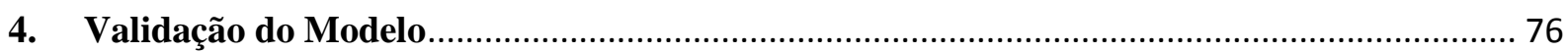

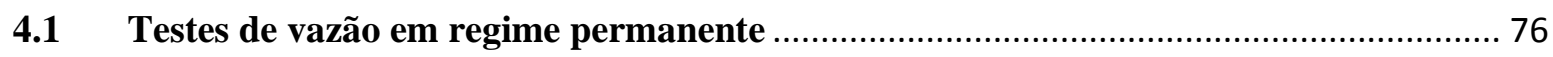

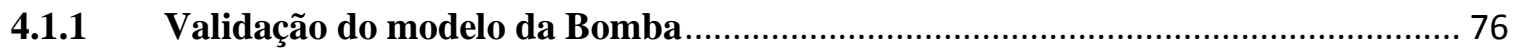

4.1.2 Validação do modelo da válvula com gaxetas de Teflon ........................................ 78

4.1.3 Validação do modelo da válvula com gaxetas de grafite.......................................... 79

4.2 Comportamento da vazão em regime transitório ....................................................... 85

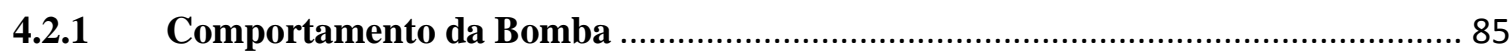

4.2.2 Comportamento dinâmico das válvulas de controle ............................................. 89

4.2.3 Comportamento dinâmico da válvula com gaxetas de grafite ............................... 92

4.3 Validação do controle e variabilidade do processo …................................................... 94

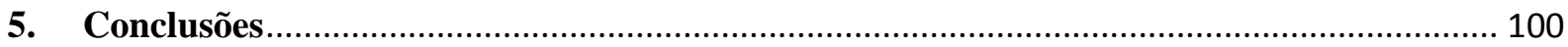

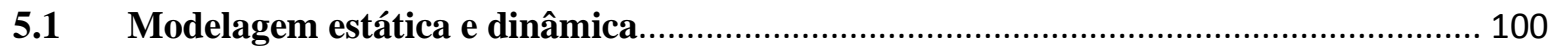

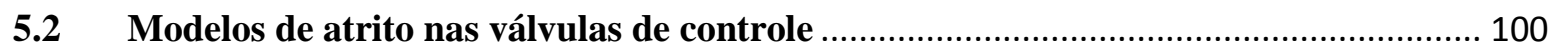

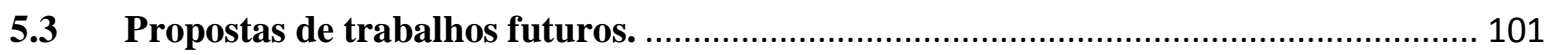

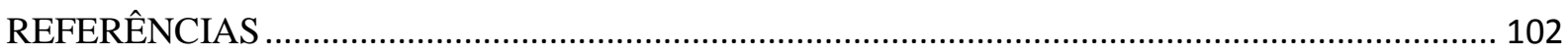

ANEXO A - Loop Diagrams da Planta de Vazão ........................................................................... 106

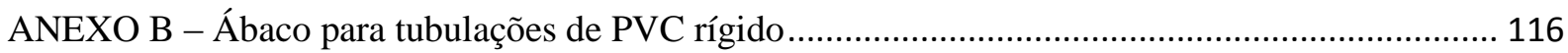




\section{INTRODUÇÃO}

\subsection{Motivações}

$\mathrm{Na}$ época dos anos 40, as indústrias trabalhavam quase manualmente, sendo necessários muitos operadores para poder ter um bom controle do processo. Com os avanços tecnológicos, os equipamentos ficaram cada vez mais difíceis de operar, sendo quase impossível ter uma planta sem controladores automáticos para controlar as variáveis mais críticas. No final da década de 1960, os engenheiros começaram a aplicar técnicas de controle nos processos, para ter cada vez mais variáveis da planta unificadas em uma única unidade de controle, incluindo todas as interações e todas as estratégias para controlar a planta. Esta técnica foi chamada de system engineering (LUYBEN,1990).

Para poder descrever matematicamente os sistemas reais, é necessário ter conhecimento dos conceitos básicos de modelagem e ser capaz de determinar a resposta dinâmica do sistema, para dessa forma poder resolver problemas relacionados a eles. Daí surgiram muitas técnicas de modelagem de sistemas físicos que, dependendo do objetivo de estudo ou da complexidade do processo, são utilizadas. Uma destas técnicas é chamada de modelo caixa branca (AGUIRRE, 2007), em que é necessário conhecer muito bem o sistema. A base para construir o modelo é fazer uma descrição deste, a partir das leis da Física, as quais, dependendo da aplicação, têm diferentes equações, mas a maioria estão baseadas nas leis da conservação de massa e energia.

Dentro do estudo de modelagem, existem aplicações que incluem vazão, as quais estão em todo tipo de indústria, por exemplo, nas indústrias petroquímicas, onde uma das principais preocupações é a perda gerada por diversos fatores, tal como manutenção da instrumentação. Por isto, as empresas têm avançado muito em obter modelos computacionais para aumentar a produção e fazer testes, para desta forma diminuir a quantidade de paradas na planta.

O Laboratório de Controle de Processos Industriais (LCPI), que faz parte da Escola Politécnica da Universidade de São Paulo, possui uma Planta de Vazão, emulando um ambiente industrial, a qual é utilizada para realizar experimentos diversos, envolvendo os 
principais conceitos da Engenharia de Automação e Controle, para familiarizar os estudantes com o uso de instrumentos muito comuns na indústria.

Muitas pessoas que fazem testes nessa planta não têm muita experiência na manipulação de processos industriais, o que pode danificar os instrumentos que estão presentes. Por exemplo, ao colocar muita pressão nas tubulações isto pode rompê-las, por isto foi estudada a viabilidade de fazer um modelo computacional da planta e, devido à disponibilidade dos computadores presentes no laboratório, foi considerada viável a ideia de gerar um modelo dinâmico da mesma, no qual seja possível fazer ensaios antes de realizar testes na prática. Por outro lado, ter um modelo é uma boa ferramenta para fazer diagnóstico e detecção de possíveis problemas na planta, já que ele tem a facilidade de poder isolar componentes e realizar testes.

Para começar o trabalho de modelagem é necessário fazer um estudo das não linearidades do sistema e ter em conta as mais significativas no processo. Por isso é fundamental trabalhar com os valores dados pelos fabricantes de cada um dos instrumentos presentes na planta. Isto ajuda o modelo a ser o mais próximo da realidade.

O sistema de controle da planta de vazão possui um controlador proporcional-integral para manter a vazão em um valor desejado variando a abertura da válvula. Para fazer uma modelagem mais precisa da planta é necessário ter em conta o atrito que as válvulas possuem e aplicar um método para modelar estes valores de atrito.

Em trabalhos realizados na Planta de Vazão, foram testadas técnicas de compensação de atrito em válvulas de controle. Foram aplicados dois modelos, o primeiro proposto em (KANO et al; 2004), o qual necessita de dois coeficientes relacionados ao atrito e está baseado na análise de dois sinais, a posição da haste da válvula e da saída do controlador. E o segundo, o modelo de Karnopp (KARNOPP, 1985) o qual se baseia em três parâmetros de forças de atrito. Estes modelos foram descritos e testados em (GARCIA, 2008) e posteriormente validados no trabalho de (CASTRO, 2013). 


\subsection{Objetivos}

O principal objetivo deste projeto é desenvolver um modelo matemático da Planta de Vazão, que seja capaz de representar as perdas de carga em cada um dos instrumentos da planta, e modelar o comportamento da bomba hidráulica e das válvulas de controle, para depois ser representados em valores de vazão. Este objetivo conduz aos seguintes objetivos específicos:

- Realizar uma descrição dos principais equipamentos que influem no processo e que vão ser modelados.

- Encontrar as equações que descrevem de melhor forma a perda de carga dos equipamentos para obter o valor de vazão medida final.

- Modelar o efeito de atrito nas válvulas de controle.

- Implementar o modelo no software Matlab ${ }^{\circledR}$ disponível no Laboratório de Automação e Controle.

- A partir de ensaios experimentais, fazer comparações dos resultados estáticos e dinâmicos obtidos no modelo com dados obtidos diretamente da Planta de Vazão.

- Implementar os modelos de atrito mencionadas anteriormente e verificar os resultados no modelo realizado.

\subsection{Organização da dissertação}

A dissertação está organizada em 6 capítulos. O primeiro capítulo apresenta os objetivos do projeto, e as motivações que levaram ao desenvolvimento do mesmo.

O capítulo 2 apresenta a descrição da Planta de Vazão e dos instrumentos que influem no processo, incluindo alguns dos fatores importantes que vão ser considerados na modelagem do processo.

O capítulo 3 apresenta o procedimento realizado para encontrar as equações que descrevem cada um dos instrumentos que compõem a Planta de Vazão e são apresentados os modelos implementados em MATLAB ${ }^{\circledR}$ e Simulink $^{\circledR}$. 
O capítulo 4 apresenta os testes feitos para a validação do modelo, mudando a rotação da bomba, abertura das válvulas e dos controladores, comparando com dados experimentais coletados na Planta de Vazão.

O capítulo 5 apresenta as conclusões deste trabalho e são sugeridos os próximos passos a serem seguidos nesta linha de pesquisa. 


\section{APRESENTAÇÃO DA PLANTA DE VAZÃO}

A Planta de Vazão do Laboratório de Controle de Processos Industriais foi projetada para o estudo de técnicas de estimação e compensação de atrito em válvulas de controle, simulando um processo real, com o objetivo de pesquisar soluções para tornar o processo produtivo industrial mais eficiente e sustentável.

Os equipamentos que a planta possui são muito comuns na indústria, tais como válvulas de controle, sensores, atuadores etc. Neste capítulo é feita uma descrição geral dos equipamentos mais importantes para a modelagem do processo.

\subsection{Diagrama P\&ID}

O P\&ID (Piping \& Instrumentation Diagram) da Figura 2-1 contém as malhas da planta com seus equipamentos.

A caixa de água possui dois sensores de nível, um de nível alto (LSH-18) e outro de nível baixo (LSL-18), os quais são utilizados para avisar quando o nível de água está muito alto ou muito baixo. Além disso, a caixa tem uma válvula de tipo ON-OFF (FV-38) que habilita a entrada de água filtrada.

FV-14 e FV-16 são também válvulas do tipo ON-OFF que habilitam a entrada e saída de água no processo, as quais podem ser ativadas nas telas do sistema supervisório ou manualmente pelas chaves HS-14 e HS-16. A válvula FV-15, também de tipo ON-OFF, é usada para esvaziar a planta quando se quer fazer manutenção nas tubulações ou para fazer limpeza da caixa de água, é acionada por meio de uma chave disponível no painel da planta (HS-15).

A vazão é controlada pelo sistema bomba-inversor. O inversor mantém uma rotação constante no motor, a qual por segurança está entre $30 \%$ e $80 \%$ da rotação máxima. O sinal que é enviado ao inversor pode vir do SDCD ou diretamente por um potenciômetro disponível no CLP os dois podem-se encontrar no painel da planta. 
Figura 2-1 Diagrama P\&ID

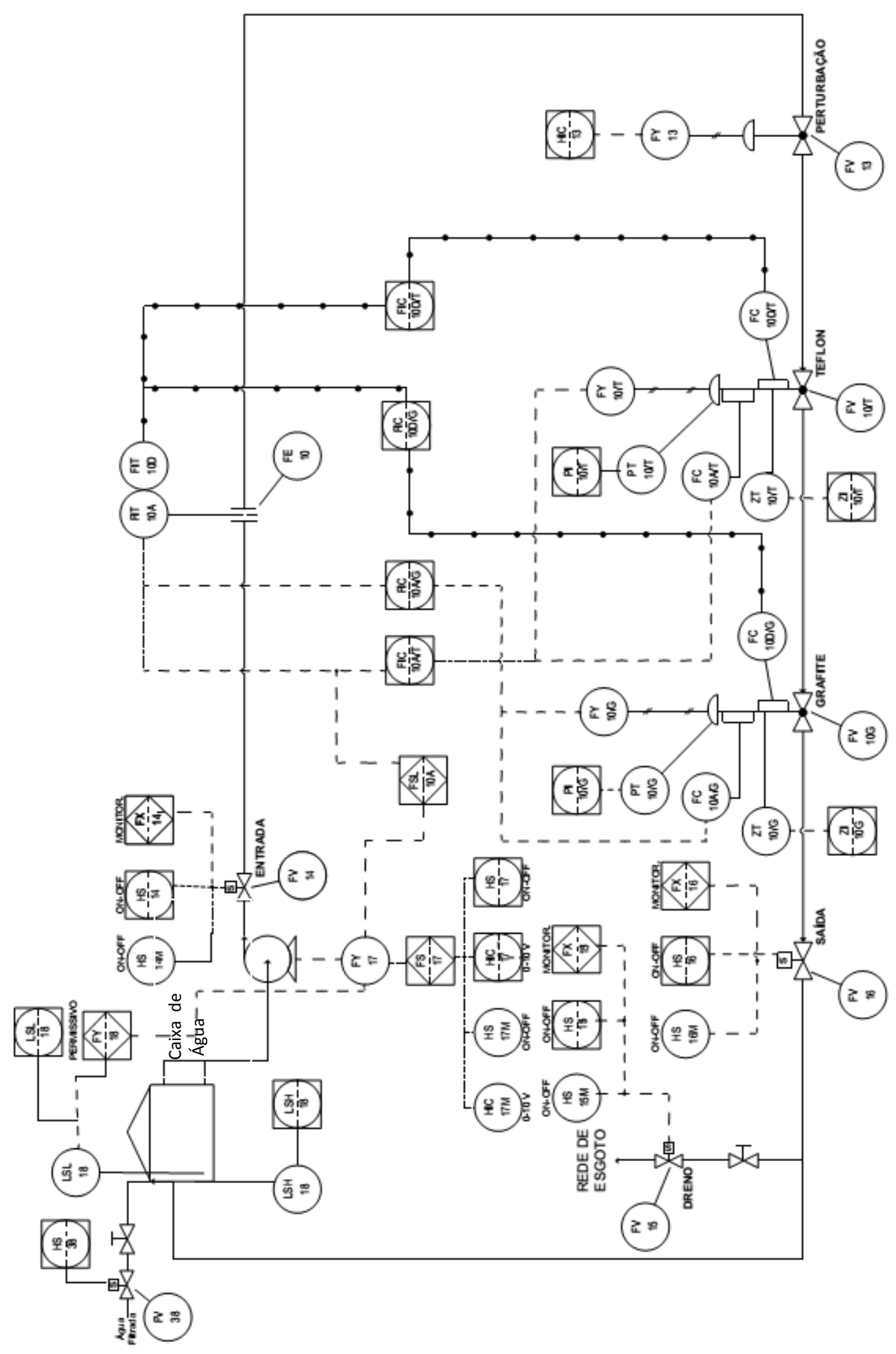

Fonte: Autor. 
A placa de orifício (FE-10) gera o valor de pressão diferencial e a vazão é transmitida por meio dos transmissores. A planta possui dois transmissores, um digital (FIT-10D) e um analógico (FIT-10A), eles medem a vazão e enviam sinais para o painel, o transmissor digital transmite por meio do protocolo Foundation Fieldbus e o analógico por meio de sinal 4$20 \mathrm{~mA}$.

As válvulas com gaxetas de teflon $(\mathrm{FV}-10 / \mathrm{T})$ e grafite $(\mathrm{FV}-10 / \mathrm{G})$ podem ser operadas de três formas: analógica pelo conversor I/P (FY-10/T para teflon, FY-10/G para grafite), digital pelo posicionador digital (FC-10D/T para teflon, FC-10D/G para grafite) ou pelo posicionador eletropneumático (FC-10A/T para teflon, FC-10A/T para grafite).

No anexo A podem-se encontrar os Loop Diagrams das malhas que utilizadas na planta.

\subsection{Bomba de Água}

A bomba de água apresentada na Figura 2-2, do tipo centrífuga, é responsável pelo bombeamento da água para toda a linha do processo. O motor é controlado por um inversor de frequência, o qual é comandado pelo SDCD existente no laboratório ou controlado manualmente por meio de um potenciômetro, permitindo fazer um controle da velocidade da água que circula pela linha.

Figura 2-2 Bomba de água filtrada

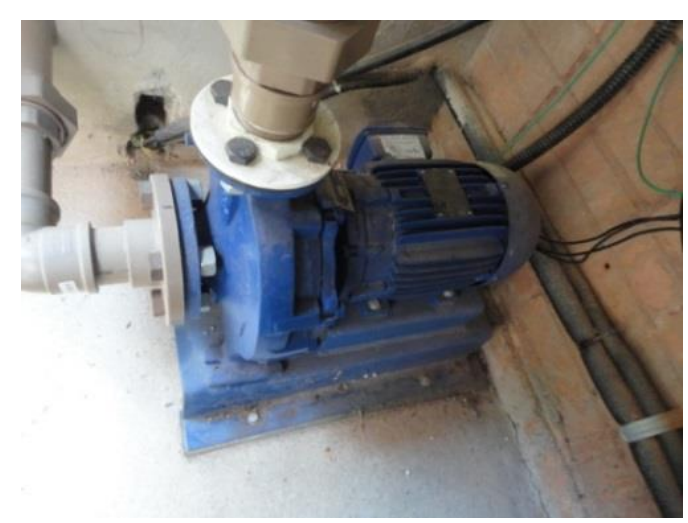

Fonte: Autor.

O motor é de quatro polos e $60 \mathrm{~Hz}$, o fabricante da bomba é a KSB, modelo MEGABLOC e tem uma rotação nominal de $1725 \mathrm{rpm}$. 


\subsection{Caixa de Água}

A caixa de água é o ponto mais elevado do processo e armazena toda a água que circula nas tubulações, gerando um circuito fechado e garantindo que a linha sempre esteja cheia de água.

Na Figura 2-3 é apresentada a caixa fabricada pela Amanco. Com capacidade de 1000 litros.

Figura 2-3 Caixa de água

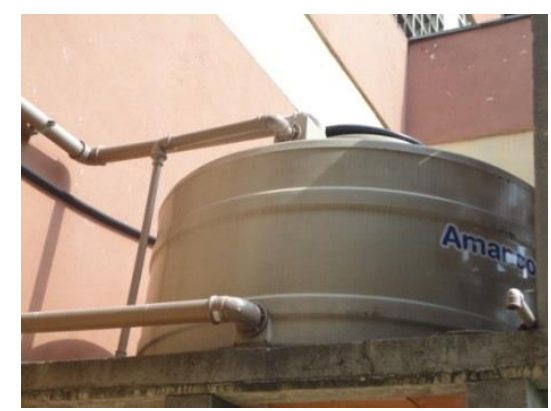

Fonte: Autor.

\subsection{Tubulação}

Na Figura 2-4 são mostrados trechos das tubulações que conectam os diferentes equipamentos. Elas são de PVC, com diâmetro externo (DE) de 60mm. Também existem conexões de linha tipo T, curvas e joelhos.

Figura 2-4 Tubulações de PVC
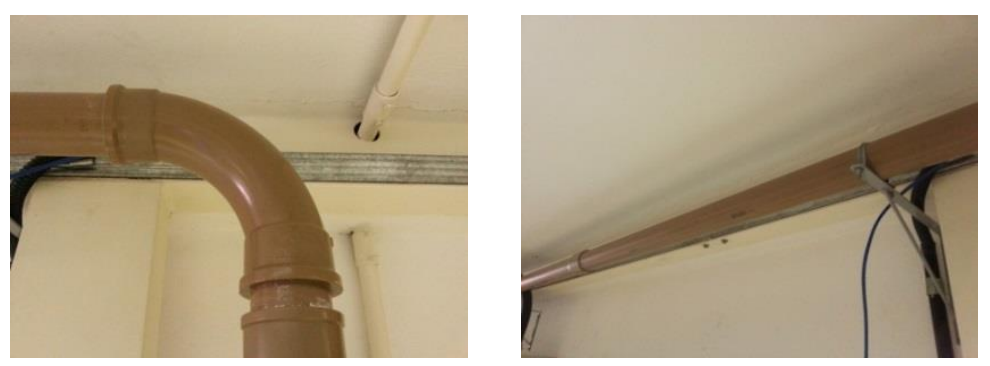

Fonte: Autor. 
A planta possui $34,53 \mathrm{~m}$ de trecho reto de tubulação. Além disso, tem diferentes tipos de singularidades. Na Tabela 2-1 pode-se ver a quantidade de cada tipo.

Tabela 2-1 Quantidade de singularidades na Planta de Vazão

\begin{tabular}{lc}
\hline Singularidade & Quantidade (peças) \\
\hline Joelho $^{\mathbf{9}}$ & 19 \\
Joelho $^{\mathbf{0}} \mathbf{4 5}^{\circ}$ & 1 \\
Curva 90 & \\
Tê com passagem direta & 2 \\
Tê com saída de lado & 1 \\
\hline Fonte: & Autor.
\end{tabular}

\subsection{Placa de Orifício}

A placa de orifício (Figura 2-5), de tipo concêntrico, é usada para medir e gerar pressão diferencial na linha. O diâmetro de seu orifício é de $36,32 \mathrm{~mm}$, gerando uma mudança de velocidade no fluido.

Figura 2-5 Placa de orifício

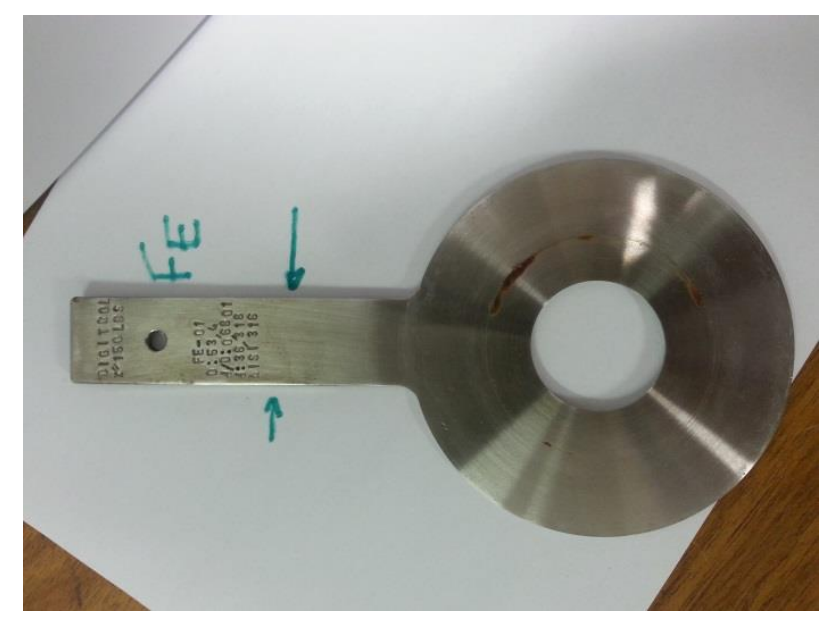

Fonte: Autor. 
A diferença de pressão na linha é medida por meio de um sensor/transmissor de pressão diferencial, emitindo um sinal de saída de 4-20mA, como pode-se ver na Figura 2-6.

Figura 2-6 Transmissor de vazão

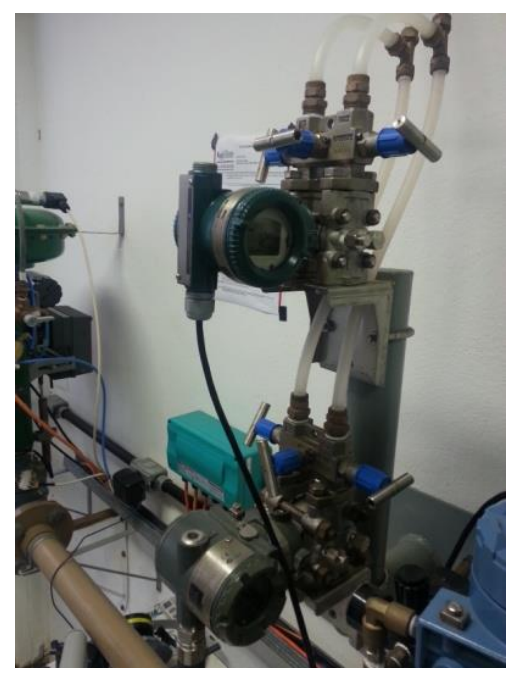

Fonte: Autor.

\subsection{Válvulas de Controle}

As duas válvulas de controle de vazão presentes no laboratório são do tipo globo, operando com ar para fechar, fabricadas pela FISHER. As válvulas podem ser operadas de forma analógica pelo conversor I/P ou pelo posicionador eletropneumático, ou de forma digital pelo posicionador Fieldbus. Elas têm as mesmas características, a única diferença entre elas é o material das gaxetas, uma possui gaxetas de teflon (Figura 2-7a) e a outra de grafite (Figura 2-7b). As gaxetas são aneis de vedação que são inseridos nas válvulas para impedir que o fluido do processo saia pelo orifício que permite a passagem da haste que abre ou fecha a válvula. 
Figura 2-7 (a) Válvula com gaxetas de teflon. (b) Válvula com gaxetas de grafite

(a)

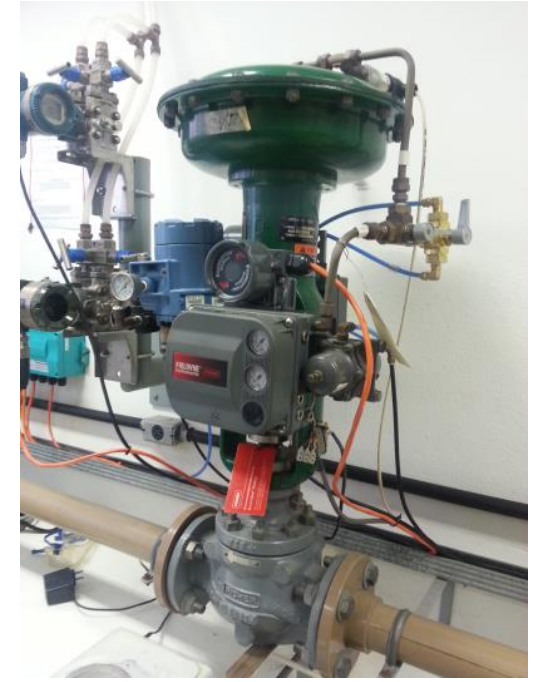

(b)

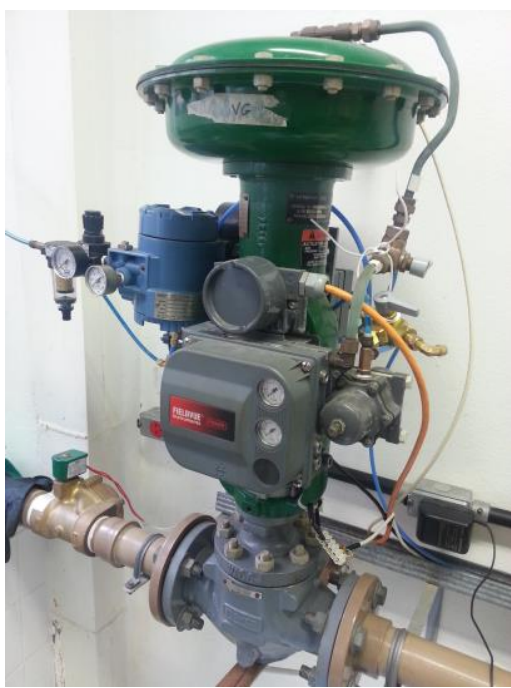

Fonte: Autor.

A diferença entre os materiais das gaxetas é o coeficiente de atrito que possuem. O teflon é de baixo atrito e é o mais utilizado na indústria, o grafite tem um coeficiente mais alto de atrito mas tem mais resistência às temperaturas altas.

As válvulas de controle têm um valor de $C v$ (coeficiente de vazão) associado, que é relacionado com a geometria da válvula. Corresponde à quantidade de galões de água por minuto que flui através da válvula aplicando uma libra por polegada de queda de pressão. Em países que utilizam o sistema métrico este coeficiente é chamado de " $K v$ " que é o fluxo de água em metros cúbicos por hora que passa através de uma válvula totalmente aberta com uma perda de carga de $1 \mathrm{kgf} / \mathrm{cm}^{2}$ (FISHER, 2005).

A equivalência entre os coeficientes é expressa da seguinte forma:

$$
\begin{aligned}
& K v=0,8566^{*} C v \\
& C v=1,1674^{*} K v
\end{aligned}
$$

Na curva da Figura 2-8 o fabricante fornece os valores de $C v$ para as válvulas presentes na Planta de Vazão que corresponde a válvulas do tipo igual porcentagem. 
Figura 2-8 Curva Cv da válvula de controle

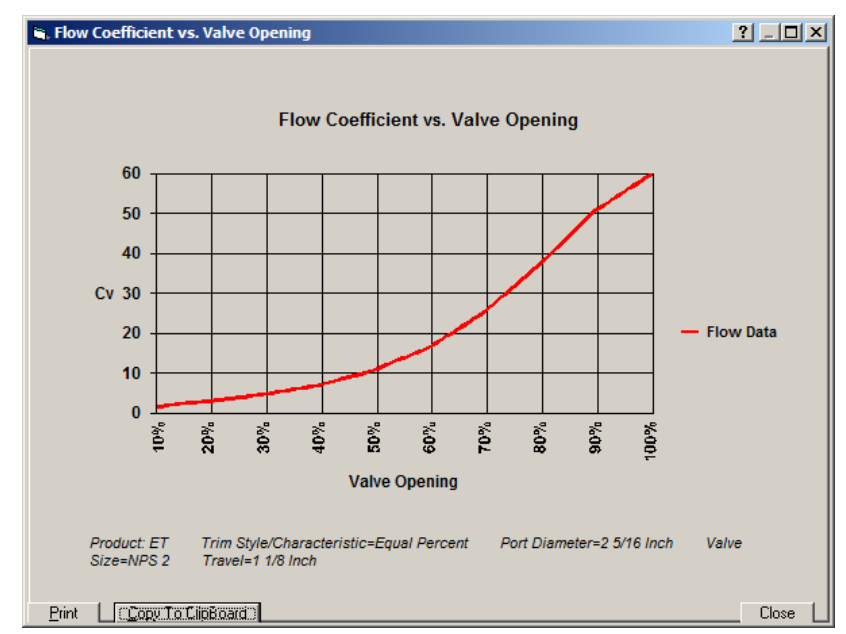

Fonte: Autor.

O valor de $C v$ para a válvula totalmente aberta é de 59,7 e de 1,66 quando está totalmente fechada.

\subsection{Válvula de Perturbação}

A válvula de perturbação (Figura 2-9) é de tipo globo, fabricada pela Valtek Sulamericana. Ela permite introduzir distúrbios no sistema.

Figura 2-9 Válvula de perturbação

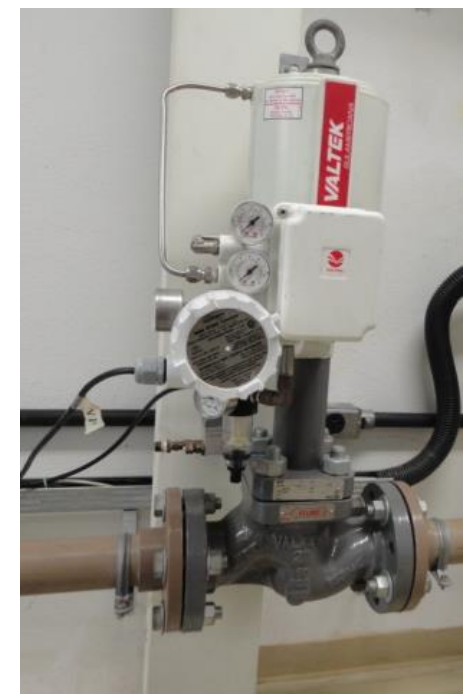

Fonte: Autor. 
A válvula de perturbação é de tipo igual porcentagem, da mesma forma que as outras válvulas. Tem um valor de $C v$ associado para cada abertura conforme mostrado na Figura 210.

Figura 2-10 Cv Válvula de Perturbação

COEFICIENTES dE VAZÃO (Cv) - IGUAL PORCENTAGEM * (TABELA XIII)

\begin{tabular}{|c|c|c|c|c|c|c|c|c|c|c|c|c|c|}
\hline \multicolumn{14}{|c|}{ COEFICIENTES DE VAZÃO (Cv) - IGUAL PORCENTAGEM * (TABELA XIII) } \\
\hline \multirow{2}{*}{$\begin{array}{l}\text { DLÁMEETRO MOMIMAL } \\
\text { DA VÁLVULA (POL.) }\end{array}$} & \multirow{2}{*}{$\begin{array}{l}\text { IITERMOS - TAMANHO } \\
\text { MOMINAL. ( T.M.) }\end{array}$} & \multicolumn{2}{|c|}{ curso } & \multicolumn{10}{|c|}{ PORCENTACEM DE ABERTURA } \\
\hline & & $\mathrm{mm}$ & pol. & 100 & 90 & 80 & 70 & 60 & 50 & 40 & 30 & 20 & 10 \\
\hline \multirow{6}{*}{2} & $\Leftrightarrow=11,63)$ & 38.10 & 1.50 & 47 & 45 & 41 & 30 & 16.4 & 10.6 & 7.0 & 4.6 & 3.1 & 2.2 \\
\hline & $32(1.25)$ & 25.40 & $1 . \overline{00}$ & 30 & 29 & 24 & 15.6 & 70.1 & $\overline{6.4}$ & 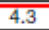 & 2.8 & 1.86 & 1.25 \\
\hline & $25(1.00)$ & 19.05 & 0.75 & 23 & 22 & 17.7 & 11.4 & 6.7 & 4.6 & 3.0 & 1.89 & 1.27 & 0.88 \\
\hline & $21(0.81)$ & 19.05 & 0.75 & 17.5 & 17.1 & 12.5 & 7.9 & 5.1 & 3.3 & 2.1 & 1.35 & 0.93 & 0.61 \\
\hline & $16(0.63)$ & 19.05 & 0.75 & 10.1 & 9.1 & 6.7 & 4.5 & 2.7 & 1.80 & 1.16 & 0.74 & 0.44 & 0.28 \\
\hline & $10(0.38)$ & 19.05 & 0.75 & 3.1 & 2.9 & 2.6 & 1.95 & 1.24 & 0.81 & 0.50 & 0.33 & 0.21 & 0.147 \\
\hline
\end{tabular}

Fonte: (Valtek Sulamericana, 2007)

\subsection{Válvulas Solenoide}

Estas válvulas (Figura 2-11), fabricadas pela Ascoval, são do tipo ON-OFF, normalmente fechadas (NF).

A planta tem três válvulas do tipo solenoide, sendo uma válvula de entrada e uma de saída, as quais permitem a passagem de água no processo, e uma válvula de dreno, que é acionada quando se quer fazer manutenção na planta.

Figura 2-11 Válvula solenoide.

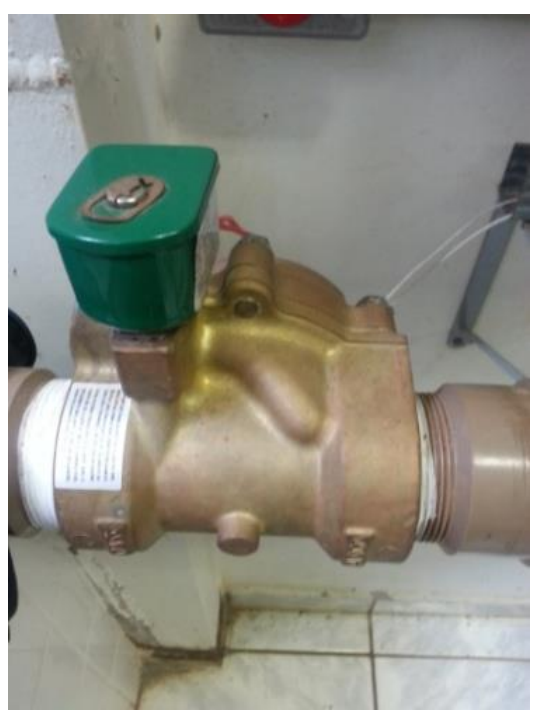

Fonte: Autor 
As válvulas solenoide são de 2" e têm um $K v$ (coeficiente de vazão) de $37\left(\mathrm{~m}^{3} / \mathrm{h}\right) /$ $\sqrt{\left(\mathrm{kgf} / \mathrm{cm}^{2}\right)}$, as unidades foram obtidas diretamente do fabricante. Na Figura 2-12 pode-se ver algumas especificações das válvulas presentes no laboratório.

Figura 2-12 Características das Válvulas Solenoide.

\begin{tabular}{|c|c|c|c|c|c|c|c|c|c|c|c|c|c|c|c|}
\hline \multirow{4}{*}{ 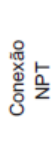 } & \multirow{4}{*}{ 은 } & \multirow{4}{*}{$\mathrm{KV}$} & \multicolumn{7}{|c|}{ Pressão Dif. (Kgf/cm²) } & \multirow{3}{*}{\multicolumn{2}{|c|}{$\begin{array}{c}\text { Máxima } \\
\text { Temperatura } \\
\text { do Fluido }{ }^{\circ} \mathrm{C}\end{array}$}} & \multicolumn{4}{|c|}{ Prefixos } \\
\hline & & & \multirow{3}{*}{ Min. } & \multicolumn{6}{|c|}{ Máxima } & & & \multicolumn{3}{|c|}{ Áreas Classificadas } & \multirow{2}{*}{ IP-65 } \\
\hline & & & & \multicolumn{2}{|c|}{ Arlgás (\#) } & \multicolumn{2}{|c|}{ Água (\#) } & \multicolumn{2}{|c|}{ Óleo (\#) } & & & $\begin{array}{l}1 \\
\text { Exdm }\end{array}$ & Ex e mb & Exd & \\
\hline & & & & C.A. & c.c. & C.A. & c.c. & C.A. & C.C. & C.A. & C.C. & $\begin{array}{l}\mathrm{EF} \\
\text { (EV) }\end{array}$ & $\begin{array}{c}\text { EM } \\
\text { (WSEM) }\end{array}$ & (2) & SC \\
\hline
\end{tabular}

\begin{tabular}{|c|c|c|c|c|c|c|c|c|c|c|c|c|c|c|c|}
\hline \multirow{4}{*}{$1^{n}$} & 25 & 11,0 & 0,34 & 9 & 9 & 9 & 9 & 7 & 9 & 82 & 65 & $\bullet$ & (3) & $\bullet$ & $\bullet$ \\
\hline & 25 & 11,5 & 0,7 & 21 & 15 & 21 & 14 & 21 & 14 & 93 & 82 & (4) & (3) & $\bullet$ & (4) \\
\hline & 25 & 11,5 & 0 & 21 & - & 16 & - & 8 & - & 93 & - & $\bullet$ & - & $\bullet$ & • \\
\hline & 25 & 11,0 & 0 & 9 & 7 & 9 & 7 & 9 & 5,6 & 82 & 25 & (4) & - & - & - \\
\hline \multirow{4}{*}{$11 / 2^{\prime \prime}$} & 32 & 19,2 & 0,34 & 9 & 9 & 9 & 9 & 7 & 9 & 82 & 65 & $\bullet$ & (3) & $\bullet$ & $\bullet$ \\
\hline & 32 & 19,2 & \begin{tabular}{|l|}
0,7 \\
\end{tabular} & 21 & 15 & 21 & 14 & 21 & 14 & 93 & 82 & (4) & (3) & - & (4) \\
\hline & 32 & 19,2 & 0 & 9 & 7 & 9 & 7 & 9 & 5,6 & 82 & 25 & (4) & - & - & $\bullet$ \\
\hline & 25 & 11,0 & 0 & 9 & 7 & 9 & 7 & 9 & 5.6 & 82 & 25 & (4) & $\bullet$ & $\bullet$ & $\bullet$ \\
\hline$\Leftrightarrow 2$ & $4 \overline{45}$ & 37,0 & 0,34 & 9 & 3,4 & 9 & 3,4 & 6 & 3,4 & 82 & 65 & $\bullet$ & (3) & $\bullet$ & 9 \\
\hline $3^{\prime \prime}$ & 76 & $8 \overline{6,0}$ & 0,7 & 17 & $\overline{5}$ & 17 & 75 & 17 & 75 & 93 & $\overline{82}$ & ${ }^{\circ}$ & (3) & $\bullet$ & $\bullet$ \\
\hline
\end{tabular}

Fonte: (Ascoval,2011)

\subsection{Sistema digital de controle distribuído}

O SDCD é um dos equipamentos mais importantes no controle de processos. Sua função principal é o monitoramento e o controle das variáveis que atuam na planta. O sistema possui dois módulos para entradas e saídas analógicas e dois para sinais digitais, que são atualizadas em tempo real nas telas de operação. A Figura 2-13 mostra o SDCD ABB 800xA disponível no laboratório.

Figura 2-13 SDCD ABB 800xA

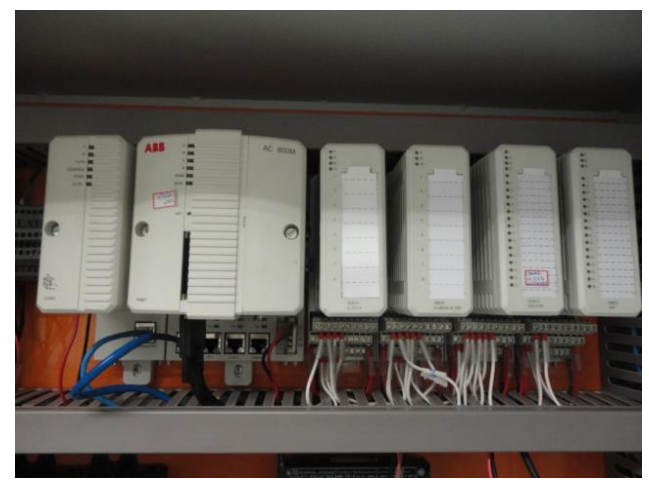

Fonte: Autor. 
A Tabela 2-2 mostra as conexões relacionadas com o sistema da ABB.

Tabela 2-2 Conexões do sistema ABB

\begin{tabular}{|c|c|}
\hline $\begin{array}{l}\text { ENDEREÇO } \\
\text { FÍSICO }\end{array}$ & SERVIÇO \\
\hline & DO810 \\
\hline DO 1 & Válvula solenóide de entrada FV-14 \\
\hline DO 2 & Válvula solenóide de dreno FV-15 \\
\hline DO 3 & Válvula solenóide de saída FV-16 \\
\hline DO 4 & Seleciona controle Da FV-11 \\
\hline DO 5 & Seleciona controle FV-12 \\
\hline DO 6 & Seleciona controle FV-13 \\
\hline DO 7 & Comando partida controle da bomba \\
\hline DO 8 & $\begin{array}{l}\text { Seleciona modo de drenagem } \\
\text { manual }\end{array}$ \\
\hline DO 9 & $\begin{array}{l}\text { Válvula de enchimento da caixa } \\
\text { d'água }\end{array}$ \\
\hline & DI810 \\
\hline DI 1 & Alarme de vazão baixa \\
\hline DI 2 & Sobrecarga do motor \\
\hline DI 3 & Chave de nível baixo do reservatório \\
\hline \multirow[t]{2}{*}{ DI 4} & Chave de nível alto do reservatório \\
\hline & $\mathbf{A 0 8 1 0}$ \\
\hline AO 1 & Comando válvula de Teflon (FV-12) \\
\hline AO 2 & Comando válvula de grafite (FV-11) \\
\hline AO 3 & $\begin{array}{l}\text { Comando válvula de perturbação } \\
\text { (FV-13) }\end{array}$ \\
\hline \multirow[t]{2}{*}{ AO 4} & Controle de rotação do motor \\
\hline & AI810 \\
\hline AI 1 & LVDT válvula de teflon FV-12 \\
\hline AI 2 & PT válvula de teflon FV-12 \\
\hline AI 3 & LVDT válvula de grafite FV-11 \\
\hline AI 4 & PT válvula de grafite FV-11 \\
\hline AI 5 & $\begin{array}{l}\text { Vazão na linha - Transmissor } \\
\text { analógico }\end{array}$ \\
\hline
\end{tabular}

\section{Fonte: Autor}

O sistema oferece uma interface homem-máquina (IHM) que permite o interfaceamento com controladores lógicos programáveis (CLP), controladores single loop, equipamentos de comunicação digital e sistemas em rede. Na Figura 2-14 pode-se ver a tela principal para operar a planta. 
Figura 2-14 Tela de operação da Planta de vazão

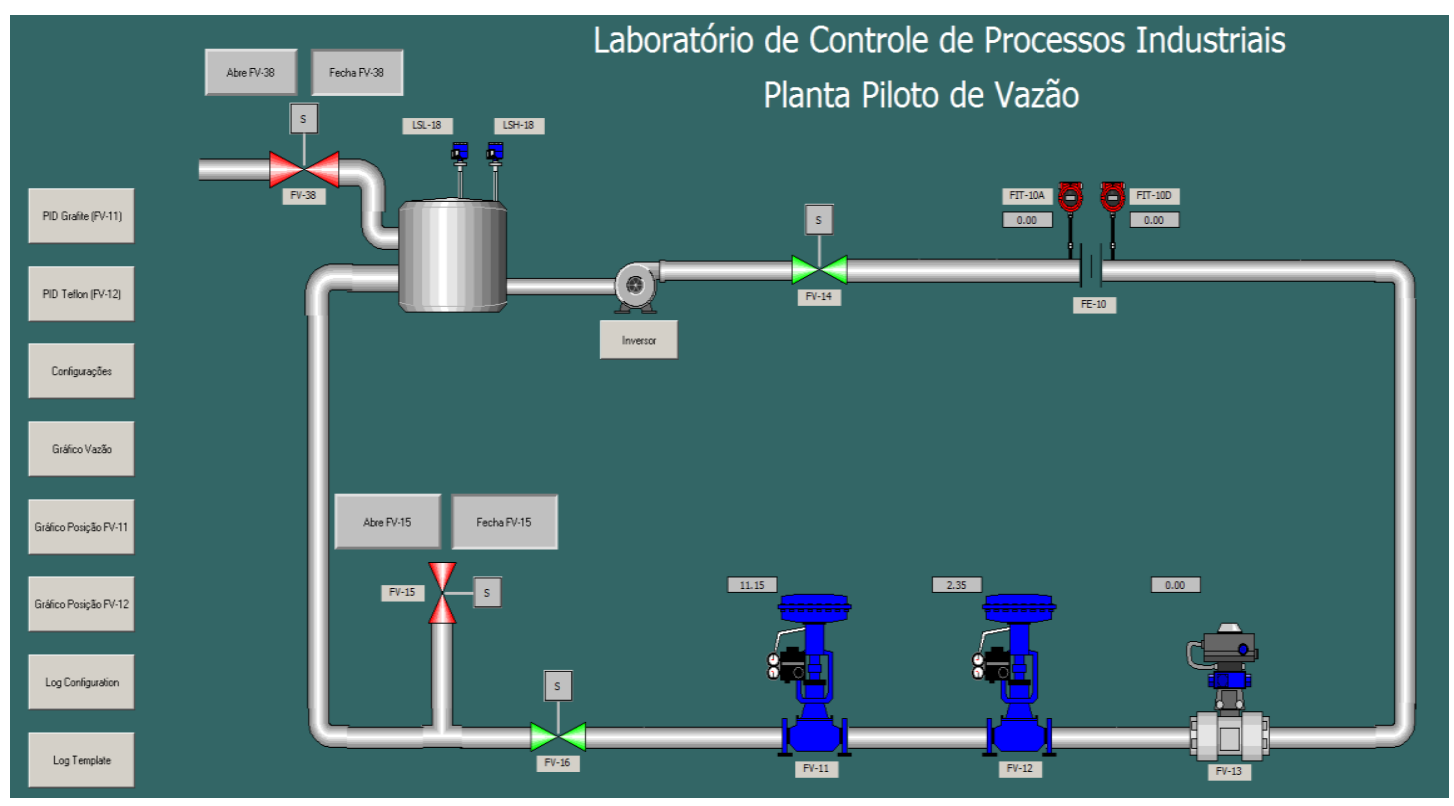

Fonte: Autor

\subsection{CLP Rockwell SLC 500}

O CLP Rockwell SLC 500 (Figura 2-15) tem capacidade para 8 entradas e saídas digitais, 4 entradas e saídas analógicas e um módulo TTL. Na Planta de Vazão ele é usado para funções de segurança.

Figura 2-15 CLP Rockwell SLC 500

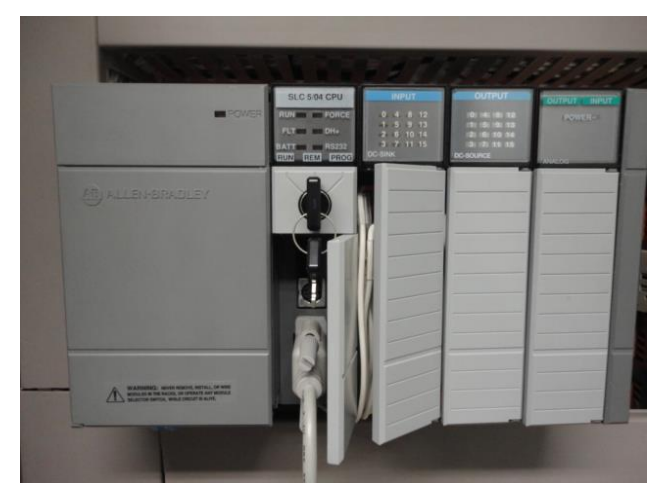

Fonte: Autor

A Tabela 2-3 mostra as conexões correspondentes ao CLP Rockwell. 
Tabela 2-3 Conexões do CLP Rockwell SLC 500.

\begin{tabular}{|c|c|}
\hline \multicolumn{2}{|l|}{ FÍSICO } \\
\hline \multicolumn{2}{|r|}{ OB16 } \\
\hline OUT 0 & Desaceleração rápida (Motor) \\
\hline OUT 1 & Parada por inércia (Motor) \\
\hline OUT 2 & Alarme de vazão baixa \\
\hline OUT 3 & $\begin{array}{l}\text { Permissivo de acionamento } \\
\text { da bomba }\end{array}$ \\
\hline \multicolumn{2}{|r|}{ IB16 } \\
\hline IN 0 & Monitoração FV-15 (Dreno) \\
\hline IN 1 & Monitoração FV-16 (Saída) \\
\hline IN 2 & Monitoração FV-14 (Entrada) \\
\hline N 3 & Sobrecarga no motor \\
\hline IN 4 & $\begin{array}{l}\text { Chave de nível baixo do } \\
\text { reservatório }\end{array}$ \\
\hline IN 5 & $\begin{array}{l}\text { Seleciona modo normal ou } \\
\text { drenagem automática }\end{array}$ \\
\hline IN 6 & $\begin{array}{l}\text { Monitoração do comando de } \\
\text { partida da bomba }\end{array}$ \\
\hline IN 7 & Chave Automático/Manual \\
\hline \multicolumn{2}{|r|}{ AI16 } \\
\hline IN 0 & $\begin{array}{l}\text { Vazão na linha - Transmissor } \\
\text { analógico }\end{array}$ \\
\hline
\end{tabular}

Fonte: Autor 


\section{MODELAGEM DA PLANTA DE VAZÃO}

A modelagem de sistemas fluídicos se concentra em duas variáveis principalmente, vazão e pressão. As leis básicas para este tipo de sistemas são a Equação de Bernoulli e o Princípio da Conservação de Massa.

O princípio da conservação de massa pode ser definido como a massa e volume de um fluido incompressível que se mantém constante em um escoamento ao longo de uma tubulação (HALLIDAY; RESNICK, 1996).

Para diferenciar um fluido incompressível de um fluido compressível, basta verificar se a massa específica do fluido se mantém constante. Caso se mantenha, o fluido é considerado incompressível.

A equação de Bernoulli é uma reformulação da lei da conservação da energia mecânica em uma forma mais adequada à mecânica dos fluidos.

$P+\frac{\rho \cdot v^{2}}{2}+\rho \cdot g \cdot h=c t e$

onde $P$ é a pressão interna, $\rho$ é a massa específica do fluido, $v$ é a velocidade com que o fluido está escoando, $g$ é a aceleração normal da gravidade e $h$ é a altura do ponto da tubulação.

Para encontrar a diferença de pressões entre dois pontos da linha, a equação (3-1) pode ser reescrita da seguinte forma:

$$
P_{1}=P_{0}-\rho \cdot g\left(h_{1}-h_{0}\right)-\frac{\rho}{2}\left(v_{1}^{2}-v_{0}^{2}\right)
$$

As equações (3-1) e (3-2) só são válidas quando é considerado um fluido ideal. Em condições reais existem perdas de energia no processo, devido ao atrito viscoso, que são chamadas na industria de perdas de carga, portanto é necessário adicionar uma expressão na equação (3-2):

$P_{1}=P_{0}-\rho \cdot g\left(h_{1}-h_{0}\right)-\frac{\rho}{2}\left(v_{1}^{2}-v_{0}^{2}\right)+D P$

onde DP é a diferença de pressão entre os dois pontos gerados pelo atrito viscoso. 
Existem dois tipos de perda de carga em um processo. A primeira é uma perda de carga distribuída em um trecho reto de tubulação, e a segunda é uma perda localizada, como por exemplo, uma válvula, uma placa de orifício ou também pode se apresentar em singularidades como cotovelos, curvas, tês, etc. No caso da Planta de Vazão, ela possui os dois tipos de geradores de perda de carga. Ao somar as perdas de carga de cada um deles, obtém-se o valor da perda total na planta. A seguir vai se apresentar como foram obtidos esses valores.

\subsection{Perdas de Carga na Tubulação}

As tubulações apresentam os dois tipos de perdas, tanto distribuídas como localizadas. Para encontrar o valor total é necessário obter cada uma em separado e fazer a soma das duas.

Os trechos retos são os geradores de perdas distribuídas. Para poder calcular esse valor de perda é necessário calcular o comprimento total da tubulação, que é dado por $L_{r e t}=$ $34,53 \mathrm{~m}$.

No caso das singularidades, é necessário calcular o equivalente em metros de trecho reto de tubulação de cada uma delas. Na Tabela 3-1 pode-se ver os dados da empresa Tigre, que é o fabricante das singularidades, que mostra o equivalente de cada uma delas em metros de tubulação de PVC.

Tabela 3-1 Equivalência das singularidades em metros de tubulação

\begin{tabular}{|c|c|c|c|c|c|c|c|c|c|c|c|c|c|c|c|c|c|}
\hline \multicolumn{18}{|c|}{ Perdas de carga localizadas - Sua equivalência em metros de tubulação de PVC rígido } \\
\hline & & $\begin{array}{l}\text { Joelho } \\
90^{\circ}\end{array}$ & $\begin{array}{l}\text { Joelho } \\
45^{\circ}\end{array}$ & $\begin{array}{l}\text { Curva } \\
90^{\circ}\end{array}$ & Curva & $\begin{array}{c}\text { Tê } 90^{\circ} \\
\text { Passagem } \\
\text { Direita }\end{array}$ & $\begin{array}{l}\text { Tê } 90^{\circ} \\
\text { Saida } \\
\text { de ladb }\end{array}$ & $\begin{array}{l}\text { Tê90 } \\
\text { Saidda } \\
\text { Bilateral }\end{array}$ & $\begin{array}{l}\text { Entrada } \\
\text { Normal }\end{array}$ & $\begin{array}{l}\text { Entrada } \\
\text { de Borda }\end{array}$ & $\begin{array}{l}\text { Saída de } \\
\text { Canalizaçato }\end{array}$ & $\begin{array}{l}\text { Váluula de } \\
\text { Pée ecrivo }\end{array}$ & $\begin{array}{l}\text { Váluila de } \\
\text { Retencio } \\
\text { Tipo leve }\end{array}$ & $\begin{array}{l}\text { Valvia de } \\
\text { Retençao } \\
\text { Tipo Pesado }\end{array}$ & $\begin{array}{l}\text { Registo } \\
\text { de Globo } \\
\text { Abento }\end{array}$ & $\begin{array}{l}\text { Registro } \\
\text { de Gaveta } \\
\text { Aberto }\end{array}$ & $\begin{array}{c}\text { Registro } \\
\text { deAngulo } \\
\text { Aberto }\end{array}$ \\
\hline $\mathrm{DE}(\mathrm{mm})$ & D. ref. & 듬 & $\Delta$ & & & स्म & 旨 & 4 & 工地。 & . & 它 & & & & & & \\
\hline 20 & $1 / 2^{*}$ & 1,1 & 0,4 & 0,4 & 0,2 & 0,7 & 2,3 & 2,3 & 0,3 & 0,9 & 0,8 & 8,1 & 2,5 & 3,6 & 11,1 & 0,1 & 5,9 \\
\hline 25 & $3 / 4^{\prime \prime}$ & 1,2 & 0,5 & 0,5 & 0,3 & 0,8 & 2,4 & 2,4 & 0,4 & 1,0 & 0,9 & 9,5 & 2,7 & 4,1 & 11,4 & 0,2 & 6,1 \\
\hline 32 & $1^{*}$ & 1,5 & 0,7 & 0,6 & 0,4 & 0,9 & 3,1 & 3,1 & 0,5 & 1,2 & 1,3 & 13,3 & 3,8 & 5,8 & 15,0 & 0,3 & 8,4 \\
\hline 40 & $1 y_{4}^{*}$ & 2,0 & 1,0 & 0,7 & 0,5 & 1,5 & 4,6 & 4,6 & 0,6 & 1,8 & 1,4 & 15,5 & 4,9 & 7,4 & 22,0 & 0,4 & 10,5 \\
\hline 50 & $11_{2}^{\prime \prime}$ & 32 & 13 & 12 & 0,6 & $2,2-$ & 7,7 & 7,3 & 1,0 & 2,3 & 3,2 & $-18,3$ & $-6,8$ & 21 & 358 & 0,7 & 17,0 \\
\hline 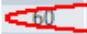 & $2^{n}$ & 3,4 & 1,5 & 1,3 & 0,7 & 2,3 & 7,6 & 7,6 & 1,5 & 2,8 & 3,3 & $\begin{array}{l}23,7 \\
\end{array}$ & 7,1 & 10,8 & 37,9 & 0,8 & $18,5=$ \\
\hline 75 & $2 y_{2}^{\prime \prime}$ & $3, T$ & $T, T$ & 1,4 & 0,0 & 2,4 & 7,0 & 7,0 & $-1,0$ & -3, & 3,5 & $-25,0$ & 8,2 & $T 2,5$ & 38,0 & $\overline{0,9}$ & $\overrightarrow{19,0}$ \\
\hline 85 & $3^{n}$ & 3,9 & 1,8 & 1,5 & 0,9 & 2,5 & 8,0 & 8,0 & 2,0 & 3,7 & 3,7 & 26,8 & 9,3 & 14,2 & 40,0 & 0,9 & 20,0 \\
\hline 110 & $4^{\prime \prime}$ & 4,3 & 1,9 & 1,6 & 1,0 & 2,6 & 8,3 & 8,3 & 2,2 & 4,0 & 3,9 & 28,6 & 10,4 & 16,0 & 42,3 & 1,0 & 22,1 \\
\hline
\end{tabular}

Fonte: (TIGRE, 2008). 
O valor total de trecho equivalente de tubulação devido às singularidades é o somatório dos valores equivalentes de cada uma delas. Na Tabela 2-1 foi mostrada a quantidade de singularidades presentes na planta, portanto se obtém:

$$
L_{\mathrm{sin}}=\left(3,4 \cdot N_{j o e} 90^{\circ}\right)+\left(1,5 \cdot N_{\text {joe } 45^{\circ}}\right)+\left(1,3 \cdot N_{\mathrm{cuv} 90^{\circ}}\right)+\left(2,3 \cdot N_{\text {Tểir }}\right)+\left(7,6 \cdot N_{\text {TếLado }}\right)
$$

Substituindo-se os dados da Tabela 2-1, obtém-se:

$$
L_{\text {sin }}=(3,4 \cdot 19)+(1,5 \cdot 1)+(1,3 \cdot 2)+(2,3 \cdot 1)+(7,6 \cdot 1)
$$

Resultando:

$$
L_{\text {sin }}=78,60 \mathrm{~m}
$$

Este valor obtido, somado com o valor total de comprimento reto de tubulação, é o comprimento total.

$$
L_{t o t}=(34,53+78,60) \mathrm{m}
$$

Obtendo-se:

$$
L_{t o t}=113,13 \mathrm{~m}
$$

No catálogo da Tigre é apresentado um Ábaco para o cálculo da perda de carga em tubulações de PVC, dependendo do diâmetro da tubulação e da velocidade do líquido (Ver Anexo A). Para representar este ábaco é necessário fazer uso da ferramenta Lookup Table disponível no Simulink ${ }^{\circledR}$ (ver Figura 3-1). Este bloco faz a interpolação/extrapolação linear de pontos fornecidos de uma curva. Como o gráfico fornecido pelo fabricante está em escala logarítmica, é necessário fazer uma adequação dos valores de entrada e de saída do bloco Lookup Table. Os dados do fabricante são apresentados no anexo B. 
Figura 3-1 Bloco Lookup Table (DPtub x Qtub)

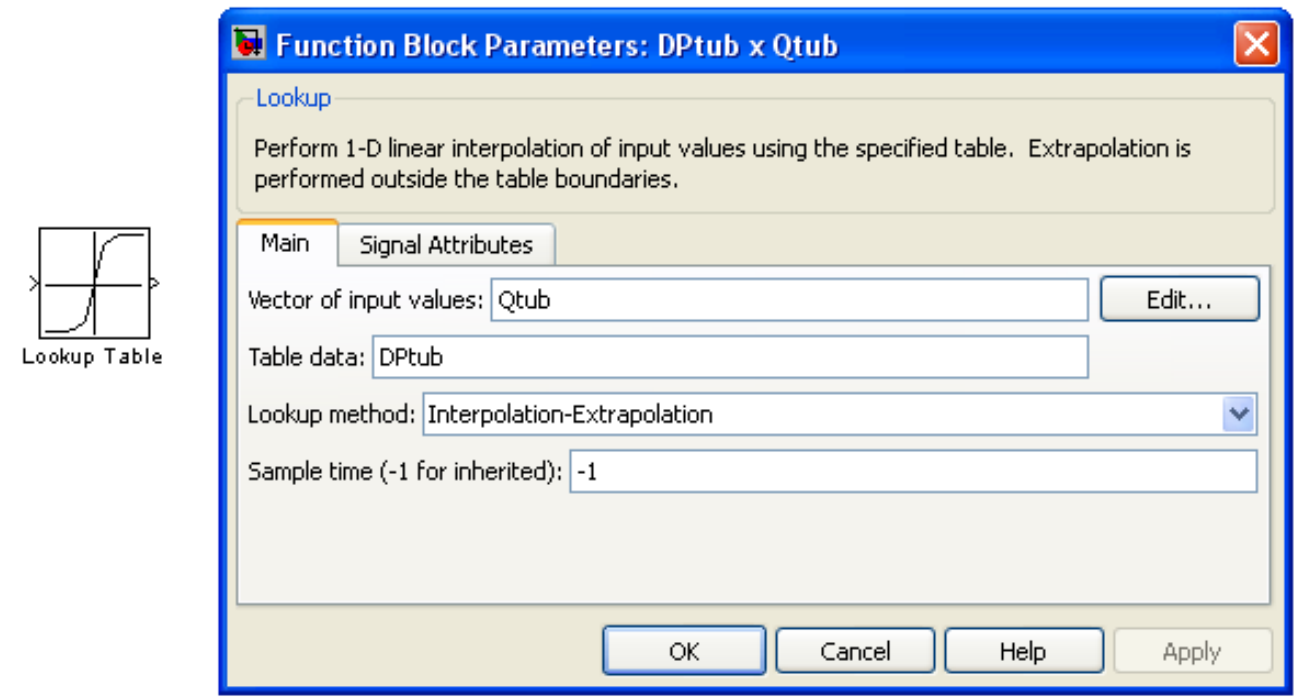

Fonte: Autor

A variável de entrada do gráfico é vazão em [1/s] e sua saída é perda de carga unitária em $[\mathrm{m} / \mathrm{m}]$, mas no modelo as variáveis trabalhadas são $\left[\mathrm{m}^{3} / \mathrm{s}\right]$ para a vazão e para perda é [mH2O] portanto é necessário fazer uma adequação das variáveis antes e depois de entrar no Lookup Table. Na Figura 3-2 pode-se encontrar o modelo implementado para calcular a perda de carga nas tubulações.

Figura 3-2 Modelo de perda de carga nas tubulações

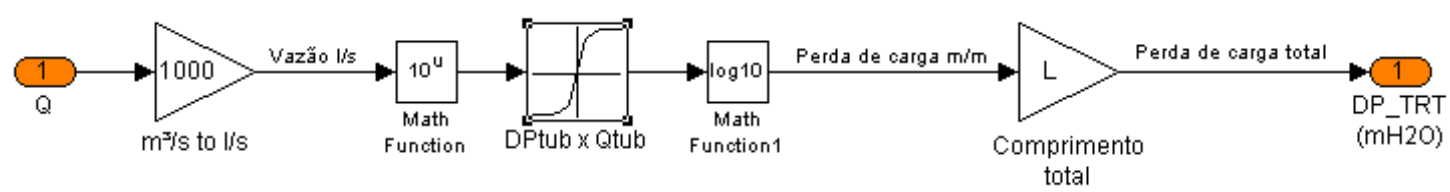

Fonte: Autor

O valor que sai do Lookup Table é multiplicado pelo valor total do comprimento das tubulações e, desta forma, obtém-se o valor de perda de carga total nas tubulações. 


\subsection{Perda de Carga nas Válvulas Solenoide}

Mencionado no Capítulo 2, as válvulas solenoides só têm a função de permitir a passagem de água no processo. Estas também têm uma perda de carga associada que deve ser considerada no modelo. Estas válvulas são operadas totalmente abertas ou totalmente fechadas, portanto podem ser consideradas como um elemento gerador de pressão diferencial simples. A equação (3-8) mostra a expressão para o cálculo da vazão em válvulas solenoides (ASCOVAL, 2011):

$Q=K_{v} \cdot \sqrt{\Delta P}$

onde $Q$ é a vazão volumétrica em $\left[\mathrm{m}^{3} / \mathrm{h}\right], \Delta P$ é a pressão diferencial ou a perda de carga através da válvula solenoide em $\left[\mathrm{kgf} / \mathrm{cm}^{2}\right]$ e $K v$ é um coeficiente de resistência à vazão, o qual é fornecido pelo fabricante. A variável de interesse é o valor de pressão diferencial, portanto da equação (3-8) obtém-se:

$$
\Delta P=\left(\frac{Q}{K_{v}}\right)^{2}
$$

O valor de $\Delta P$ resultante da equação (3-9) tem unidade de pressão $\left[\mathrm{kgf} / \mathrm{cm}^{2}\right]$, portanto é necessário aplicar um fator de conversão para obter a perda de carga em [mH2O], da mesma forma o sinal de entrada é convertido para $\left[\mathrm{m}^{3} / \mathrm{h}\right]$. O modelo em MATLAB ${ }^{\circledR}$ para as válvulas solenoides pode ser visto na Figura 3-3.

Figura 3-3 Perda de carga nas válvulas solenoide

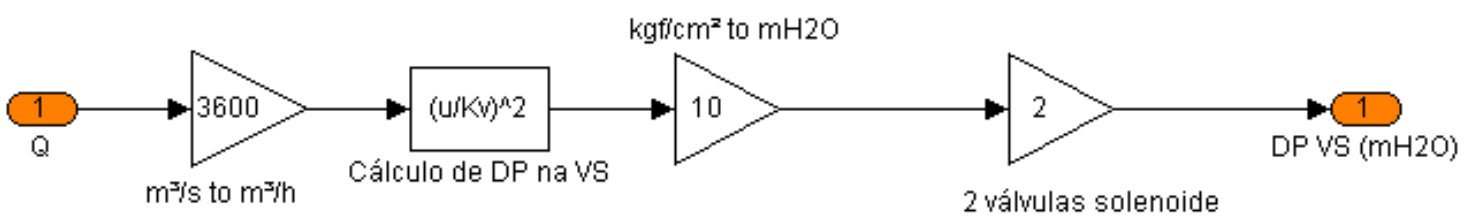

Fonte: Autor 
O valor de perda de carga é multiplicado por dois, pois há duas válvulas solenoide no processo.

\subsection{Perda de Carga nas Válvulas de Controle}

Para modelar as válvulas de controle, é necessário ter em conta o seu comportamento inerente, neste caso, o comportamento é do tipo igual porcentagem (ver Figura 2.8).

A equação básica para relacionar a vazão $Q$ em [gpm] com a perda de carga $\Delta P$ em [psi] na válvula é descrita da seguinte forma (GARCIA, 2009):

$$
Q=C_{v} \cdot \sqrt{\frac{\Delta P}{G_{f}}}
$$

onde $C v$ é o coeficiente de vazão da válvula, normalmente fornecido em $g p m / \sqrt{p s i}$, e $G_{f}$ é o valor de densidade relativa, no caso, água, portanto $G_{f}=1$.

A equação (3-10) somente é aplicada para válvulas totalmente abertas, portanto é necessário adicionar um termo que corresponde à curva de atuação da válvula através de seu atuador (GARCIA, 2009). A equação (3-11) representa a vazão na válvula dependendo da abertura da mesma.

$$
Q=C_{v} \cdot f(X) \cdot \sqrt{\frac{\Delta P}{G_{f}}}
$$

A abertura da válvula é representada por $f(X)$, a qual varia de 0 a 1 , onde 0 significa que a válvula esta totalmente fechada e 1 que esta totalmente aberta. 
A variável de interesse é a diferença de pressão, portanto resulta:

$\Delta P=\left(\frac{Q}{C_{v} \cdot f(X)}\right)^{2} \cdot G_{f}$

É necessário adicionar mais um termo para ajuste de unidades $K_{a j}$, obtendo-se:

$\Delta P=\left(\frac{Q}{C_{v} \cdot f(X) \cdot K_{a j}}\right)^{2} \cdot G_{f}$

O fabricante das válvulas fornece uma equação equivalente à (3-13) para calcular a perda de carga nas válvulas (FISHER, 2005).

$\Delta P=\left(\frac{Q}{C_{v r e l} \cdot F_{p} \cdot N}\right)^{2} \cdot G_{f}$

sendo $F p$ um fator geométrico da tubulação, o qual tem que ser considerado quando as válvulas são montadas entre redutores, já que eles geram perda de carga adicional. No caso deste trabalho $F p$ é igual a 1, porque as válvulas não têm redutores instalados. $N$ é uma constante de valor de unidades fornecido pelo fabricante.

Note-se que o $C v$ da equação (3-14) é relativo, já que ele está relacionado com a posição da haste, portanto é possível usar o gráfico da Figura 2-8 para obter o valor de perda de carga nas válvulas, extraindo o valor de $C v$ da curva. Os valores de $C v$ extraídos da Figura 2-8 com $X$ variando de 5\% são mostrados na Tabela 3-2.

Tabela 3-2 Valores de $\mathrm{Cv}$ para diferentes valores de abertura da válvula

\begin{tabular}{ccccccccccc}
\hline $\boldsymbol{X}[\boldsymbol{\%}]$ & $\mathbf{1 0}$ & $\mathbf{1 5}$ & $\mathbf{2 0}$ & $\mathbf{2 5}$ & $\mathbf{3 0}$ & $\mathbf{3 5}$ & $\mathbf{4 0}$ & $\mathbf{4 5}$ & $\mathbf{5 0}$ & $\mathbf{5 5}$ \\
$\boldsymbol{C} \boldsymbol{v}$ & 1,66 & 2,41 & 3,16 & 3,91 & 4,66 & 6,33 & 8 & 9,5 & 11 & 14 \\
\hline \hline $\boldsymbol{X}[\boldsymbol{\%}]$ & $\mathbf{6 0}$ & $\mathbf{6 5}$ & $\mathbf{7 0}$ & $\mathbf{7 5}$ & $\mathbf{8 0}$ & $\mathbf{8 5}$ & $\mathbf{9 0}$ & $\mathbf{9 5}$ & $\mathbf{1 0 0}$ & \\
$\boldsymbol{C} \boldsymbol{v}$ & 17 & 21,2 & 25,4 & 31,7 & 38 & 44,5 & 51 & 55,35 & 59,7 & \\
\hline
\end{tabular}

\section{Fonte: Autor}

A partir dos dados da Tabela 3-2 é possível fazer um gráfico em MATLAB ${ }^{\circledR}$ por meio do bloco Lookup Table (Figura 3-4) do Simulink e, com isto, é possível obter o valor de perda 
da carga, dependendo do valor de vazão de entrada. O gráfico gerado pode-se ver na Figura 35 .

Figura 3-4 Lookup Table para as válvulas de controle

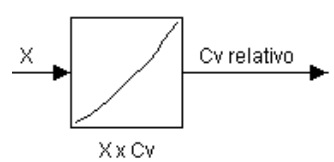

Fonte: Autor

Figura 3-5 Curva de Cv das válvulas de controle

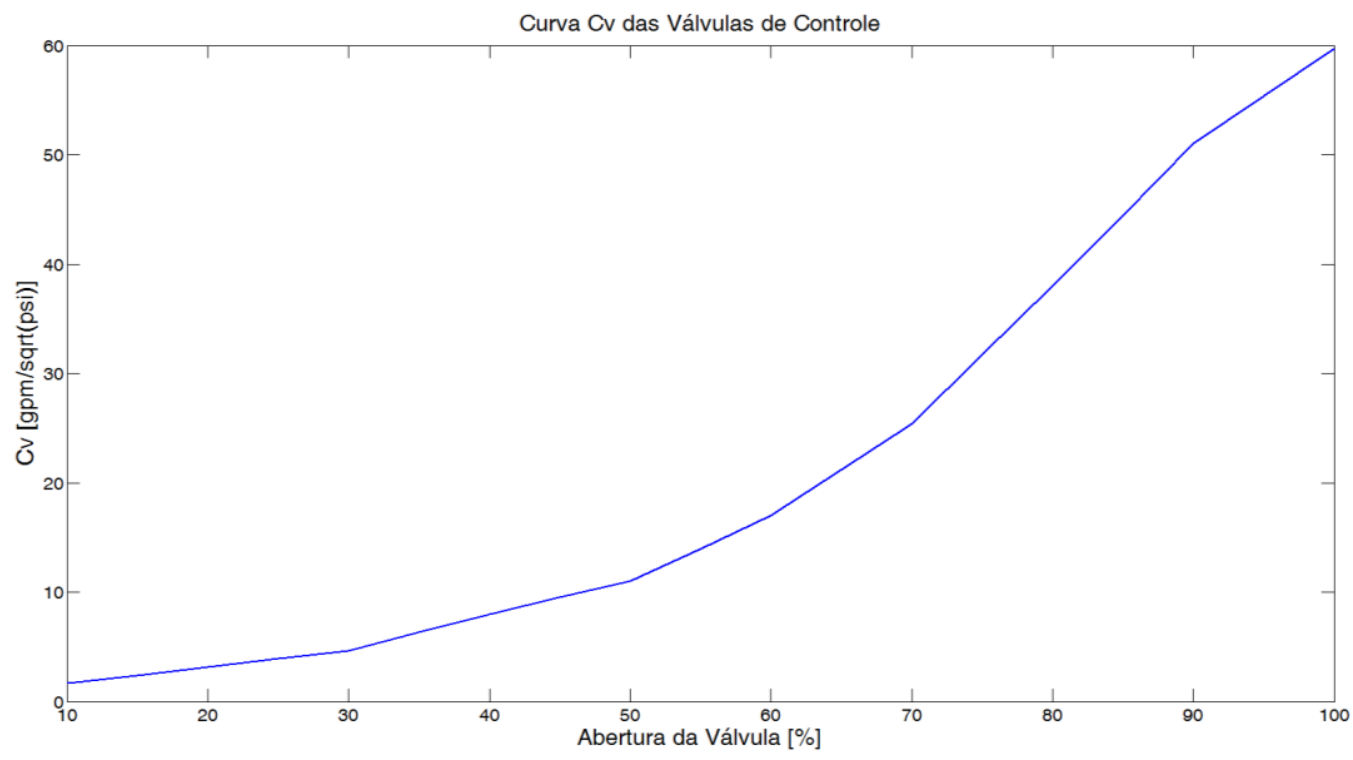

Fonte: Autor

Finalmente, o modelo gerado para calcular as perdas de carga nas válvulas de controle é o mostrado na Figura 3-6. 
Figura 3-6 Modelo de perda de carga para as válvulas de controle

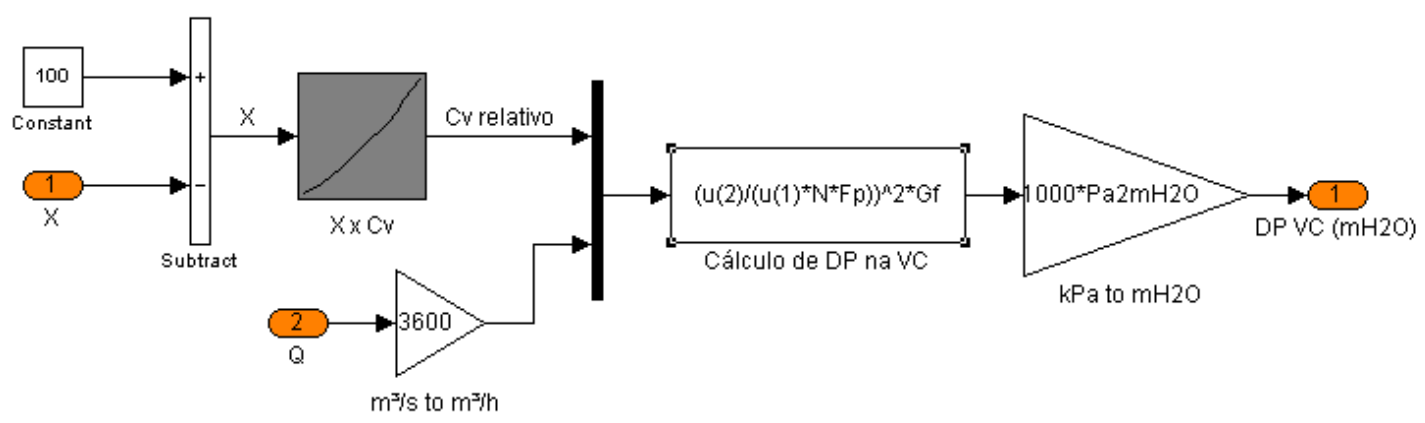

Fonte: Autor

Visto que no Lookup Table o valor de 100 é para a válvula totalmente aberta, e 0 totalmente fechada, é necessário subtrair 100 do valor da posição da haste, pois o sinal que é enviado está invertido, 0 é totalmente aberto e 100 fechado. É necessário fazer uma conversão de unidades na saída do bloco da perda de carga que está em [Pa], convertendo-a para [mH2O] para manter a homogeneidade com os outros blocos de perda de carga.

\subsection{Perda de Carga na Válvula de Perturbação}

Conforme o Capítulo 2, a válvula de perturbação tem função de gerar distúrbios no sistema. Ela tem também uma curva característica de vazão do tipo igual porcentagem, como se pode ver na Figura 2-10, onde são mostrados os valores de $C v$ para cada valor de abertura (ver Tabela 3-3). De igual forma que para as válvulas de controle, foi utilizado o bloco Lookup Table de Simulink para gerar a curva, como observado na Figura 3-7.

Tabela 3-3 $C v$ para a válvula de perturbação

\begin{tabular}{ccccccccccc}
\hline $\boldsymbol{X}[\boldsymbol{\%}]$ & $\mathbf{1 0}$ & $\mathbf{2 0}$ & $\mathbf{3 0}$ & $\mathbf{4 0}$ & $\mathbf{5 0}$ & $\mathbf{6 0}$ & $\mathbf{7 0}$ & $\mathbf{8 0}$ & $\mathbf{9 0}$ & $\mathbf{1 0 0}$ \\
$\boldsymbol{C} \boldsymbol{v}$ & 2,2 & 3,1 & 4,6 & 7,0 & 10,6 & 16,4 & 30 & 41 & 45 & 47 \\
\hline
\end{tabular}


Figura 3-7 Curva do Cv para a válvula de perturbação

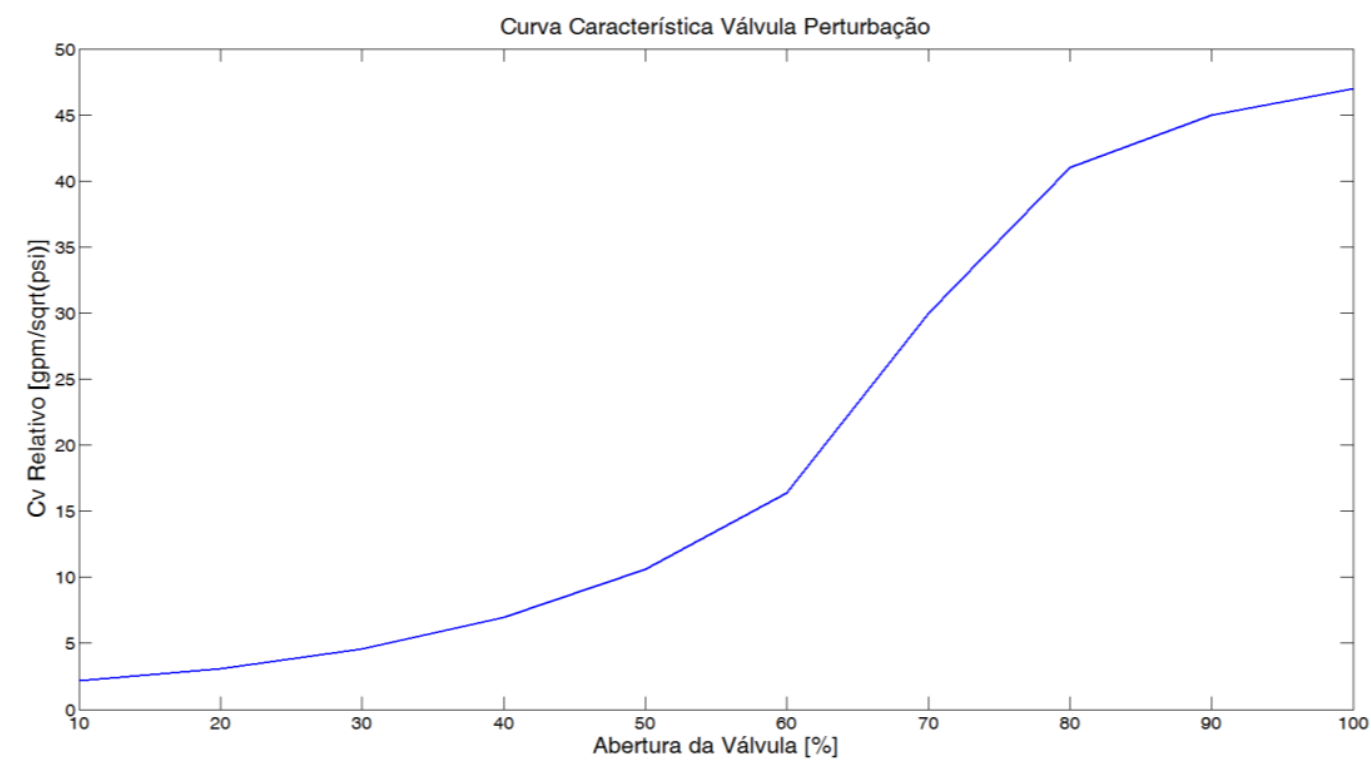

Fonte: Autor

Com esta curva gerada, pode ser utilizada a equação (3-14) para calcular a perda de carga na válvula de perturbação. Portanto, o modelo gerado em MATLAB ${ }^{\circledR}$ para a válvula é ilustrado na Figura 3-8.

Figura 3-8 Modelo em MATLAB® para a válvula de perturbação

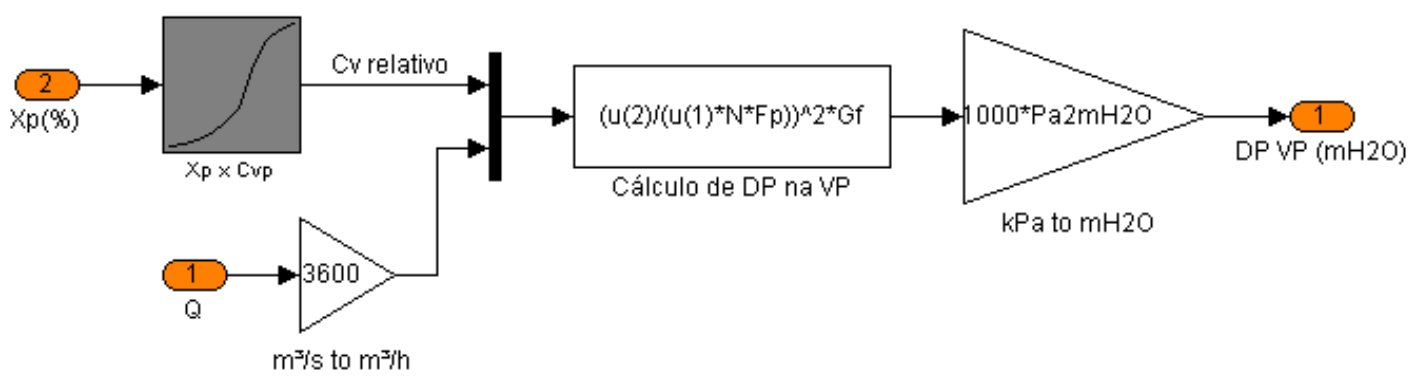

Fonte: Autor 
De igual forma que para as válvulas de controle, é necessário fazer um ajuste de unidades na entrada $\left(\mathrm{m}^{3} / \mathrm{s}\right.$ para $\left.\mathrm{m}^{3} / \mathrm{h}\right)$ e na saída do modelo ( $\mathrm{kPa}$ para $\left.\mathrm{mH} 2 \mathrm{O}\right)$.

\subsection{Perda de Carga Permanente na Placa de Orifício}

A placa de orifício (ver Figura 3-9) é um gerador de pressão diferencial, e desta forma, é possível estimar a vazão, uma vez que esta tem uma relação quadrática com a perda de pressão. Esta relação pode ser representada na seguinte equação (DELMÉE, 2003).

$Q=C \cdot E \cdot \beta^{2} \cdot A \cdot \sqrt{\frac{2 \cdot \Delta P}{\rho}}$

onde $Q$ é a vazão volumétrica $\left[\mathrm{m}^{3} / \mathrm{s}\right], C$ é o coeficiente de descarga que depende da geometria do elemento [adimensional], geralmente é fornecido pelo fabricante, $E$ é o fator de velocidade de aproximação [adimensional], $\beta$ é relação dos diâmetros $d / D$ entre o diâmetro da placa de orifício e o diâmetro interno da tubulação [adimensional], $A$ é a área da seção da tubulação $\left[\mathrm{m}^{2}\right], \Delta P$ é pressão diferencial gerada pela placa de orifício e $\rho$ é massa específica do fluido $\left[\mathrm{kg} / \mathrm{m}^{3}\right]$.

Figura 3-9 Placa de orifício desmontada

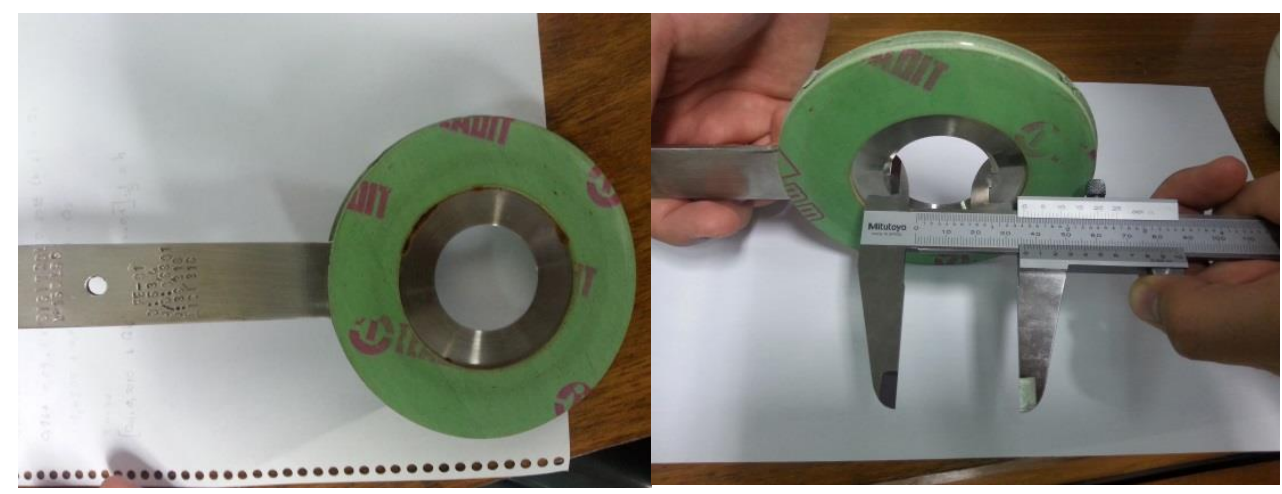

Fonte: Autor 
Da Equação (3-15) é possível obter a equação para a perda de pressão na placa de orifício, isolando $\triangle P$, obtem-se:

$$
\Delta P=\left(\frac{Q}{C \cdot E \cdot \beta^{2} \cdot A}\right)^{2} \cdot \frac{\rho}{2}
$$

A diferença de pressão da equação (3-16) corresponde à diferença de pressão medida na placa de orifício utilizada para a medição da vazão. Já a perda de carga permanente gerada pelo elemento primário de vazão é definida pela Equação (3-17) (Garcia, 2005):

$$
\Delta P_{p o}=\frac{1-C \cdot E \cdot \beta^{2}}{1+C \cdot E \cdot \beta^{2}} \cdot \Delta P
$$

Com estas equações é possível calcular o valor total de perda de carga na placa de orifício. O modelo implementado em MATLAB ${ }^{\circledR}$ para este elemento pode ser visto na Figura 3-10.

Figura 3-10 Modelo de perda de carga permanente na placa de orifício

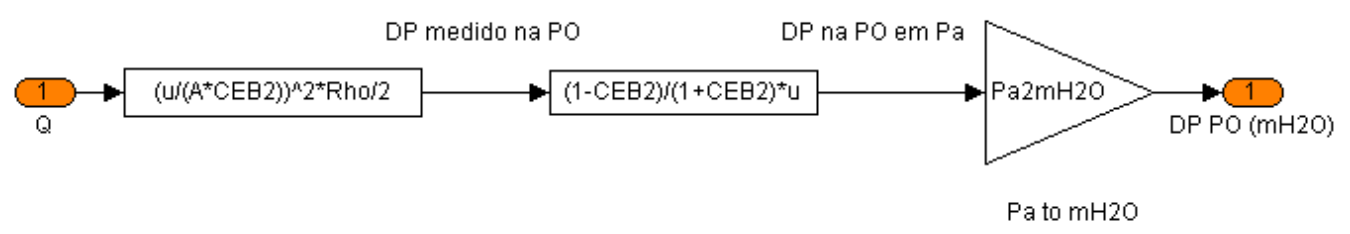

Fonte: Autor

O primeiro bloco é a representação da equação (3-16) e o segundo bloco representa a equação (3-17). No final é necessário fazer a conversão de unidades para $\mathrm{mH} 2 \mathrm{O}$, da mesma forma que nas seções anteriores. 


\subsection{Modelagem do conjunto Motor-Bomba}

A bomba centrífuga tem como principal função fornecer uma vazão constante ao sistema, e para conseguir uma vazão desejada é necessário que ela gere uma energia suficiente para que o fluido escoe de forma constante. Quanto maior for a perda de carga em um sistema de bombeamento, maior será a energia necessária na bomba. Esta energia é chamada de Altura Manométrica (MATOS; FALCÃO, 1989).

O fabricante (KSB, 2009) fornece uma curva que relaciona a altura manométrica com a vazão que a bomba é capaz de fornecer. Esta curva é comumente chamada de curva característica da bomba.

Na Figura 3-11 pode-se ver a curva característica fornecida pela KSB, fabricante da bomba disponível na Planta de Vazão.

Figura 3-11 Curva Característica da Bomba

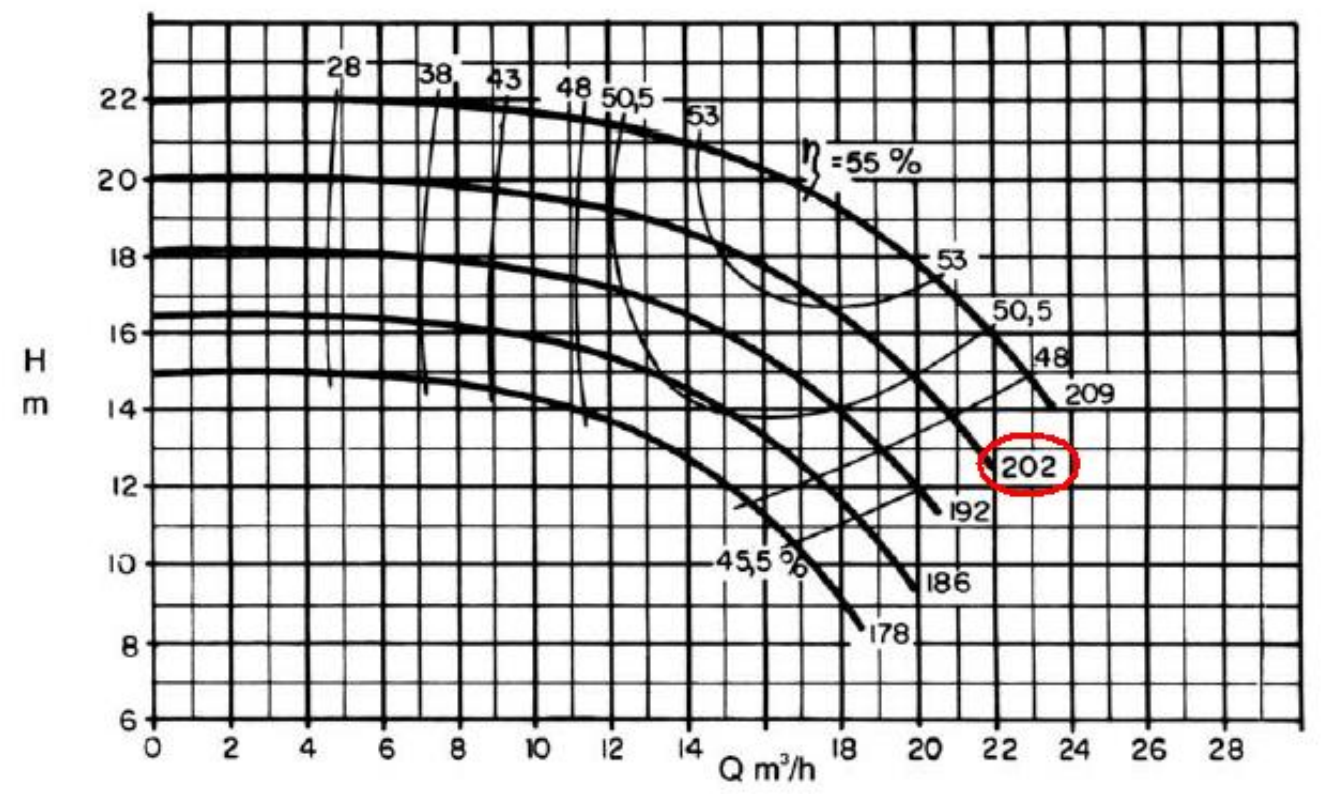

Fonte: (KSB, 2009)

A curva que representa o comportamento da bomba é a 202 da Figura 3-11. Os dados obtidos da curva podem ser vistos na Tabela 3-4. 
Tabela 3-4 Dados da Curva Manométrica da Bomba

\begin{tabular}{|c|c|c|c|c|c|c|c|c|}
\hline $\mathbf{Q}\left(\mathrm{m}^{3} / \mathrm{h}\right)$ & $\mathbf{0}$ & 1 & 2 & 3 & 4 & 5 & 6 & 7 \\
\hline H(mH2O) & 20,00 & 20,00 & 20,00 & 20,00 & 20,00 & 20,00 & 20,00 & 19,95 \\
\hline 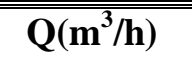 & 8 & 9 & 10 & 11 & 12 & 13 & 14 & 15 \\
\hline $\mathbf{H}(\mathbf{m H 2 O})$ & 19,90 & 19,80 & 19,70 & 19,50 & 19,25 & 19,00 & 18,70 & 18,20 \\
\hline 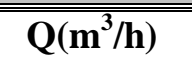 & 16 & 17 & 18 & 19 & 20 & 21 & 22 & \\
\hline H(mH2O) & 17,80 & 17,20 & 16,45 & 15,80 & 14,80 & 13,75 & 12,50 & \\
\hline
\end{tabular}

Com estes dados é possível gerar a curva usando o bloco Lookup Table. O gráfico gerado pode ser visto na Figura 3-12.

Figura 3-12 Curva Característica da bomba gerada em MATLAB®

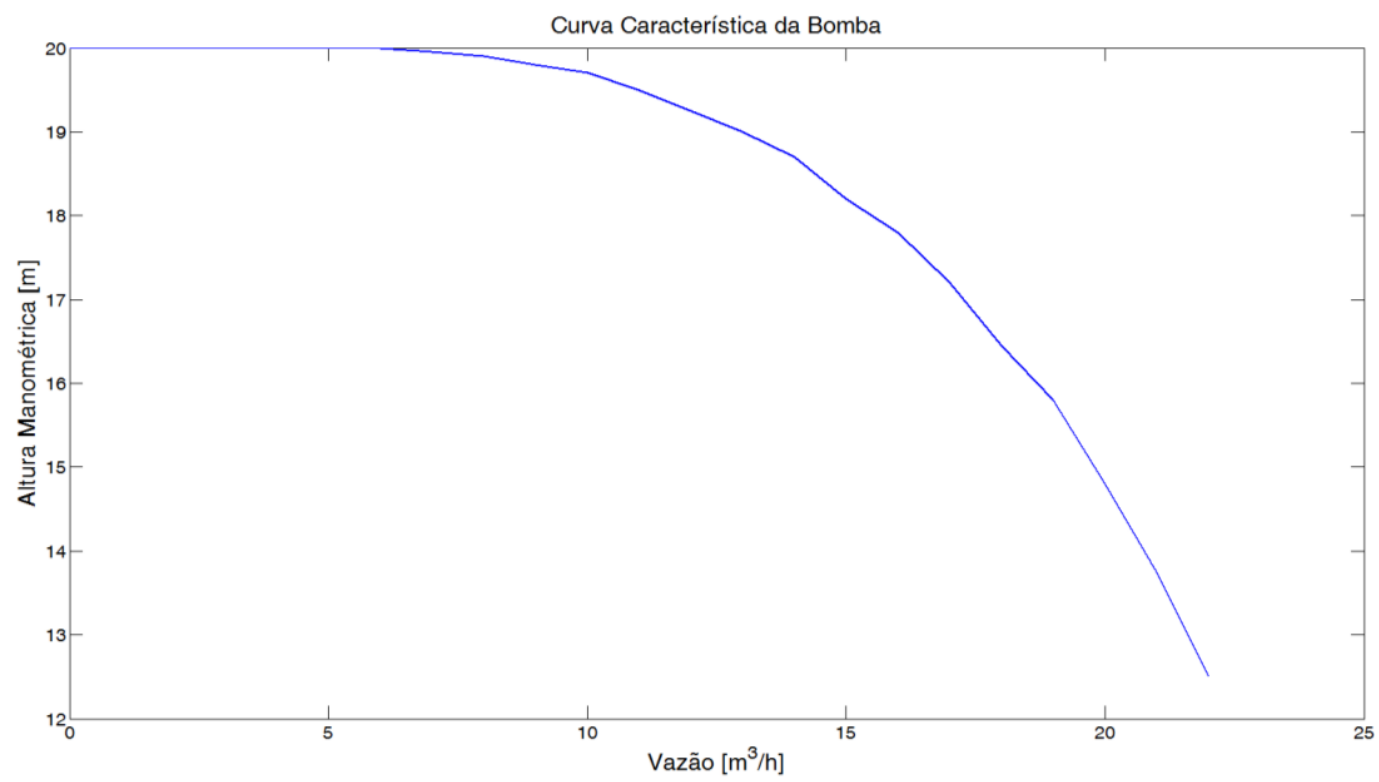

Fonte: Autor 
Esta curva só é válida para rotação nominal, que é de $1725 \mathrm{rpm}$ de acordo com (KSB, 2009) mas para o modelo é necessário obter os valores de $H$ para todas as rotações da bomba, para isto, é necessário aplicar a Lei de Semelhança.

A Lei de Semelhança é uma série de expressões matemáticas que definem mudanças na capacidade da bomba e na carga quando ocorrem mudanças na velocidade da bomba. A lei de semelhança define a proporcionalidade entre vazão e a altura manométrica com relação à rotação da bomba, como se pode ver na equação (3-18) (MATTOS; FALCÃO, 1989).

$$
\frac{N_{0}}{N_{1}}=\frac{Q_{0}}{Q_{1}}=\sqrt{\frac{H_{0}}{H_{1}}}
$$

onde $N_{0}$ é a rotação nominal e $N_{1}$ é rotação desejada, $Q_{0}$ é vazão nominal e $Q_{1}$ é vazão desejada e finalmente $H_{0}$ é a altura manométrica nominal e $H_{1}$ é a altura manométrica desejada.

Por exemplo, no caso da planta de vazão, a rotação nominal da bomba é 1725 rpm e a rotação desejada como rotação inicial para os testes a realizar no modelo é $80 \%$ da rotação nominal. Portanto, a partir da equação (3-18) resulta:

$$
\frac{N_{1}}{N_{0}}=0,8 \quad \frac{Q_{1}}{Q_{0}}=0,8 \quad \frac{H_{1}}{H_{0}}=0,8^{2}
$$

Estas equações são válidas para todas as rotações da bomba. Para o exemplo da equação (3-19), obtém-se o gráfico da Figura 3-13: 
Figura 3-13 Curva característica da bomba para $80 \%$ e $100 \%$ da rotação nominal

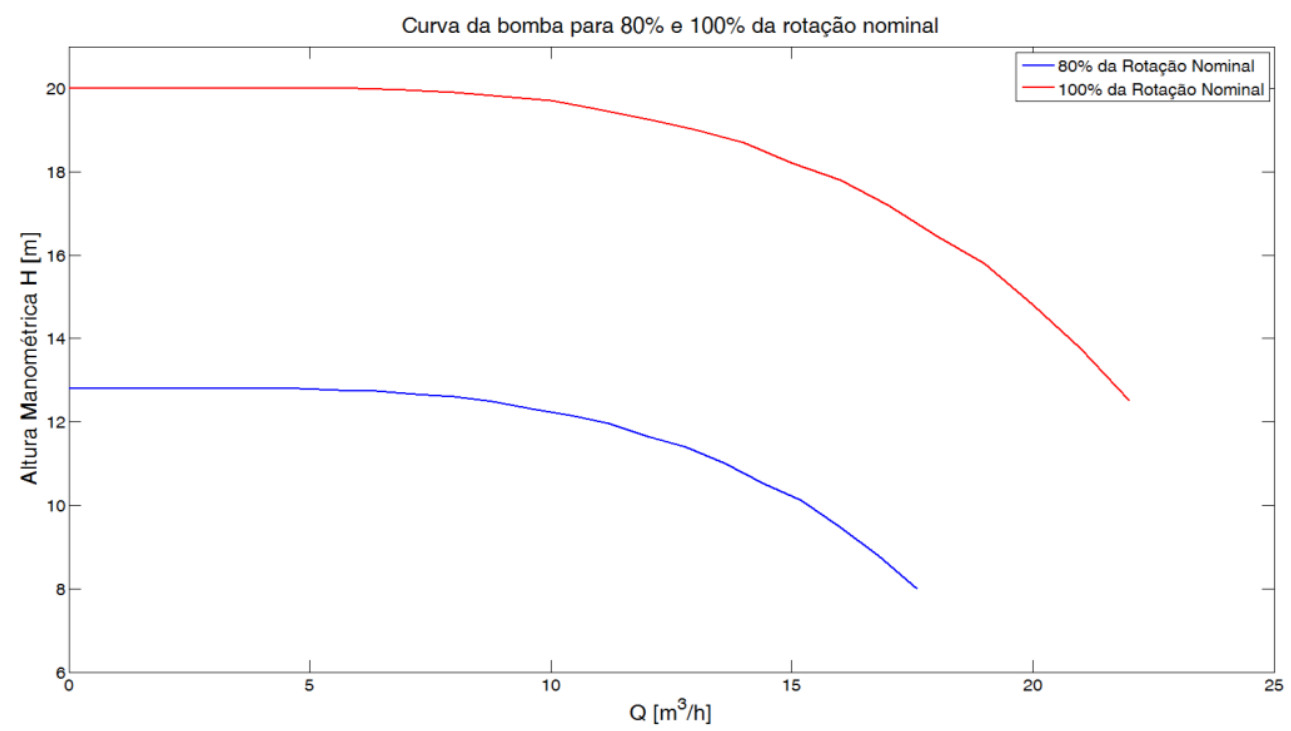

Fonte: Autor

A rotação medida no eixo da bomba apresenta uma diferença comparada com a rotação teórica. Foram realizados testes variando a rotação para obter os valores reais, os resultados podem ser vistos na Tabela 3-5.

Tabela 3-5 Erro na rotação da Bomba

\begin{tabular}{cccc}
\hline $\begin{array}{c}\text { Rotação } \\
\text { Desejada (\%) }\end{array}$ & $\begin{array}{c}\text { Rotação } \\
\text { teórica } \\
(\mathbf{r p m})\end{array}$ & $\begin{array}{c}\text { Rotação } \\
\text { Medida } \\
(\mathbf{r p m})\end{array}$ & $\begin{array}{c}\text { Erro } \\
(\boldsymbol{\%})\end{array}$ \\
\hline $\mathbf{1 0 0}$ & 1725 & 1741 & $-0,93$ \\
$\mathbf{9 0}$ & 1575 & 1621 & $-2,92$ \\
$\mathbf{8 0}$ & 1400 & 1449,6 & $-3,54$ \\
$\mathbf{7 0}$ & 1225 & 1274 & $-4,00$ \\
$\mathbf{6 0}$ & 1050 & 1096 & $-4,38$ \\
$\mathbf{5 0}$ & 875 & 915,46 & $-4,62$ \\
$\mathbf{4 0}$ & 700 & 734,53 & $-6,93$ \\
$\mathbf{3 0}$ & 525 & 555,12 & $-5,74$ \\
$\mathbf{2 0}$ & 350 & 374,63 & $-7,04$ \\
\hline $\mathbf{1 0}$ & 175 & 190,53 & $-8,87$ \\
\hline
\end{tabular}

Fonte: Autor 
Para minimizar o erro no modelo se trabalhou com a rotação real da bomba.

O modelo feito para obter o valor de vazão dependendo da altura manométrica e da rotação da bomba pode ser visto na Figura 3-14.

Figura 3-14 Modelo para a Bomba

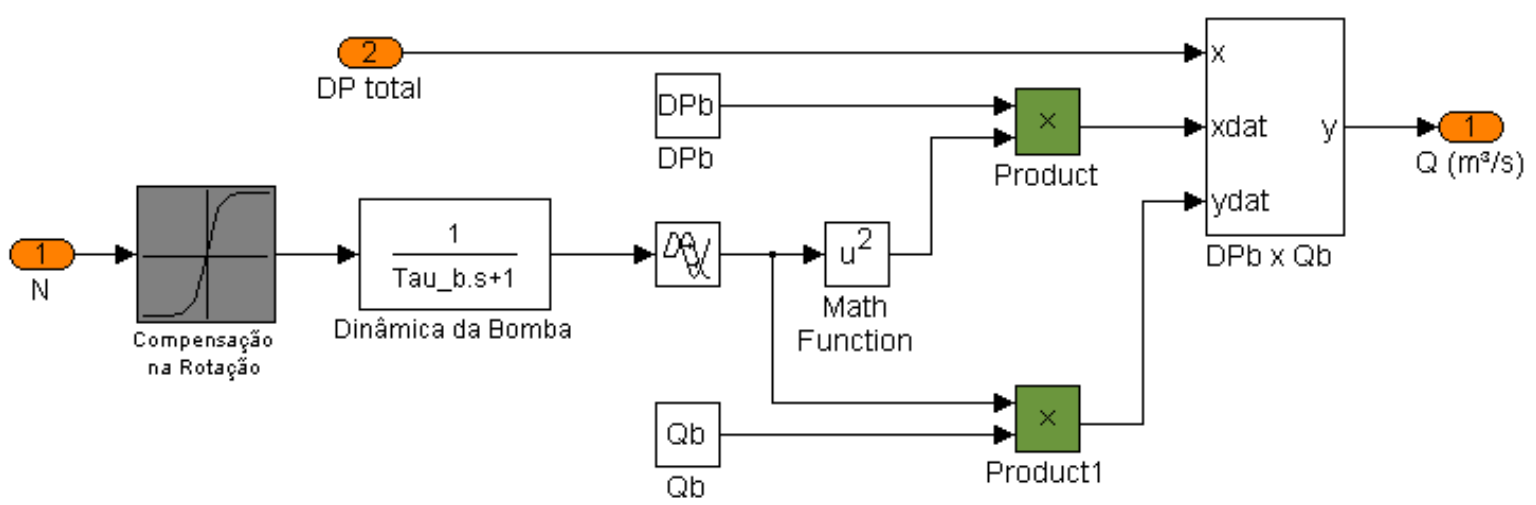

Fonte: Autor

Para este modelo é necessário usar o bloco Lookup Table, mas como os valores das variáveis que influem nesse bloco não são fixos, existe um bloco dinâmico, chamado "Lookup Table Dynamic", nomeado como "DPb x Qb" na Figura 3-14. Esta solução é necessária, pois a rotação $N$ da bomba não é um valor constante, ela pode variar no tempo dependendo do tipo de teste a ser realizado, portanto essa variação influencia diretamente nas entradas do bloco Lookup Table Dynamic, devido às expressões apresentadas na equação (3-19).

O bloco "Compensação na Rotação" representa a correção realizada na rotação de entrada da bomba. $\mathrm{Na}$ entrada se tem a porcentagem de rotação teórica e na saída se tem a porcentagem de rotação real.

O bloco "Dinâmica da bomba" corresponde à inercia da bomba, já que quando é aplicado um degrau na rotação, ela não responde de forma imediata, sendo representada como um sistema de primeira ordem e um tempo morto. 
Na saída do bloco Lookup Table Dynamic se obtém o valor de vazão em função da perda de carga total do processo, mas esse valor não é o valor final, é necessário considerar o efeito que tem o medidor de vazão na leitura final.

\subsection{Medidor de Vazão}

Os medidores de vazão também têm uma dinâmica associada que deve ser considerada. É necessário realizar um modelo para descrever este comportamento, desde o ponto que é obtida a pressão diferencial na placa de orifício até o ponto em que se faz a medição desta variável.

O bloco gerado para obter a pressão na placa pode ser visto na Figura 3-15.

Figura 3-15 Modelo da perda de pressão gerada na placa de orifício

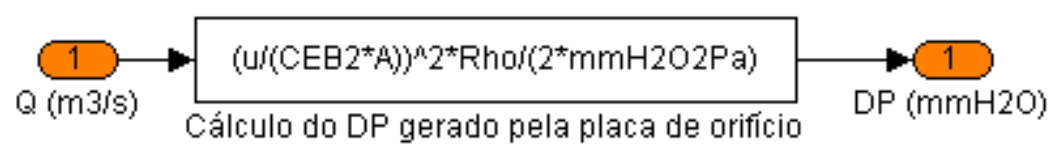

\section{Fonte: Autor}

A pressão diferencial na placa de orifício é calculada por meio da equação (3-16) e esse valor é inserido no bloco do medidor de vazão. Sua dinâmica pode ser vista na Figura 316. 
Figura 3-16 Modelo do Medidor de Vazão.

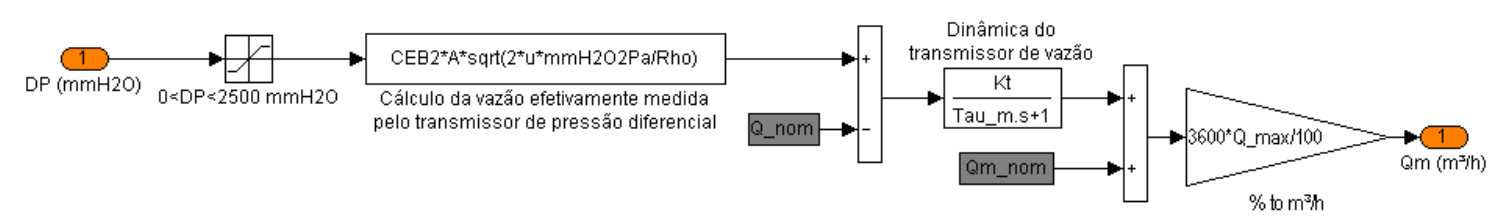

Fonte: Autor

No bloco do medidor é calculada a vazão efetivamente medida pelo transmissor, a qual tem uma relação quadrática com a pressão diferencial gerada pela placa de orifício. Além disso, o medidor tem uma dinâmica com um valor de constante de tempo "Tau_m”, este valor deve ser considerado já que a resposta do medidor possui uma certa dinâmica.

\subsection{Modelos de atrito para as válvulas de controle}

Para cada uma das válvulas foi necessário adicionar o efeito que o Stiction tem sobre as válvulas. A definição de stiction pode ser encontrada em diferentes artigos acadêmicos, este trabalho adotará a definição proposta em (CHOUDHURY et al, 2008) e posteriormente traduzida para o português por (CUADROS, 2011):

Stiction é uma propriedade de um elemento de tal forma que sua movimentação suave, em resposta a uma entrada variável, seja precedida por uma parte estática (banda morta + banda de agarramento) seguida por um salto abrupto repentino, chamado slip-jump. O slip-jump é expresso como uma porcentagem da faixa de saída. Sua origem em um sistema mecânico é o atrito estático, o qual excede o atrito dinâmico (Choudhury, Jain, Shah, 2008, p. 233).

Na Figura 3-17 pode-se observar uma curva típica de assinatura para uma válvula de controle com o efeito do stiction. 


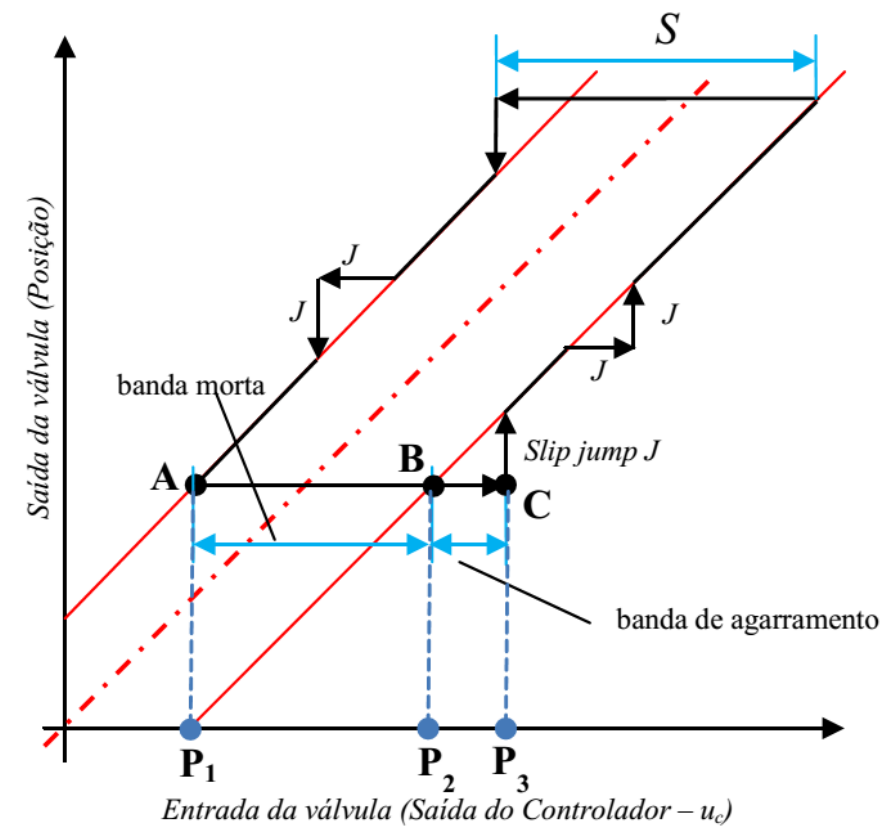

Fonte: Cuadros, (2011)

No ponto A, a válvula esta parada e a sinal do controlador sofreu uma alteração no sentido positivo, a válvula só vai sofrer uma alteração na posição quando a variação da entrada seja superior ao valor da banda morta (A-B) mais o valor da banda de agarramento (B-C). Nesse ponto, quando a válvula supera o atrito estático ocorre um movimento abrupto que é chamado de slip-jump (J), isto ocorre porque o atrito dinâmico é inferior ao atrito estático, depois disto a válvula entra numa fase de movimento, onde a entrada e a saída apresentam uma relação linear. Se a velocidade de movimento da haste da válvula for baixa em algum ponto de movimento, a válvula vai entrar na fase de agarramento e para que a válvula volte a variar na mesma direção é necessário superar novamente a banda de agarramento. Se o sinal do controlador sofre uma reversão, o processo se repete no sentido contrário.

A banda morta, definida na norma (ISA, 2000), é a faixa de valores em que um sinal pode ser variado, com reversão de direção, sem iniciar uma mudança observável no sinal de saída. 
Em (CASTRO, 2012) foram estudados diferentes modelos para representar o efeito do stiction e neste trabalho vamos considerar dois modelos, o modelo de Kano e o modelo de Karnopp.

\subsubsection{Modelo de Karnopp}

O modelo de Karnopp é um modelo analítico que emprega a Lei de Newton (equação (320)) para descrever o comportamento da haste da válvula.

$m \frac{d^{2} x}{d t^{2}}=\sum$ Forças $=F_{\text {pressão }}+F_{\text {atrito }}+F_{\text {mola }}+F_{\text {fluido }}+F_{i}$

onde:

$m$ é a massa das partes moveis da válvula (haste + obturador);

$F_{\text {pressão }}=A^{*} p$ é a força aplicada pelo atuador pneumático, onde $A$ é a área do atuador e $p$ é a pressão aplicada;

$F_{\text {atrito }}$ é a força de atrito na válvula;

$F_{\text {fluido }}$ é a força devido à perda de carga através da válvula;

$F_{i}$ é a força extra de assentamento da haste na sede da válvula.

Conforme (KAYIHAN; DOYLE III, 2000), na maioria das aplicações $F_{\text {fluido }}$ e $F_{i}$ são desprezíveis, portanto a equação pode ser reescrita como se pode ver na equação (3-21).

$$
m \frac{d^{2} x}{d t^{2}}=\sum \text { Forças }=F_{\text {pressão }}+F_{\text {atrito }}+F_{\text {mola }}
$$

Para a modelagem da força de atrito $\left(F_{\text {atrito }}\right)$ Karnopp propõe uma equação (3-22) para calcular a mudança abrupta na força de atrito no inicio do movimento da válvula. 
$F_{\text {atrito }}=\left[F_{C}+\left(F_{S}-F_{c}\right) e^{-\left(v / v_{s}\right)}\right] \operatorname{sgn}(v)+F_{v} v$

onde:

$F_{C}$ é o coeficiente de atrito de Coulomb;

$F_{S}$ é o coeficiente de atrito estático;

$F_{v}$ é o coeficiente de atrito viscoso;

$v$ é a velocidade da haste;

$v_{s}$ é a velocidade de Stribeck.

Este modelo gera uma representação mais precisa do efeito do slip-jump comparado com os outros modelos usados em (GARCIA, 2008), porem, é um modelo lento de simular, pois precisa um passo de integração de $10^{-6} \mathrm{~s}$, o qual aumenta significativamente o tempo de simulação comparado com o modelo de Kano, que pode utilizar passos de integração de $10^{-3} \mathrm{~s}$.

Para fazer o cálculo dos parâmetros de atrito aplicou-se sinal triangular com três ciclos completos nas duas válvulas sem vazão. Os dados foram coletados com uma frequência de $1000 \mathrm{~Hz}$. A Figura 3-18 apresenta a resposta do conversor I/P e a Figura 3-19 mostra a resposta da posição da haste em mm da válvula com gaxetas de teflon.

Figura 3-18 Pressão da válvula com gaxetas de teflon.

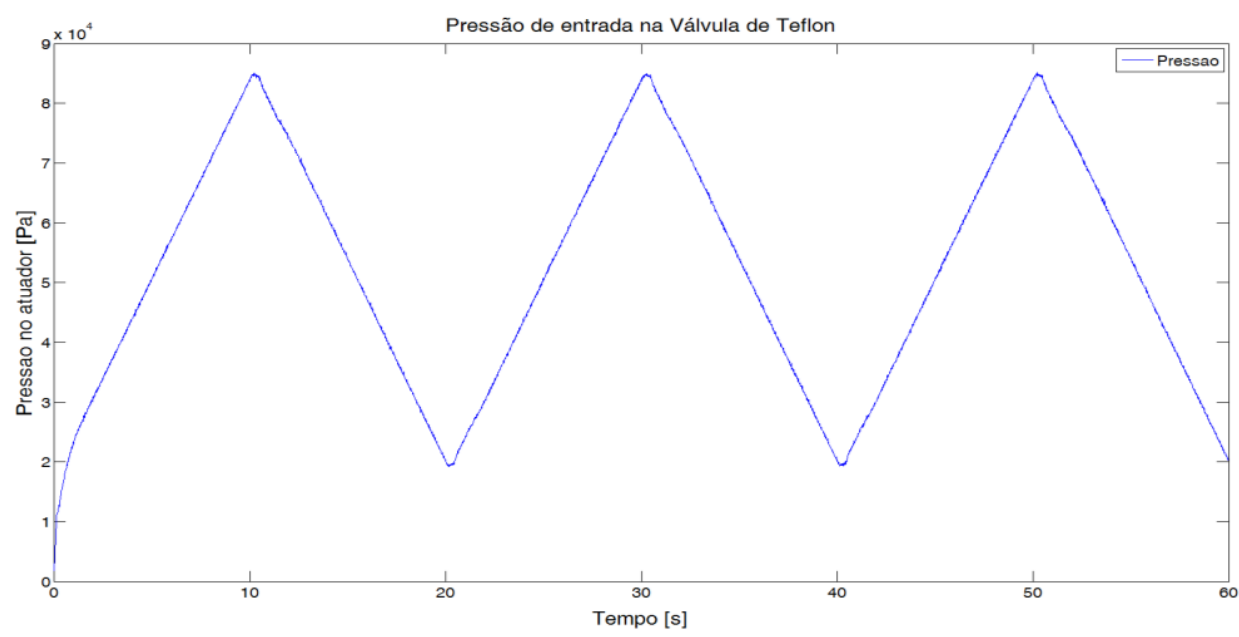

Fonte: Autor 
Figura 3-19 Posição da haste da válvula com gaxetas de teflon.

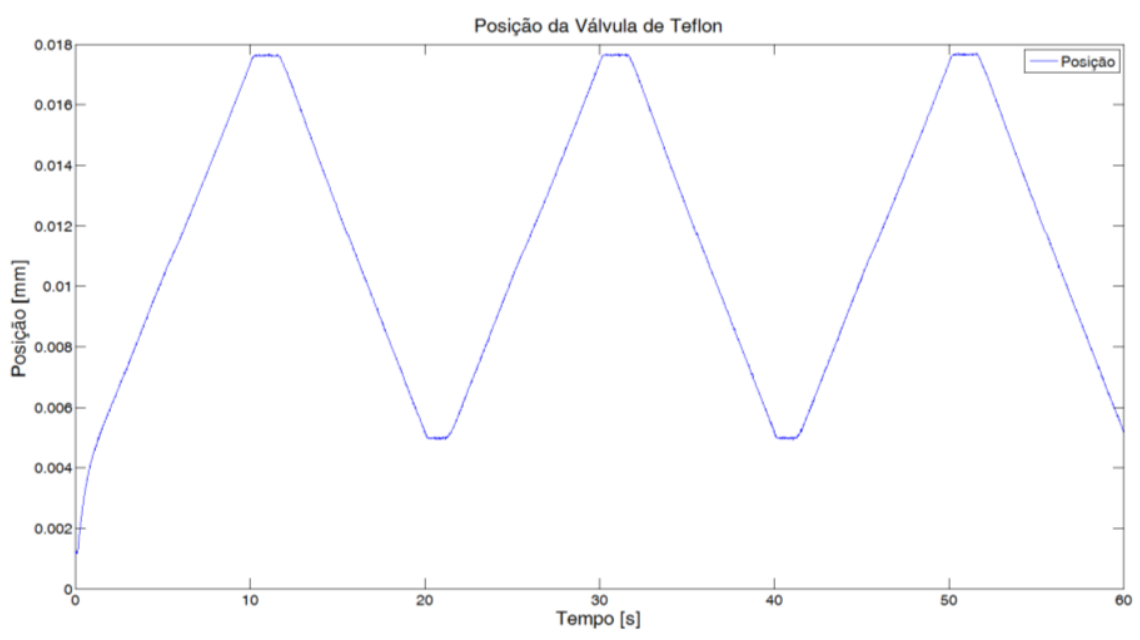

Fonte: Autor

Os resultados de pressão e posição para a válvula com gaxetas de grafite se apresentam nas Figuras 3-20 e 3-21, respetivamente.

Figura 3-20 Pressão na válvula com gaxeta de Grafite.

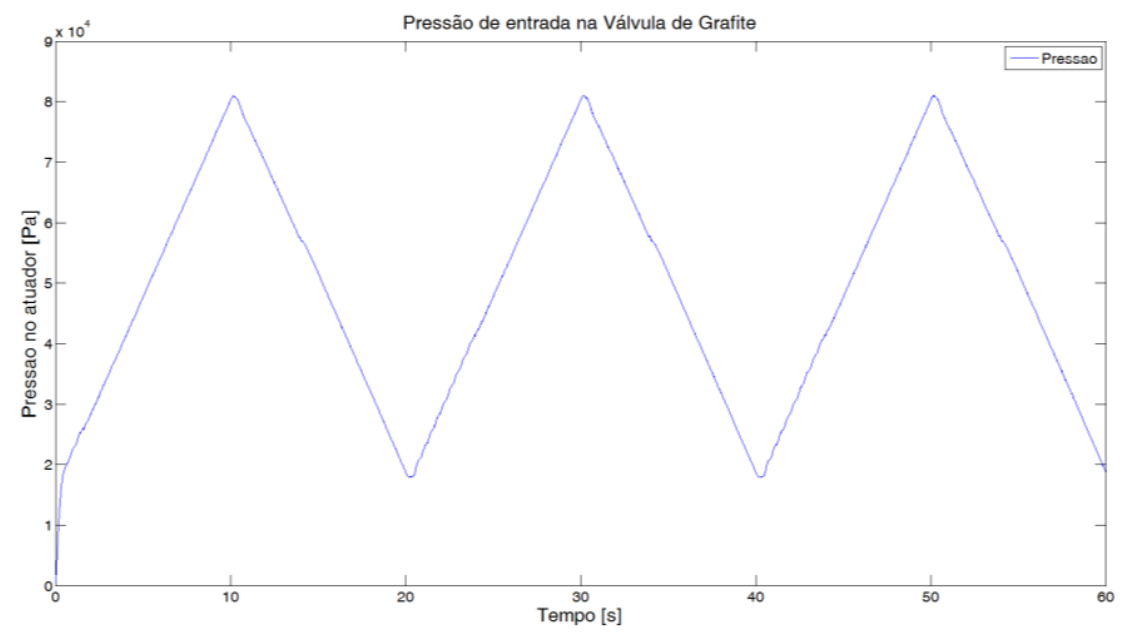

Fonte: Autor 
Figura 3-21 Posição da haste da válvula com gaxeta de Grafite

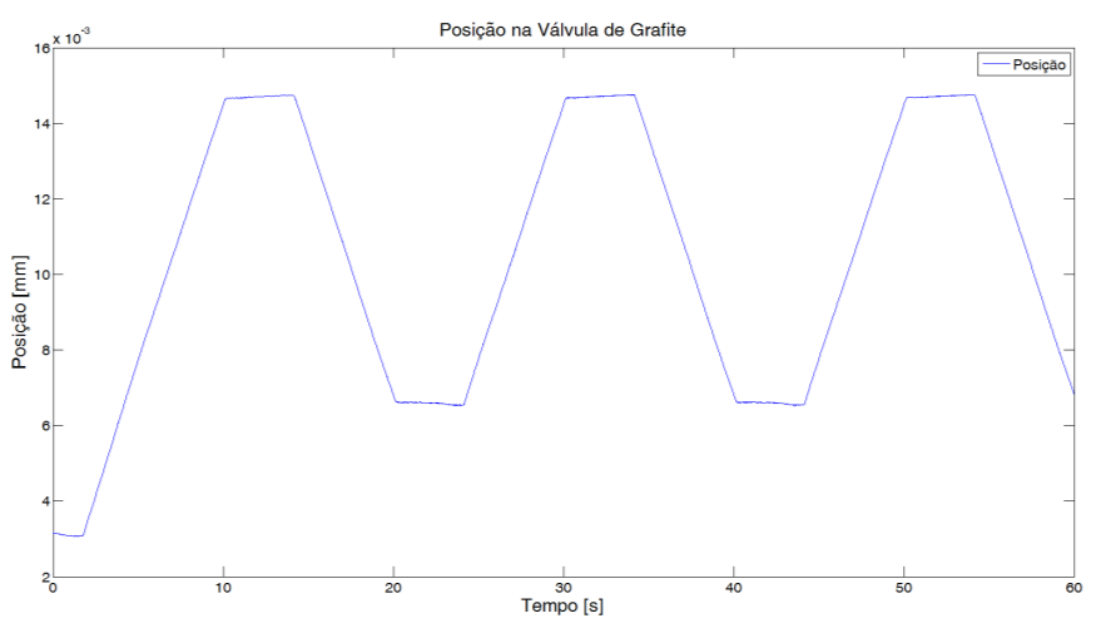

Fonte: Autor

Com os dados de pressão e posição das válvulas é possível geral o gráfico de assinatura de cada uma delas, na Figura 3-22 se apresenta o gráfico de assinatura para a válvula de teflon e a Figura 3-23 corresponde à assinatura da válvula de grafite.

Figura 3-22 Assinatura da válvula com gaxetas de teflon.

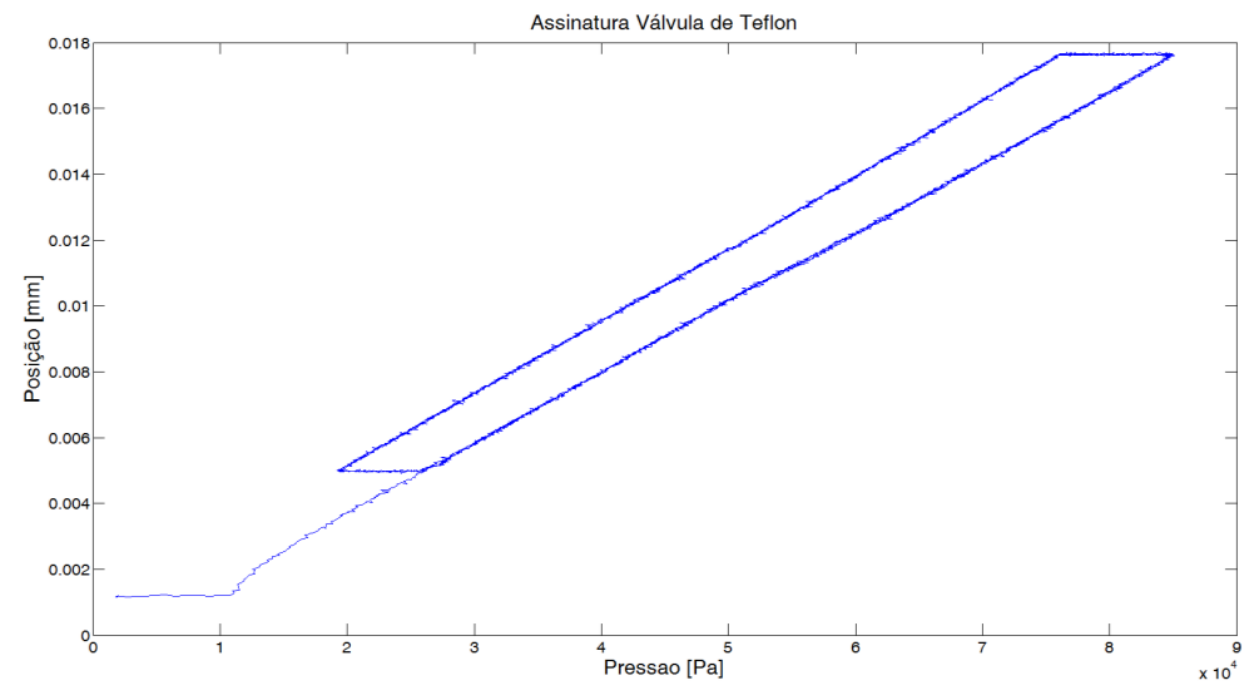

Fonte: Autor 
Figura 3-23 Assinatura da válvula com gaxetas de grafite.

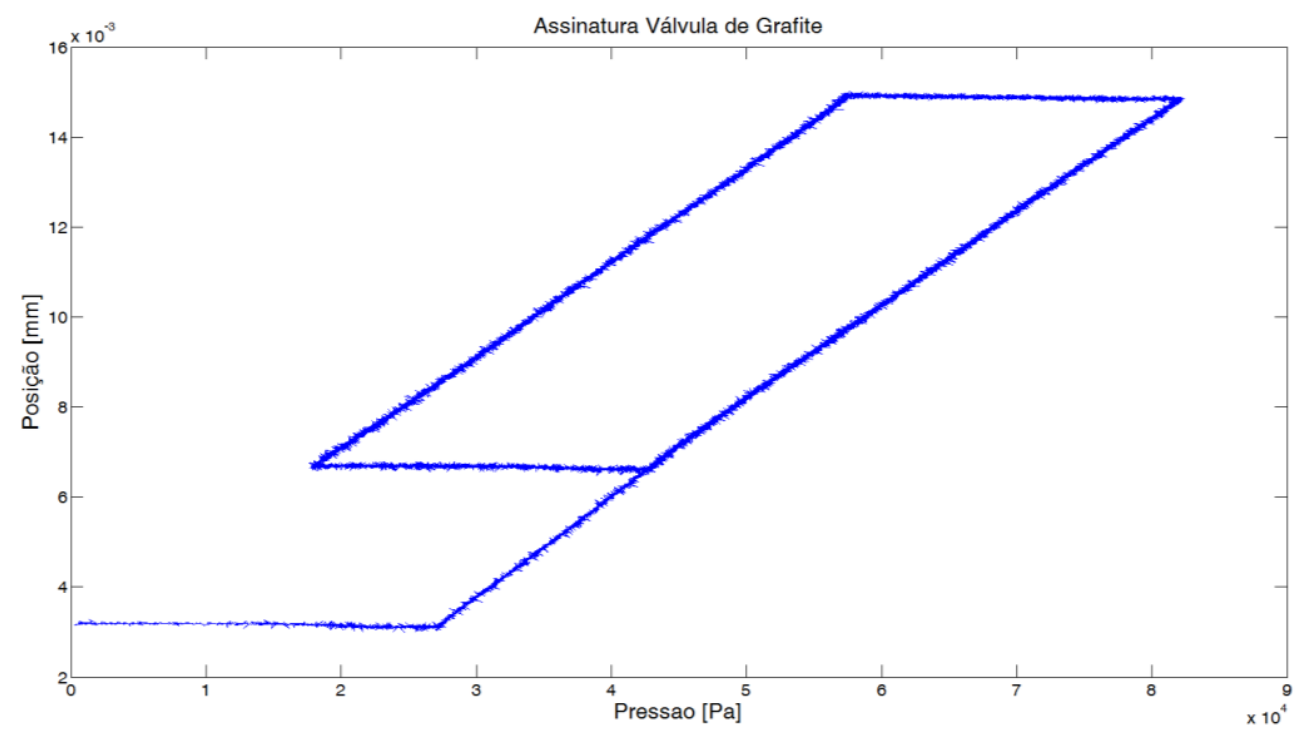

Fonte: Autor

Com os gráficos de assinatura é possível realizar uma estimação dos parâmetros de Karnopp (GARCIA, 2007). Nas rampas de subida e descida da haste, a velocidade é contínua e a aceleração é nula, portanto, de acordo com as Equações (3.21) e (3.22) são selecionados dois pontos distintos da mesma rampa, obtendo-se:

$$
\begin{aligned}
& 0=S_{a} P_{1}-F_{c} \operatorname{sgn}(v)-K x_{1}-F_{v} v \\
& 0=S_{a} P_{2}-F_{c} \operatorname{sgn}(v)-K x_{2}-F_{v} v
\end{aligned}
$$

Com as equações (3.23) e (3.24) é possível calcular o valor de $K$, obtendo-se:

$$
K=\frac{S_{a}\left(P_{1}-P_{2}\right)}{x_{1}-x_{2}}
$$

Com o valor de $K$ estimado com a equação (3.35) é possível estimar $F_{S}$ escolhendo um ponto em que a válvula esteja no ponto máximo de pressão, antes dela se movimentar, garantindo que o atrito estático esteja no ponto máximo com velocidade nula, obtendo-se: 


$$
0=S_{a} P-K x \pm F_{S}
$$

onde ( \pm ) depende da direção em que a válvula irá iniciar seu movimento.

Para estimar o valor de $F_{v}$ é necessário identificar dois pontos em que a válvula se move na mesma direção com velocidades diferentes. Das equações (3.21) e (3.22) obtém-se:

$0=S_{a} P_{1}-K x_{1}-F_{c} \operatorname{sgn}\left(v_{1}\right)-F_{v} v_{1}$

$0=S_{a} P_{2}-K x_{2}-F_{c} \operatorname{sgn}\left(v_{2}\right)-F_{v} v_{2}$

Obtendo-se:

$F_{v}=\frac{S_{a}\left(P_{2}-P_{1}\right)-K\left(x_{2}-x_{1}\right)}{\left(v_{2}-v_{1}\right)}$

Finalmente, para $F_{c}$ tem-se:

$F_{c}=\left(S_{a} P-K x-F_{v} v\right) \operatorname{sgn}(v)$

A equação (3.30) pode ser aplicada em qualquer ponto onde a haste da válvula tenha velocidade constante.

A partir destas equações se obtiveram valores para as duas válvulas. A Tabela 3-6 mostra os resultados obtidos em (CASTRO, 2013).

Tabela 3-6 Resultados obtidos em (CASTRO, 2013).

\begin{tabular}{ccccc}
\hline $\begin{array}{c}\text { Material das } \\
\text { Gaxetas }\end{array}$ & $K$ & $\boldsymbol{F s}$ & $\boldsymbol{F v}$ & $\boldsymbol{F c}$ \\
\hline Teflon & $200350 \mathrm{~N} / \mathrm{m}$ & $113,664 \mathrm{~N}$ & $7064 \mathrm{~N} \mathrm{~s} / \mathrm{m}$ & $127,895 \mathrm{~N}$ \\
Grafite & $210490 \mathrm{~N} / \mathrm{m}$ & $773,504 \mathrm{~N}$ & $23206 \mathrm{~N} \mathrm{~s} / \mathrm{m}$ & $684,069 \mathrm{~N}$ \\
\hline
\end{tabular}

Fonte: Autor 
Realizaram-se testes com os valores da Tabela 3-6 e não foram satisfatórios, apresentavam um pequeno erro com respeito aos valores reais. Assim um refinamento dos dados foi realizado para melhorar os resultados. Os resultados obtidos são apresentados na Tabela 3-7.

Tabela 3-7 Resultados obtidos dos parâmetros de Karnopp.

\begin{tabular}{ccccc}
\hline $\begin{array}{c}\text { Material das } \\
\text { Gaxetas }\end{array}$ & $K$ & $\boldsymbol{F s}$ & $\boldsymbol{F v}$ & $\boldsymbol{F c}$ \\
\hline Teflon & $203120 \mathrm{~N} / \mathrm{m}$ & 180,546 & $7064 \mathrm{~N} \mathrm{~s} / \mathrm{m}$ & $146,873 \mathrm{~N}$ \\
Grafite & $210490 \mathrm{~N} / \mathrm{m}$ & $640,504 \mathrm{~N}$ & $23206 \mathrm{~N} \mathrm{~s} / \mathrm{m}$ & $554,057 \mathrm{~N}$ \\
\hline
\end{tabular}

Fonte: Autor

Nas Figuras 3-24 e 3-25 são apresentados os resultados obtidos ao se realizar uma validação do modelo de Karnopp.

Figura 3-24 Validação do modelo de Karnopp na válvula com gaxetas de teflon

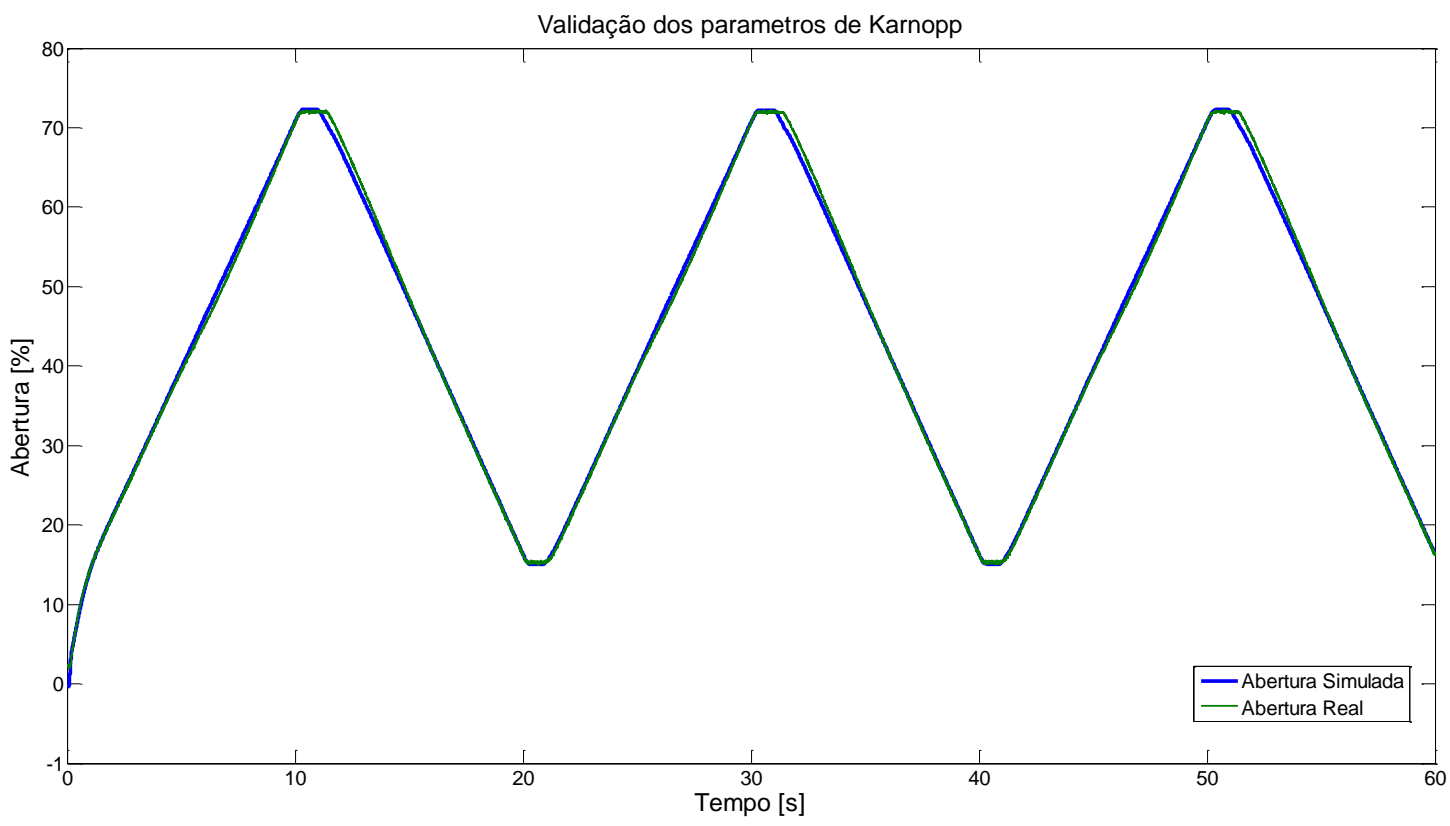

Fonte: Autor 
Figura 3-25 Validação do modelo de Karnopp na válvula com gaxetas de grafite

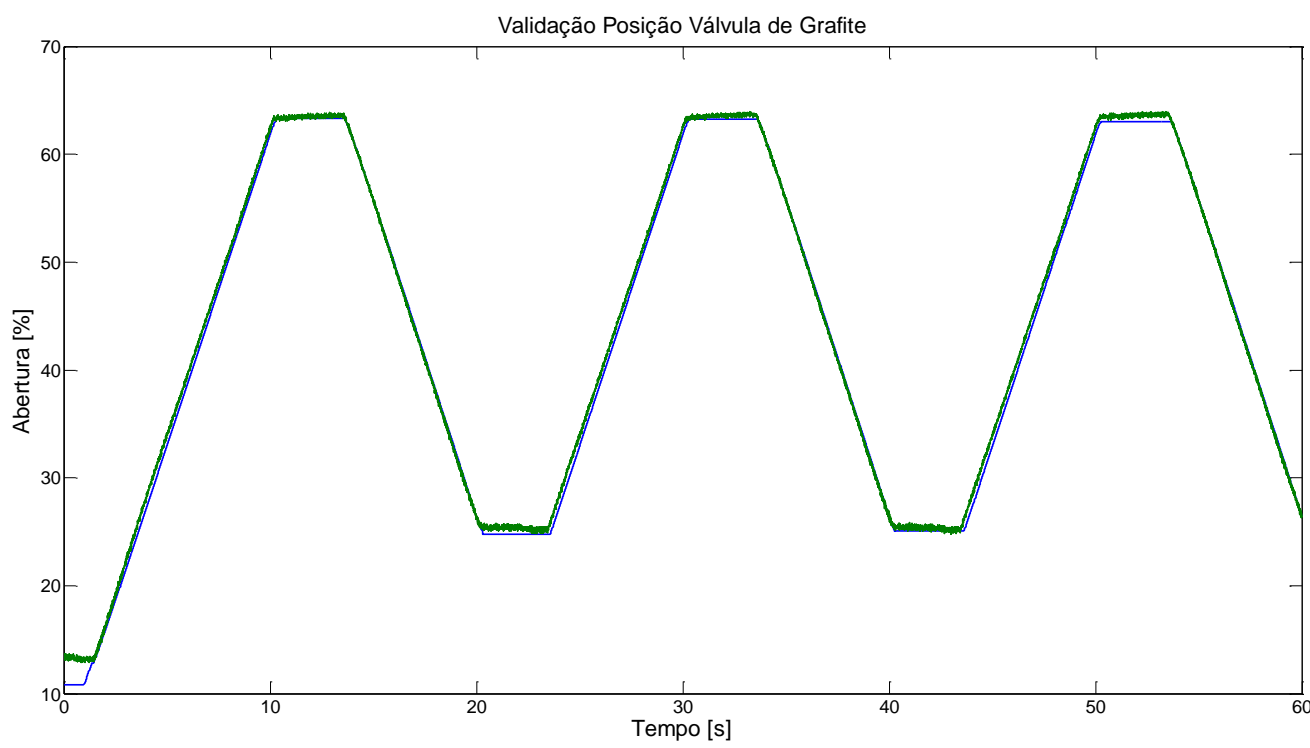

Fonte: Autor

Adicionalmente se fez uma validação com a assinatura das duas válvulas para comparar os resultados obtidos no modelo. A Figura 3-26 mostra o gráfico correspondente à assinatura da válvula com gaxetas de teflon.

Figura 3-26 Comparação da assinatura real e simulada da válvula com gaxetas de teflon

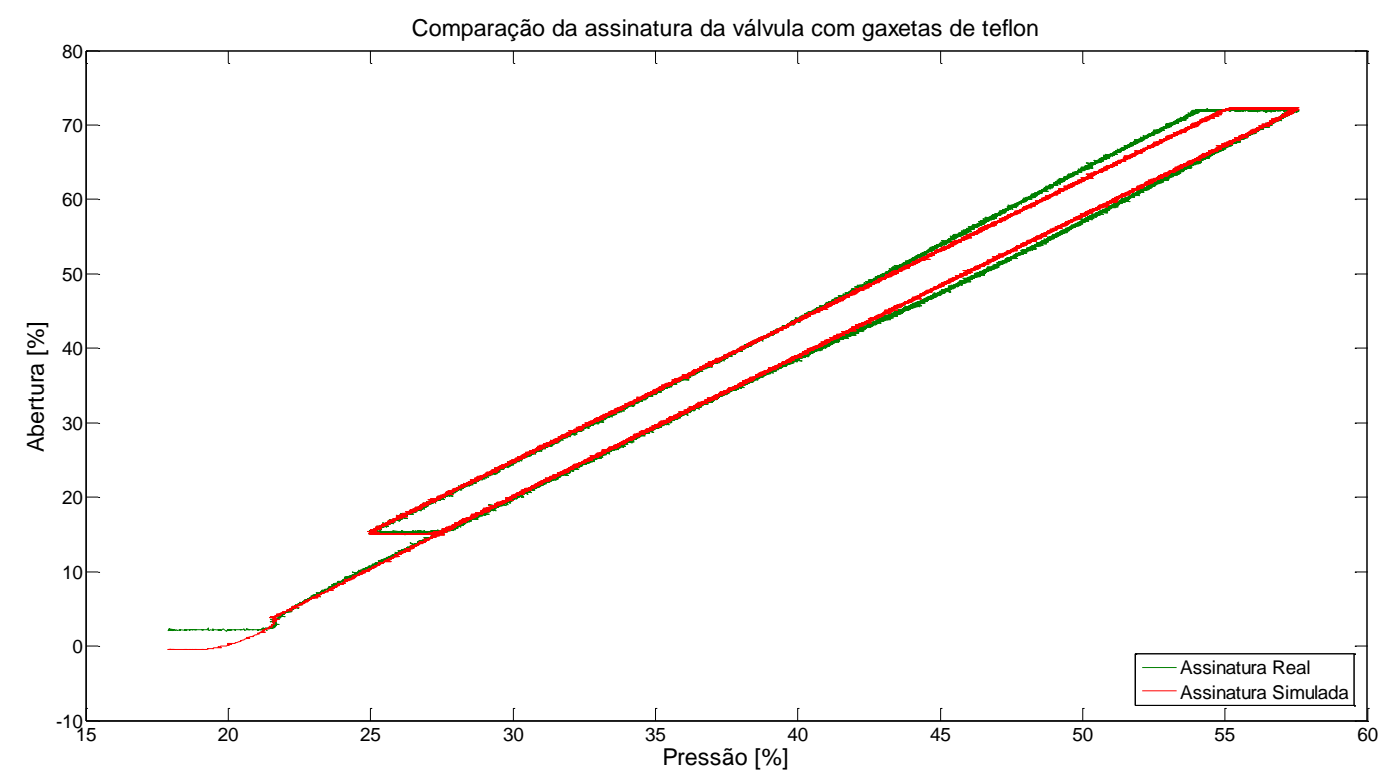

Fonte: Autor 
Pode-se ver na Figura 3-26 que o modelo teve um erro no ponto quando a válvula esta se fechando, isto é porque a válvula está apresentando um coeficiente de atrito diferente, dependendo do sentido do movimento da haste. Os modelos de Kano e Karnopp consideram válvulas que tenham o mesmo comportamento para os dois sentidos de movimento, porém, o erro foi aceitável em uma grande parte do gráfico.

A Figura 3-27 apresenta o resultado de comparar a assinatura real com a simulada da válvula com gaxetas de grafite.

Figura 3-27 Comparação da assinatura real e simulada da válvula com gaxetas de grafite

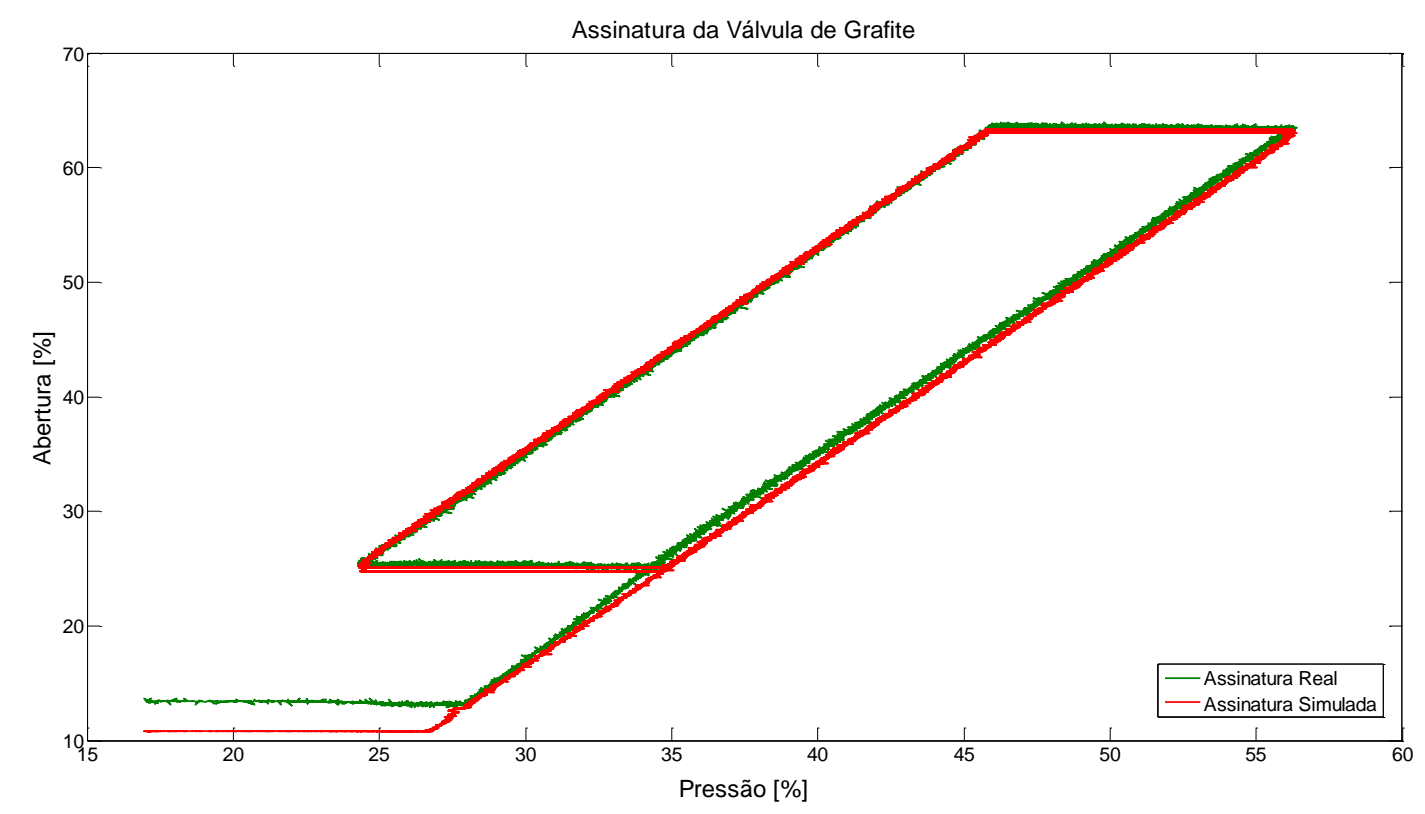

Fonte: Autor

\subsubsection{Modelo de Kano}

O modelo de Kano (2004) está baseado em dois parâmetros ( $S$ e $J$ ). Na prática é muito difícil identificar o parâmetro $J$, pois seu o efeito é muito pequeno. 
Em (KANO et al., 2004) se apresenta uma técnica para estimar o parâmetro $S$ quando $J$ é desprezível. Em (CASTRO, 2013) se apresentam os resultados pelo método de identificação de Kano, os valores obtidos para $S$ são apresentados na Tabela 3-8.

Tabela 3-8 Resultados obtidos pelo método de identificação de Kano

\begin{tabular}{ccc}
\hline $\begin{array}{c}\text { Material das } \\
\text { Gaxetas }\end{array}$ & $S$ & $J$ \\
\hline Teflon & $4,14 \%$ & - \\
Grafite & $19,82 \%$ & - \\
\hline
\end{tabular}

Fonte: (CASTRO, 2013).

Nos parâmetros de Kano também foi necessário realizar um refinamento dos valores que foram obtidos em (CASTRO, 2013). Os resultados obtidos se mostram na Tabela 3-9.

Tabela 3-9 Refinamento dos parâmetros obtidos em (CASTRO, 2013)

\begin{tabular}{ccc}
\hline $\begin{array}{c}\text { Material das } \\
\text { Gaxetas }\end{array}$ & $S$ & $J$ \\
\hline Teflon & $4,51 \%$ & - \\
Grafite & $16,01 \%$ & - \\
\hline
\end{tabular}

Fonte: (CASTRO, 2013).

Com os valores obtidos foram realizados os mesmos testes que com o modelo de Karnopp. Na Figura 3-28 se apresenta o resultado de validar a posição real com a posição simulada da válvula de Teflon. 
Figura 3-28 Validação dos parâmetros de Kano na válvula com gaxetas de teflon.

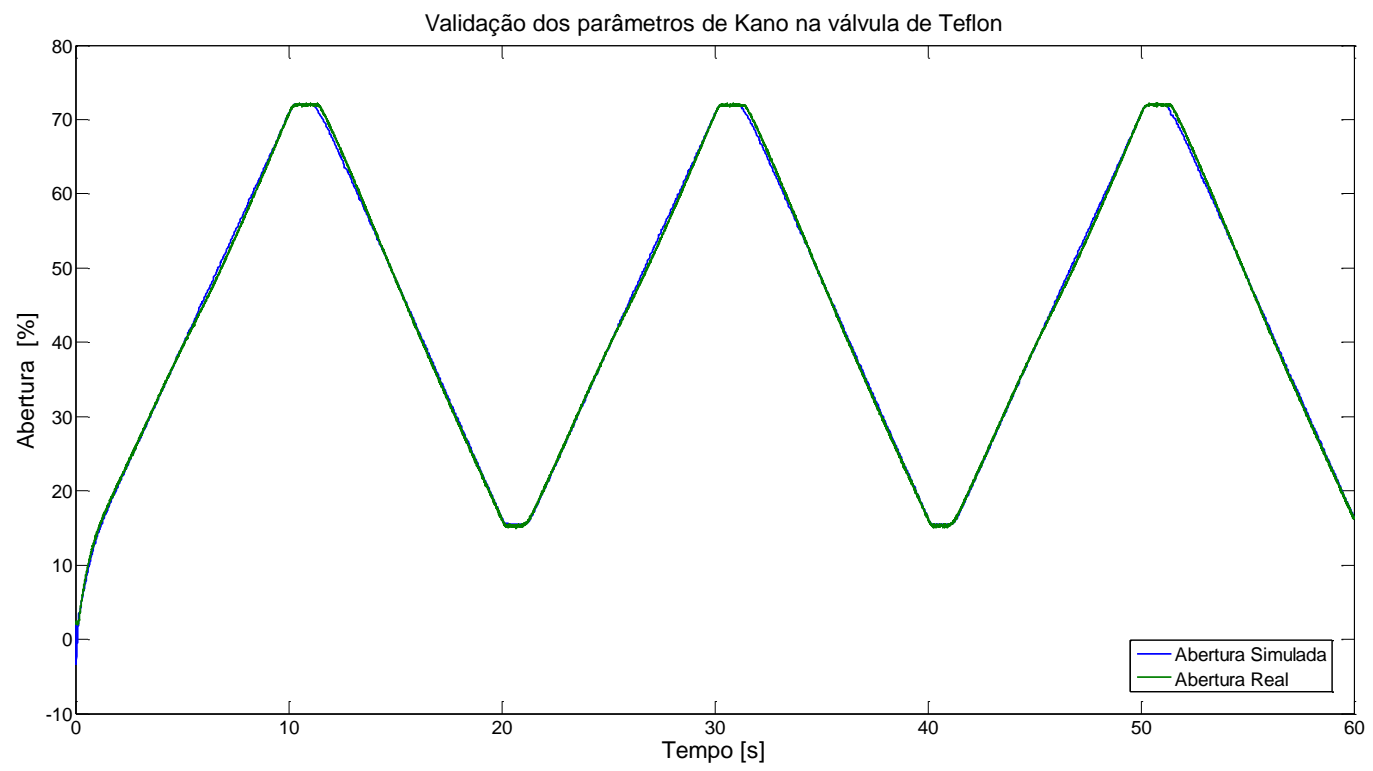

Fonte: Autor

A Figura 3-29 apresenta os resultados obtidos da validação dos parâmetros de Kano na válvula com gaxetas de grafite.

Figura 3-29 Validação dos parâmetros de Kano na válvula de Grafite

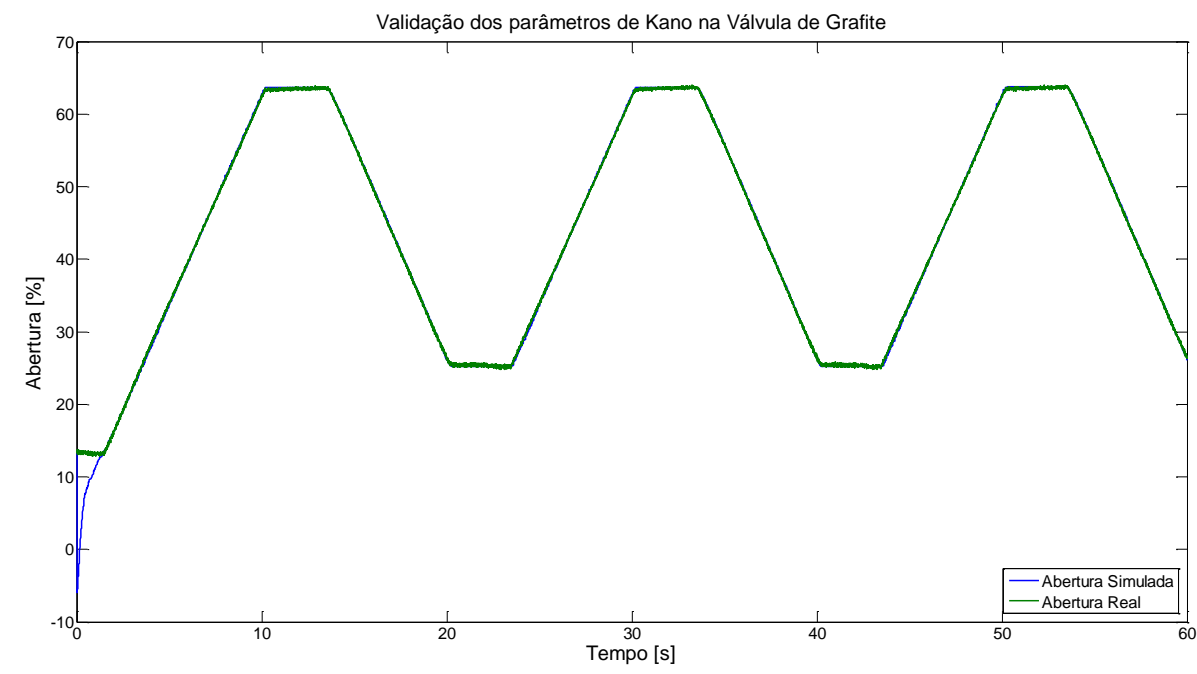

Fonte: Autor 
Realizou-se a validação das curvas de assinatura para as duas válvulas. A Figura 3-30 mostra a curva de assinatura com os parâmetros de Kano obtidos para a válvula com gaxetas de teflon e a Figura 3-31 apresenta os resultados para a válvula com gaxetas de grafite.

Figura 3-30 Assinatura da válvula com gaxetas de teflon com os parâmetros obtidos.

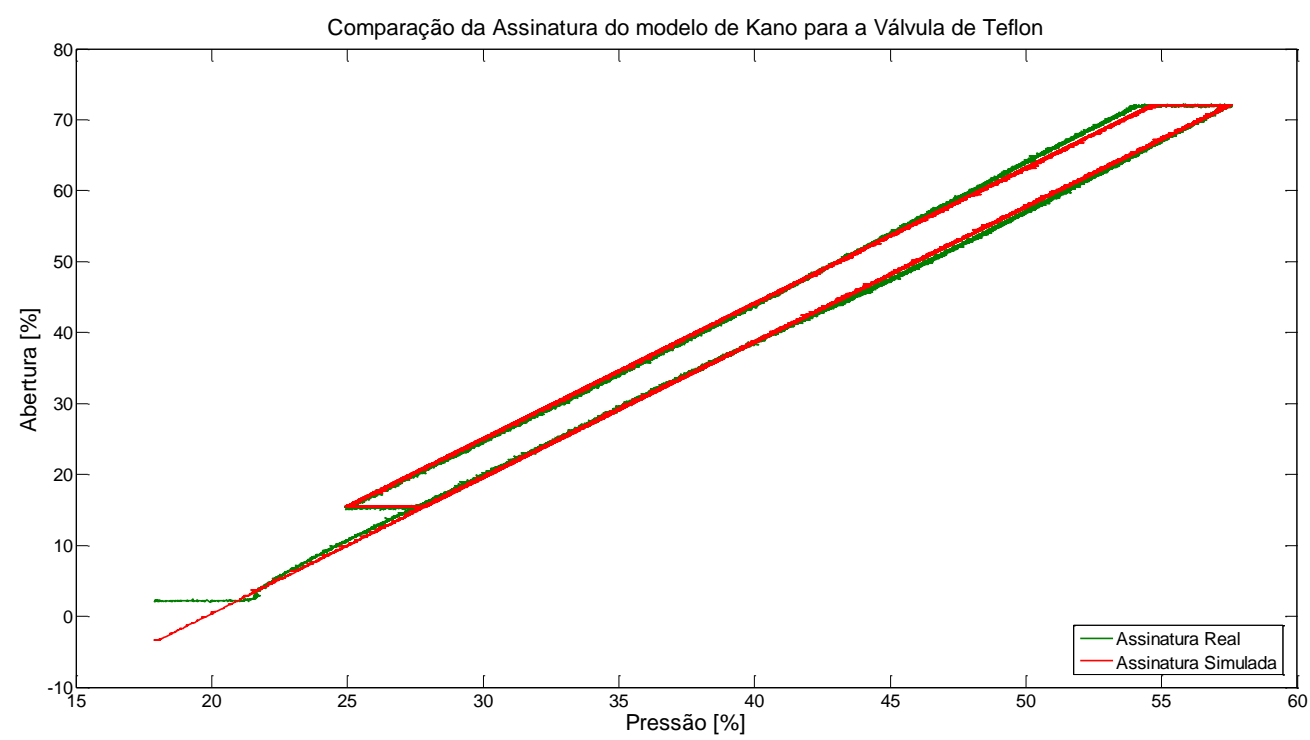

\section{Fonte: Autor}

Figura 3-31 Assinatura da válvula com gaxetas de grafite com os parâmetros obtidos.

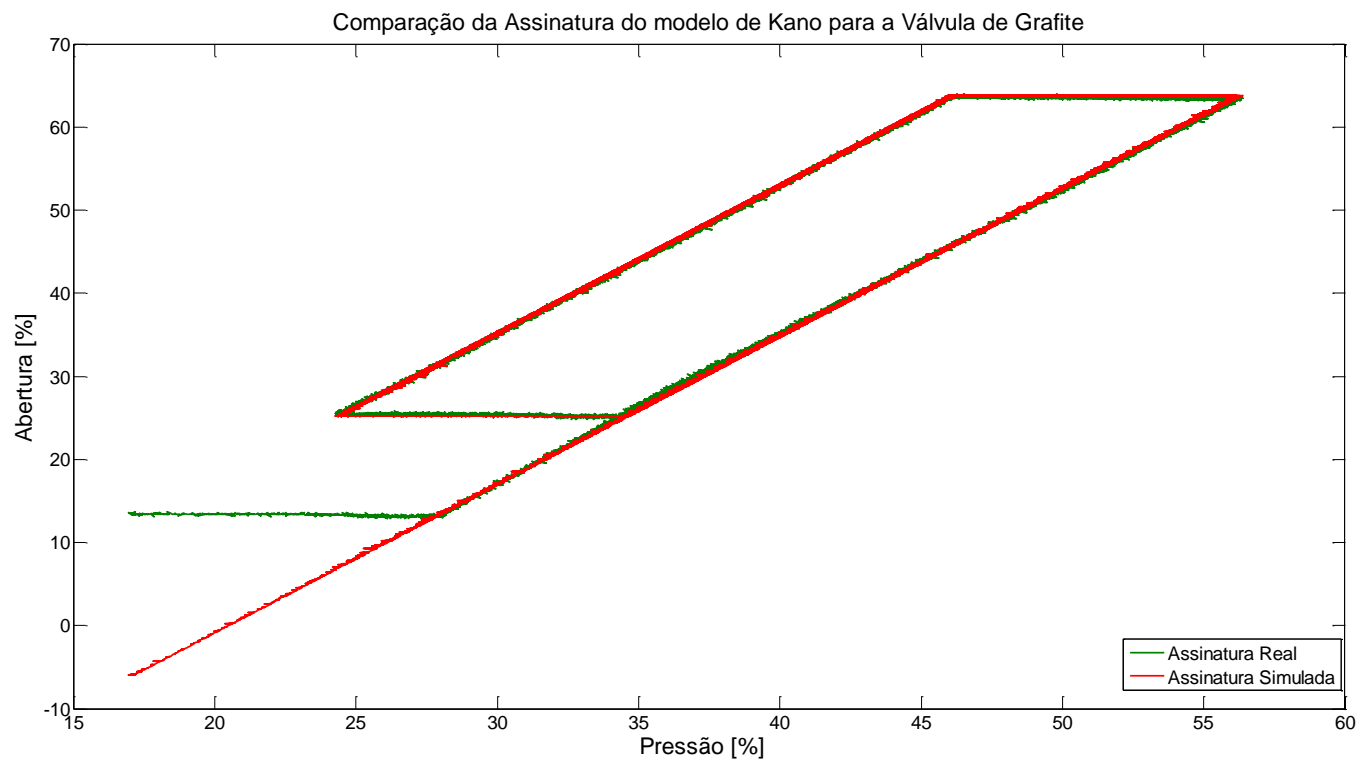

Fonte: Autor 


\subsection{Identificação do conversor I/P+Atuador}

O conjunto do conversor $\mathrm{I} / \mathrm{P}+$ atuador converte o sinal de entrada em sinal de pressão. É necessário modelá-lo, pois ele tem uma dinâmica associada e seu comportamento é não linear. Isto quer dizer que o ganho não é constante para todos os sinais que são enviados.

Realizou-se uma modelagem por métodos de identificação de sistemas, a partir de variáveis coletadas na planta.

Existem diferentes estruturas para representar o comportamento de um processo dinâmico, as mais conhecidas são as estruturas $A R X, A R M A X, O E$ e $B J$, cada uma delas tem diferentes propriedades (LJUNG, 1999). No caso da modelagem da planta de vazão vai ser usada a estrutura OE, pois neste modelo a relação entrada saída pode ser escrita como uma equação linear de diferenças e as perturbações de saída são representadas como um modelo de ruído branco na medição. O atuador não possui perturbações consideráveis onde seja necessário fazer uma descrição das propriedades delas. Portanto decidiu-se trabalhar com uma estrutura do tipo OE.

A estrutura do modelo OE pode ser vista na Figura 3-32, e a equação (3.31) que descreve o modelo.

Figura 3-32 Estrutura do modelo OE.

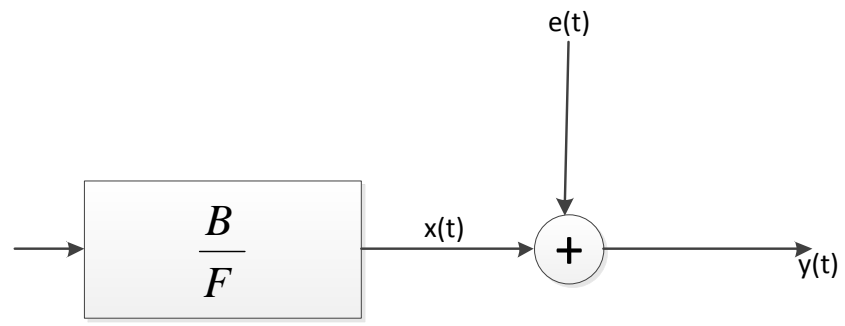

Fonte: Autor

$y(t)=\frac{\hat{B}(q)}{\hat{F}(q)} u(t)+\varepsilon(t)$ 
Para realizar a identificação do atuador foram testadas três tipos de sinais de entrada, um sinal tipo GBN (Generalized Binary Noise) (ALVARADO, 2013), um sinal tipo random number (GARCIA, 2011) e finalmente um sinal senoidal com diversas frequências (TRUNG et al., 2011). Foram coletadas amostras com tempo suficiente para poder ter uma boa descrição do comportamento dinâmico do processo.

A Figura 3-33 mostra um trecho de um dos sinais GBN gerados para avaliar a dinâmica do atuador.

Figura 3-33 Sinal GBN.

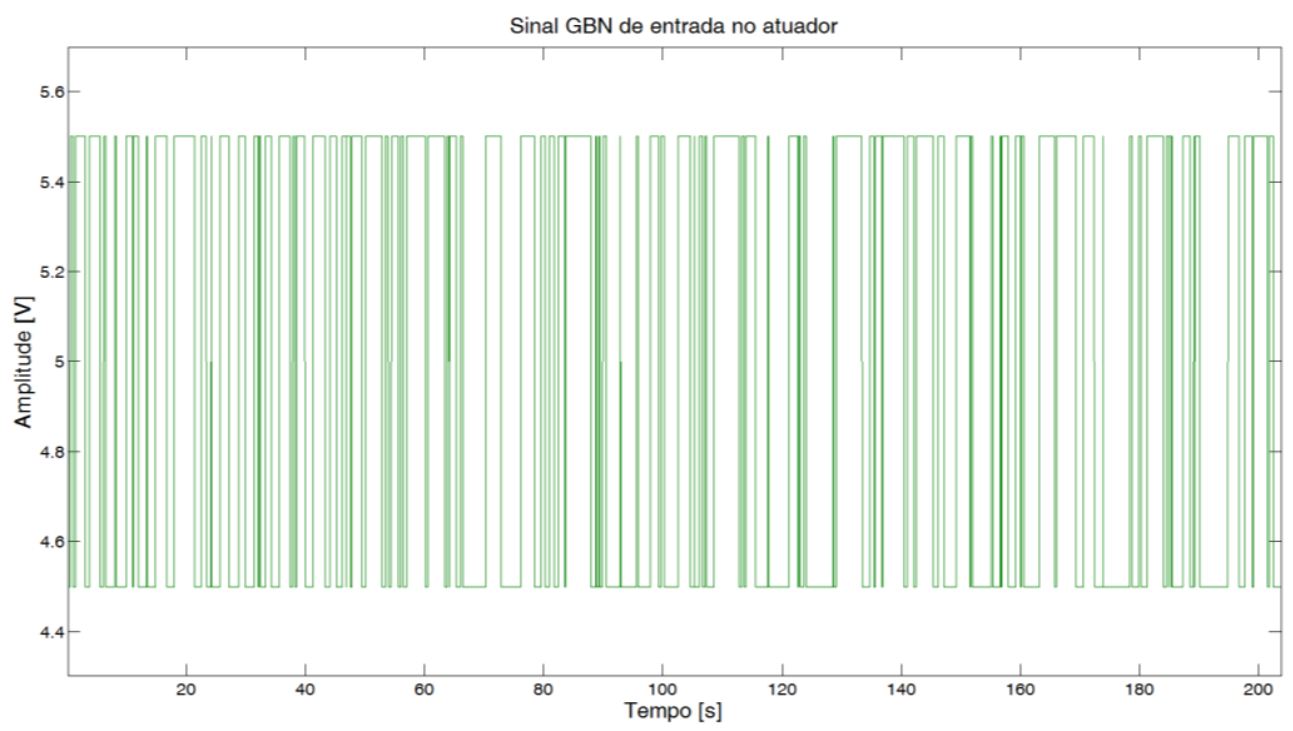

Fonte: Autor

$\mathrm{O}$ sinal GBN foi trabalhado com média $5 \mathrm{~V}$ e variância de $1,5 \mathrm{~V}$ de tal forma que possa descrever a faixa de interesse do comportamento do atuador.

O sinal tipo random number mostrado na Figura 3-34 tem duração de 10 minutos e avalia o comportamento do atuador para diferentes amplitudes e desta forma descreve a maior quantidade de dinâmicas associadas ao atuador. 
Figura 3-34 Sinal Random Number.

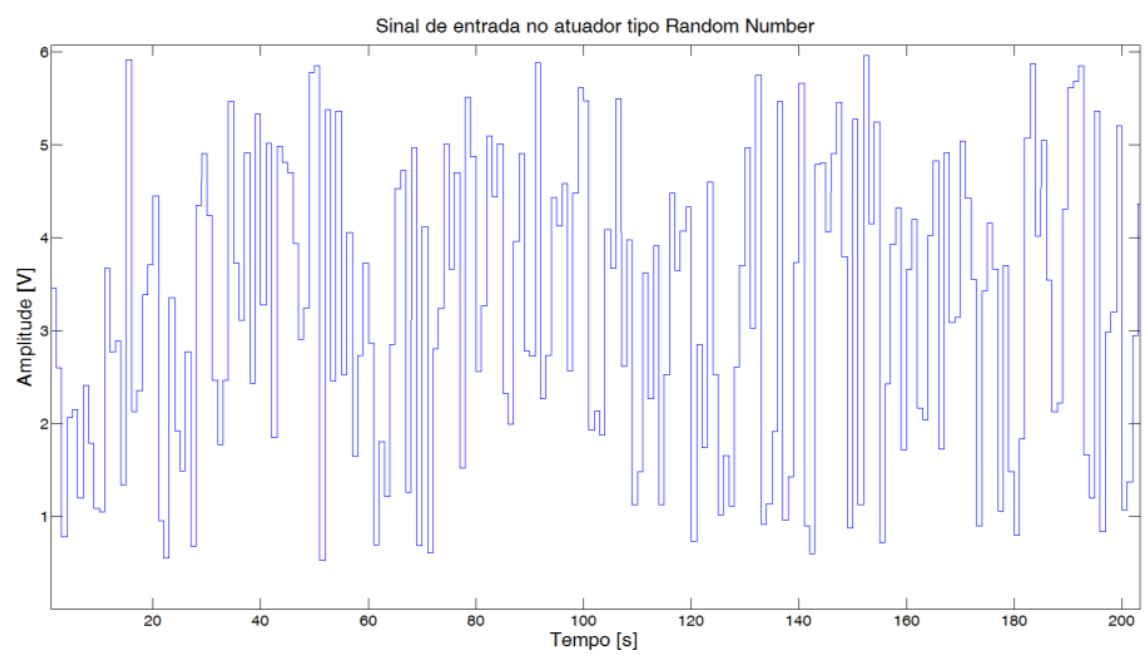

Fonte: Autor

Finalmente, em (TRUNG et al., 2011) o autor propõe realizar a identificação de um atuador pneumático usando um sinal senoidal com uma mistura de frequências com amplitude constante, para desta forma identificar a dinâmica do comportamento do atuador. No caso do atuador da planta foi aplicada uma mistura de sinal com período inicial de $T=8$ s e período final de $T=3 \mathrm{~s}$ com uma duração de 20 minutos, amplitude de $2 \mathrm{~V}$ e média de $3 \mathrm{~V}$, o sinal de entrada pode-se ver na Figura 3-35.

Figura 3-35 Trecho do sinal senoidal de entrada.

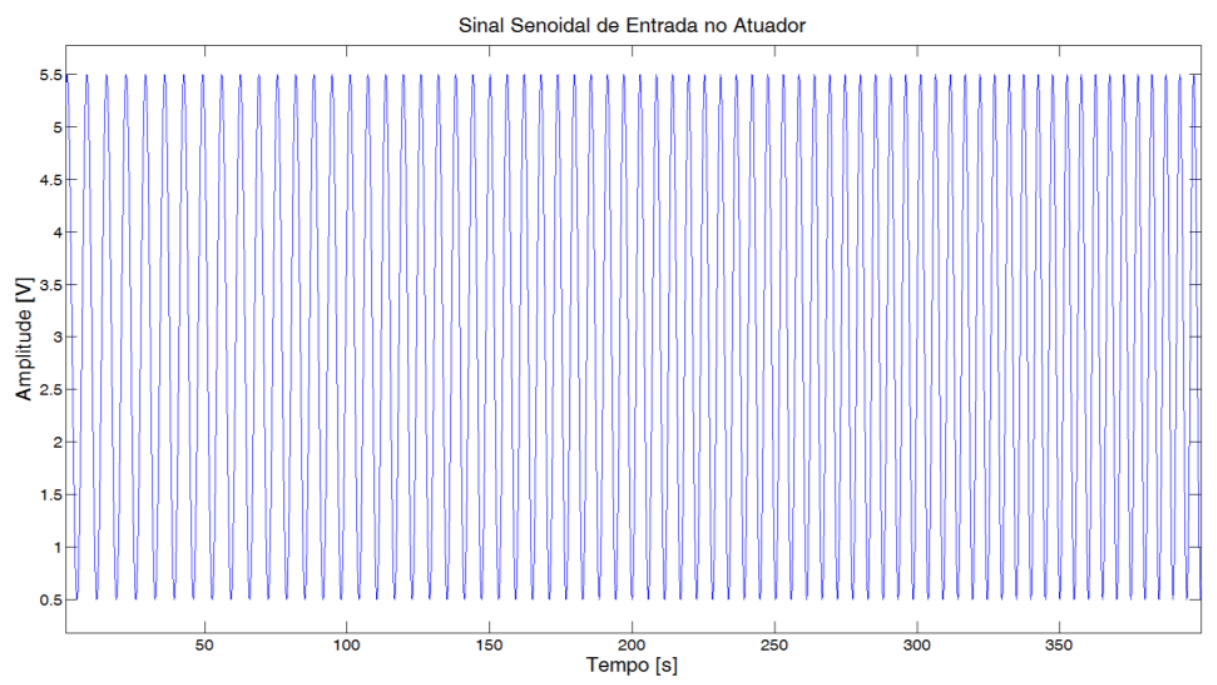

Fonte: Autor 
Com os três sinais, realizou-se a identificação do sistema. Fez-se uma variação nas ordens de B e F para obter o melhor índice de desempenho possível para cada um dos modelos. A Tabela 3-10 apresenta os resultados dos melhores índices de desempenho obtidos para cada um dos sinais.

Tabela 3-10 Melhores índices de desempenho para cada tipo de sinal.

\begin{tabular}{cccc}
\hline $\begin{array}{c}\text { Sinal de } \\
\text { entrada }\end{array}$ & nb & nf & $\begin{array}{c}\text { Índice de } \\
\text { Desempenho }\end{array}$ \\
\hline GBN & 4 & 5 & 0.00946 \\
Random & 4 & 4 & 0.00629 \\
Number & & & \\
Senoidal & 4 & 5 & 0.00519 \\
\hline
\end{tabular}

Fonte: Autor

$\mathrm{O}$ MATLAB $^{\circledR}$ calcula um índice de ajuste (fit) dado em porcentagem (equação (3.32)) o qual permite realizar uma autovalidação do modelo obtido com os dados de entrada e saída do processo. Este índice é dado em porcentagem, sendo que quanto mais próximo seja o fit de $100 \%$ melhor é o desempenho do modelo.

$f i t(\%)=100 \cdot\left(1-\frac{\|\hat{y}(t)-y(t)\|}{\|y(t)-\bar{y}\|}\right)$

sendo que $\hat{y}(t)$ é o sinal simulado, $\bar{y}$ é o valor médio do sinal medido e $y(t)$ é o sinal medido.

A Tabela 3-11 mostra os resultados do fit para os três modelos obtidos.

Tabela 3-11 Índice de ajuste para cada um dos sinais testados.

\begin{tabular}{cc}
\hline $\begin{array}{c}\text { Sinal de } \\
\text { entrada }\end{array}$ & fit \\
\hline GBN & $64,8 \%$ \\
\hline $\begin{array}{l}\text { Random } \\
\text { Number }\end{array}$ & $78,1 \%$ \\
Senoidal & $92.4 \%$ \\
\hline
\end{tabular}

Fonte: Autor 
A Figura 3-36 apresenta um trecho do resultado gráfico para o melhor fit obtido que no caso foi o sinal senoidal.

Figura 3-36 Índice de ajuste para o sinal senoidal.

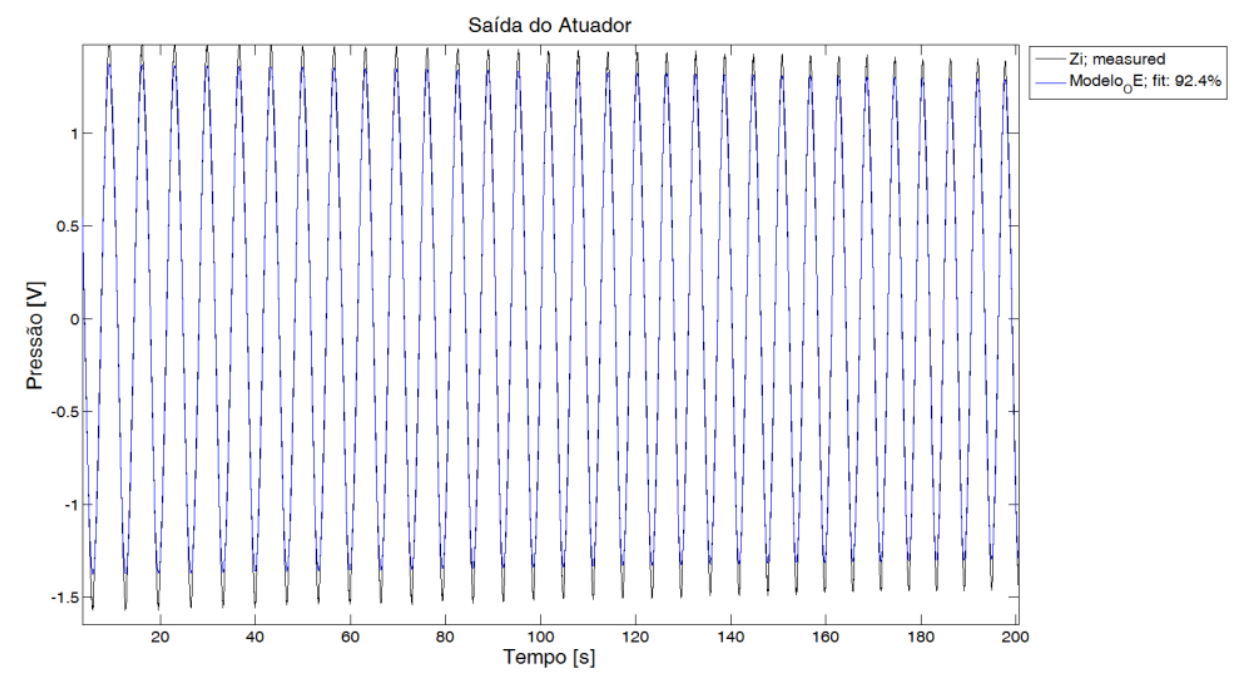

\section{Fonte: Autor}

Foram realizados testes aplicando sinais degrau para realizar a validação do modelo, a Figura 3-37 apresenta o resultado obtido ao aplicar um degrau positivo no atuador.

Figura 3-37 Degrau aplicado no atuador

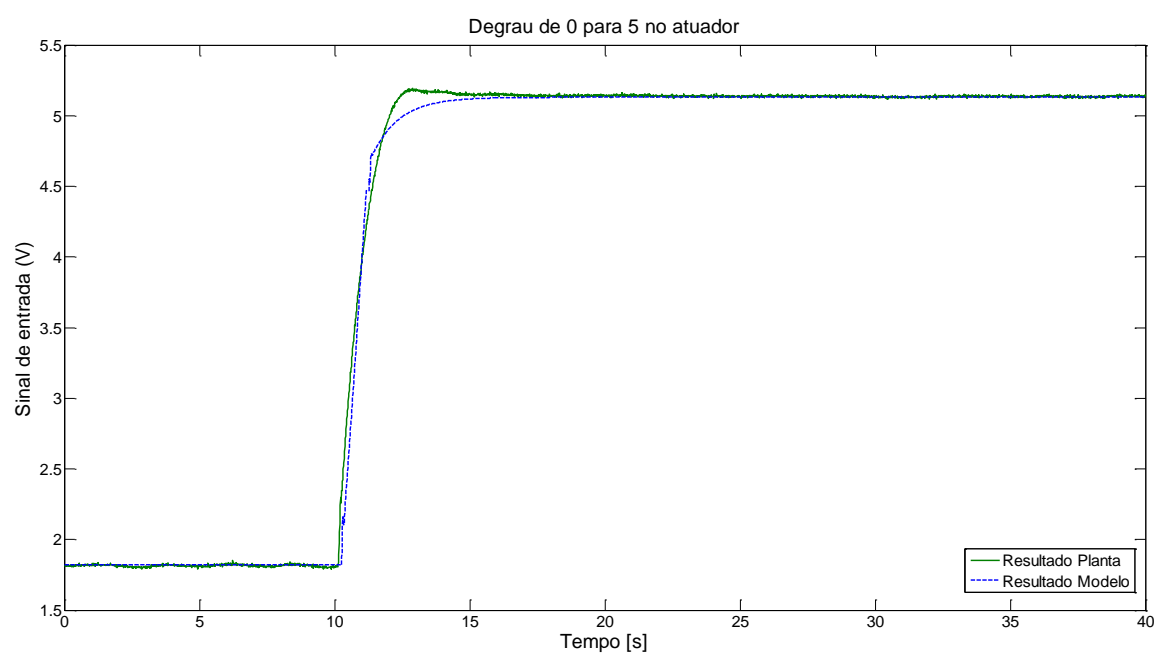

Fonte: Autor 


\subsection{Controlador de vazão}

A planta possui um controlador do tipo PI para cada uma das válvulas. Para manter o modelo o mais próximo possível aos valores da planta, tomaram-se os ganhos proporcionais e integrais diretamente dos controladores na planta. A Tabela 3-12 apresenta a sintonia para cada um dos controladores.

Tabela 3-12 Sintonia dos controladores PI.

\begin{tabular}{ccc}
\hline Válvula & $\boldsymbol{K p}$ & $\boldsymbol{T i}$ \\
\hline Teflon & 0.94 & 8.33 \\
Grafite & 0.60 & 3.60 \\
\hline
\end{tabular}

Fonte: Autor

Em Simulink realizou-se o bloco para cada um dos controladores, a referência é de vazão em $\left[\mathrm{m}^{3} / \mathrm{h}\right]$, tal como pode-se ver na Figura 3-38.

Figura 3-38 Controlador PI.

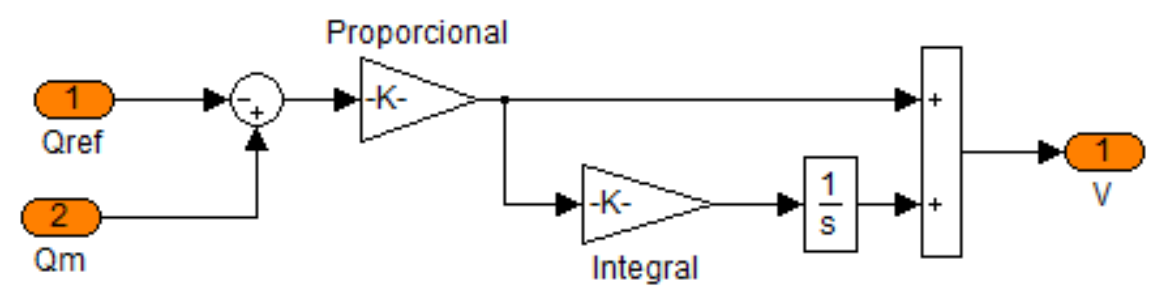

Fonte: Autor 


\subsection{Modelo geral da Planta de Vazão}

O modelo da Planta de Vazão está dividido em três partes importantes, o somatório das perdas de carga, o modelo da bomba centrífuga e os modelos de atrito para cada uma das válvulas. No somatório das perdas de carga tem-se duas entradas, a primeira é o valor de abertura das válvulas de controle e a segunda é a vazão do processo. Na bomba centrífuga também há duas entradas, o valor de rotação da bomba e o valor de perda de carga que sai do somatório. Finalmente, nos modelos de atrito o sinal de entrada é a pressão no atuador.

\subsubsection{Modelo das perdas de carga nos instrumentos}

No modelo da perda de carga a posição da haste das válvulas de controle é um dos sinais de entrada dado em [\%] e o outro é a vazão do processo [ $\left.\mathrm{m}^{3} / \mathrm{s}\right]$. Estas variáveis estão diretamente relacionadas com a perda de carga. Na Figura 3-39 pode-se ver o modelo geral criado para as perdas de carga nos instrumentos.

Figura 3-39 Modelo geral da perda de carga na Planta de Vazão

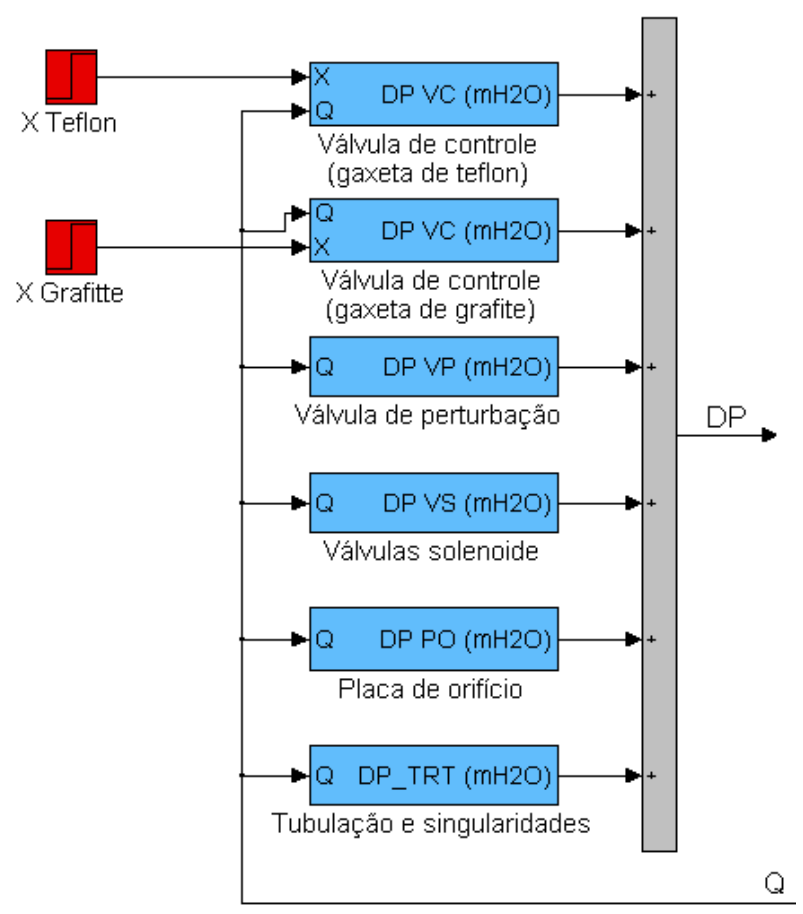




\subsubsection{Modelo da bomba centrífuga e medidor de vazão}

O modelo da bomba centrífuga (ver Figura 3-40) tem duas entradas, a rotação da bomba $(N)$, que é representada como um sinal degrau na faixa de 0 a 1 , onde 0 é $0 \%$ de rotação e 1 é $100 \%$ de rotação, o segundo sinal é a perda de carga $D P$ que sai do modelo de perda de carga na Planta de Vazão com unidade de [mH2O].

O medidor de tem como entrada a vazão em $\left[\mathrm{m}^{3} / \mathrm{s}\right]$ e na saída $\left[\mathrm{m}^{3} / \mathrm{h}\right]$.

Figura 3-40 Modelo da Bomba Centrífuga e do Medidor de Vazão.

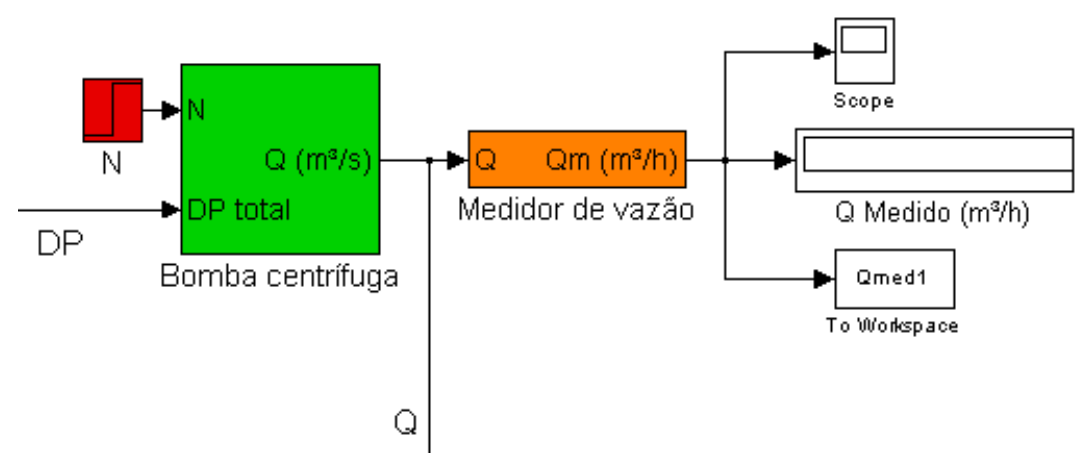

Fonte: Autor

\subsubsection{Modelos de atrito para as válvulas de controle}

Os modelos de atrito têm como entrada o valor de pressão do atuador em valores de tensão. A Figura 3-41 apresenta o modelo de Kano para as duas válvulas, para o modelo de Karnopp a estrutura é a mesma. 
Figura 3-41 Modelos de Atrito de Kano + Atuador.

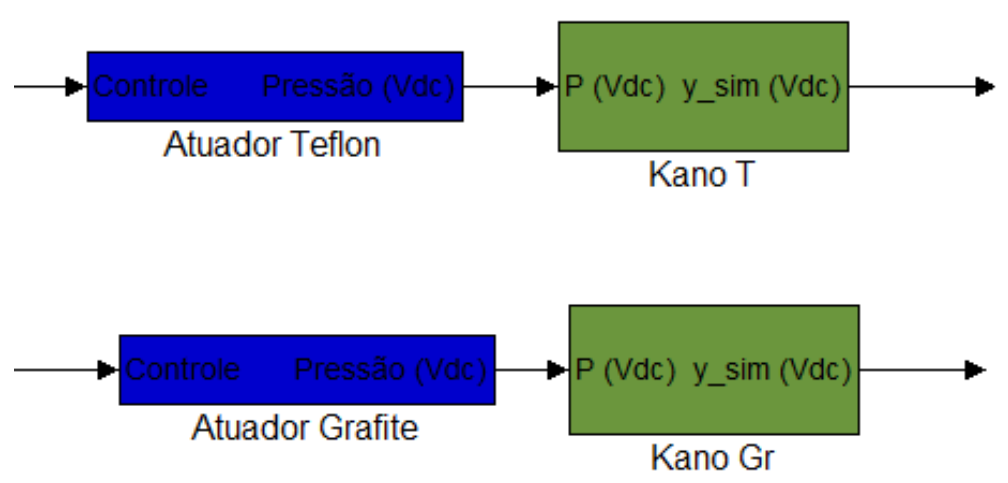

Fonte: Autor

\subsubsection{Modelo Geral da Planta de Vazão}

A Figura 3-42 apresenta o modelo geral da planta de vazão considerando o modelo de Kano. A estrutura para o modelo de Karnopp é a mesma. 
Figura 3-42 Modelo Geral da Planta de Vazão

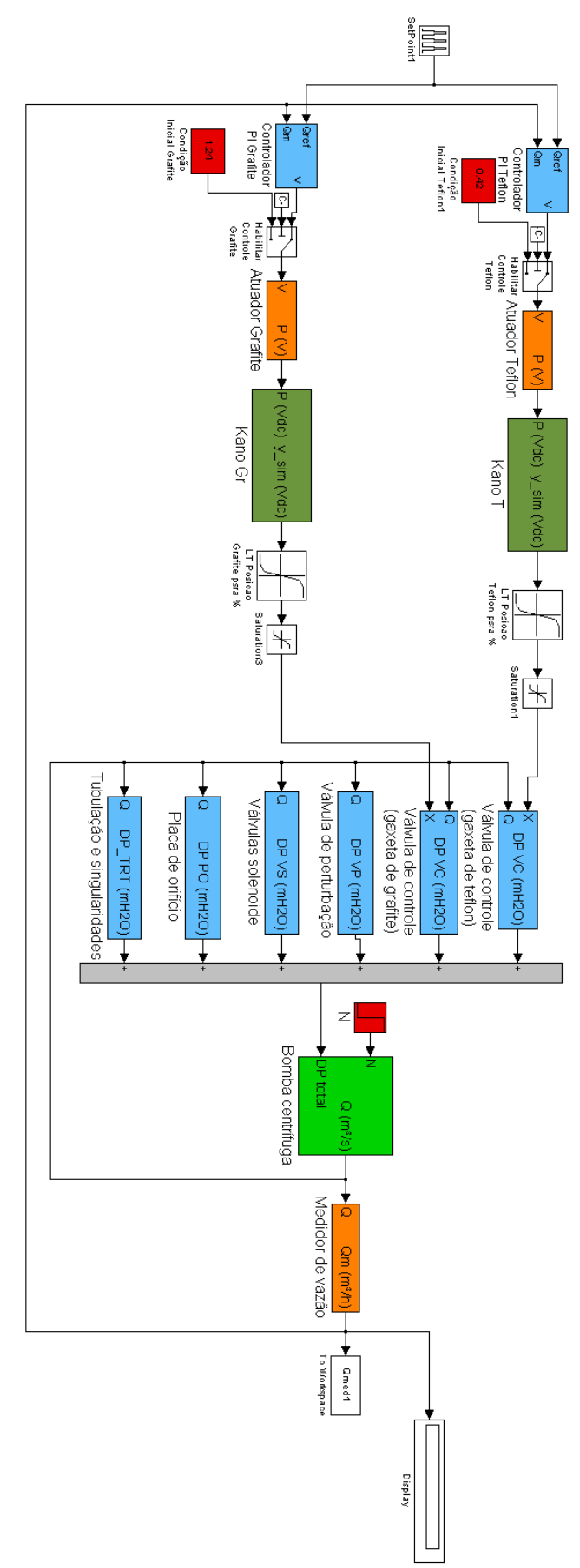

Fonte: Autor 


\section{Validação do Modelo}

Neste capítulo são apresentados os testes realizados para validar o modelo realizado em Simulink ${ }^{\circledR}$, fazendo comparações entre os dados obtidos em MATLAB ${ }^{\circledR}$ com aqueles obtidos nos ensaios realizados na Planta de Vazão.

Os testes realizados estão focados na vazão, variando a rotação da bomba e variando a abertura das válvulas de teflon e de grafite, inicialmente, em malha aberta. Na bomba são realizados dois tipos de testes, no primeiro são feitas diferentes variações na rotação da bomba com as válvulas totalmente abertas para analisar o comportamento estático do modelo. No segundo teste são dadas variações na rotação da bomba com as válvulas totalmente abertas para comparar o comportamento dinâmico do modelo com a planta real. Por outro lado, nas válvulas também são feitos testes estáticos e dinâmicos, com uma rotação constante da bomba ajustada em $80 \%$ da rotação máxima.

Finalmente, são feitos testes para avaliar o controle, fazendo variações no set point para testar o comportamento da vazão com as sintonias para cada uma das válvulas.

\subsection{Testes de vazão em regime permanente}

Para fazer a análise estática de uma variável, é necessário realizar a aquisição de dados no processo quando ela está em regime estacionário. Foram realizados testes estacionários na bomba e nas válvulas de controle.

\subsubsection{Validação do modelo da Bomba}

A planta possui um inversor de frequência que permite variar a rotação da bomba. Este valor de rotação pode ser inserido em valores de porcentagem por meio do software disponível na planta. Na Figura 4-1 (a) é apresentado o inversor de frequência e na Figura 4.1 (b) sua tela de configurações no sistema supervisório. 
Figura 4-1 (a) Inversor de frequência Siemens SINAMIC G110, (b) Tela de configurações do inversor/bomba.

(a)

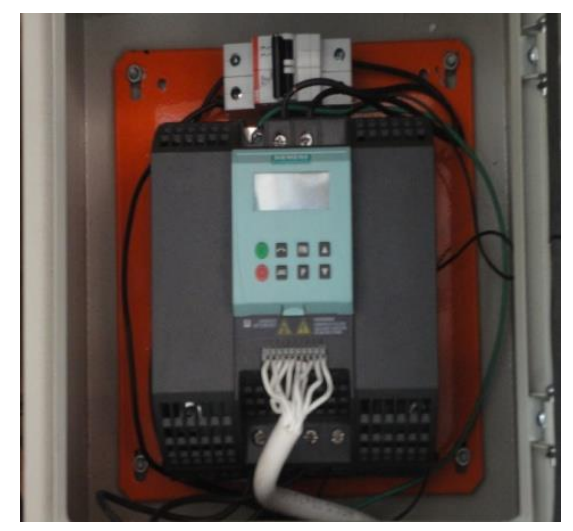

(b)

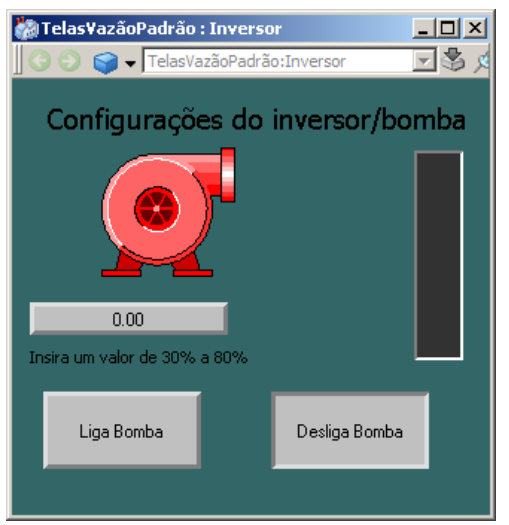

\section{Fonte: Autor}

Os valores recomendados para operar a bomba são entre 30\% e 100\%, o valor mínimo é devido a que a placa de orifício perde precisão para valores pequenos de vazão, pois sua rangeabilidade é de 3:1. Na Tabela 4-1 são apresentados testes realizados do comportamento estático da vazão para diferentes rotações da bomba.

Tabela 4-1 Comportamento estático para diferentes valores de rotação da bomba.

\begin{tabular}{cccc}
\hline $\begin{array}{c}\text { Rotação da } \\
\text { bomba (\%) }\end{array}$ & $\begin{array}{c}\text { Planta } \\
Q_{p}\left(\mathbf{m}^{3} / \mathrm{h}\right)\end{array}$ & $\begin{array}{c}\text { Simulink } \\
\mathbf{Q}_{s}\left(\mathrm{~m}^{3} / \mathrm{h}\right)\end{array}$ & Erro (\%) \\
\hline $\mathbf{3 0}$ & 4,26 & 4,91 & 15,25 \\
$\mathbf{4 0}$ & 6,4 & 6,47 & 1,09 \\
$\mathbf{5 0}$ & 7,96 & 8,05 & 1,50 \\
$\mathbf{6 0}$ & 9,69 & 9,74 & 0,51 \\
$\mathbf{7 0}$ & 11,09 & 11,13 & 0,36 \\
$\mathbf{8 0}$ & 13 & 13,01 & 0,07 \\
$\mathbf{9 0}$ & 14,34 & 14,38 & 0,27 \\
$\mathbf{1 0 0}$ & 15,45 & 15,74 & 1,87 \\
\hline
\end{tabular}

Fonte: Autor 
$Q_{p}$ é o valor medido na planta para os diferentes valores de rotação quando o sinal já está em valor estacionário. Foram realizados 5 testes e se tomou o valor médio entre as medidas. $Q_{s}$ é o valor obtido no Simulink ${ }^{\circledR}$. Os valores obtidos foram comparados e foi obtido o valor de erro por meio da equação (4-1).

$$
E(\%)=\frac{Q_{s}-Q_{p}}{Q_{p}} \cdot 100
$$

Os erros obtidos foram aceitáveis na maioria dos casos. Para a vazão de $30 \%$ o erro aumentou de forma considerável, isto é devido à placa de orifício, pois para valores pequenos ela perde precisão.

\subsubsection{Validação do modelo da válvula com gaxetas de Teflon}

Para validar o modelo das válvulas de controle manteve-se a rotação da bomba em um valor constante, isto é, $80 \%$ da rotação nominal, e variou-se a abertura da válvula com gaxeta de teflon mantendo a válvula de grafite totalmente aberta.

Foram enviados sinais de abertura de $0 \%$ até $50 \%$, sendo $0 \%$ válvula totalmente aberta e $100 \%$ válvula totalmente fechada. Não foram enviados sinais maiores que $50 \%$, pois a vazão começa a ficar muito baixa e devido à placa de orifício, a medição de vazão perde precisão. Realizaram-se vários testes do mesmo tipo e, dos resultados obtidos, tomou-se o valor médio. Na Tabela 4-2 são apresentados os valores finais dos testes na Planta de Vazão e os respectivos resultados do simulador em Simulink ${ }^{\circledR}$. 
Tabela 4-2 Comportamento estático da vazão para diferentes valores de abertura na válvula com gaxetas de Teflon.

\begin{tabular}{cccc}
\hline $\begin{array}{c}\text { Sinal de } \\
\text { abertura da } \\
\text { válvula de } \\
\text { controle (\%) }\end{array}$ & $\begin{array}{c}\text { Planta } \\
\boldsymbol{Q}_{p}\left(\mathbf{m}^{\mathbf{3}} / \mathbf{h}\right)\end{array}$ & $\begin{array}{c}\text { Simulink } \\
\boldsymbol{Q}_{s}\left(\mathbf{m}^{\mathbf{3}} / \mathbf{h}\right)\end{array}$ & $\begin{array}{c}\text { Erro } \\
\mathbf{( \% )}\end{array}$ \\
\hline $\mathbf{5 0}$ & 8,41 & 7,87 & $-6,42$ \\
$\mathbf{4 5}$ & 9,8 & 8,92 & $-8,47$ \\
$\mathbf{4 0}$ & 10,99 & 9,8 & $-10,82$ \\
$\mathbf{3 5}$ & 11,76 & 10,52 & $-10,54$ \\
$\mathbf{3 0}$ & 12,21 & 11,51 & $-5,73$ \\
$\mathbf{2 5}$ & 12,54 & 12,27 & $-2,15$ \\
$\mathbf{2 0}$ & 12,71 & 12,68 & $-0,23$ \\
$\mathbf{1 5}$ & 12,83 & 12,85 & 0,155 \\
$\mathbf{1 0}$ & 12,9 & 12,97 & 0,54 \\
$\mathbf{5}$ & 12,95 & 13 & 0,38 \\
\hline $\mathbf{0}$ & 12,99 & 13,01 & 0,15 \\
\hline
\end{tabular}

Fonte: Autor

Como se pode ver na Tabela 4-2, o erro aumentou de forma considerável quando a abertura passou de $25 \%$.

\subsubsection{Validação do modelo da válvula com gaxetas de grafite}

Da mesma forma que para os testes da válvula com gaxetas de teflon, foram enviados sinais de $0 \%$ para 50\%, os resultados são mostrados na Tabela 4-3. 
Tabela 4-3 Comportamento da vazão aplicando diferentes valores de abertura na válvula com gaxetas de grafite

\begin{tabular}{cccc}
\hline $\begin{array}{c}\text { Sinal de } \\
\text { abertura da } \\
\text { válvula de } \\
\text { controle }(\boldsymbol{\%})\end{array}$ & $\begin{array}{c}\text { Planta } \\
\boldsymbol{Q}_{p}\left(\mathbf{m}^{\mathbf{3}} / \mathbf{h}\right)\end{array}$ & $\begin{array}{c}\text { Simulink } \\
\boldsymbol{Q}_{s}\left(\mathbf{m}^{\mathbf{3}} / \mathbf{h}\right)\end{array}$ & $\begin{array}{c}\text { Erro } \\
(\boldsymbol{\%})\end{array}$ \\
\hline $\mathbf{5 0}$ & 9,9 & 7,74 & $-21,81$ \\
$\mathbf{4 0}$ & 11,6 & 9,92 & $-14,48$ \\
$\mathbf{3 0}$ & 12,64 & 11,6 & $-8,22$ \\
$\mathbf{2 0}$ & 13 & 12,73 & $-2,07$ \\
$\mathbf{1 0}$ & 13 & 13,01 & 0,07 \\
$\mathbf{0}$ & 13,01 & 13,01 & 0 \\
\hline
\end{tabular}

Fonte: Autor

Os resultados com a curva fornecida pelo fabricante apresentaram erros grandes quando a válvula teve valores de $40 \%$ e $50 \%$ de sinal na válvula de controle. Uma das possíveis causas sería que a válvula há um tempo está apresentando alguns problemas de funcionamento, portanto foi realizada uma manutenção nela, fazendo-se a troca da maioria das peças internas que compõe a válvula (ver Figura 4-2).

Figura 4-2 Peças internas da válvula com gaxetas de Grafite

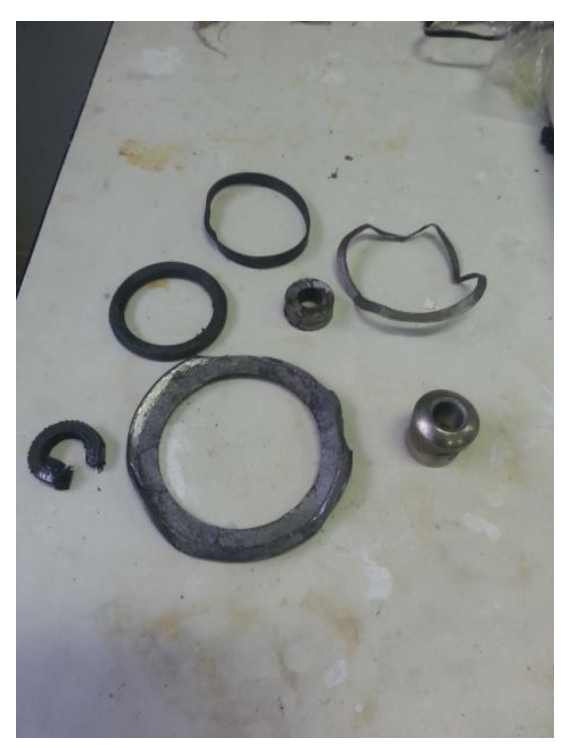

Fonte: Autor 
Tanto as peças como a válvula internamente apresentavam desgaste, porém, a troca das peças não solucionou o problema.

Em (ARAGÓN et al., 2007) apresenta-se um método para validar a curva de $C v$ da válvula.

Figura 4-3 Esquema para validar o valor de Cv das válvulas.

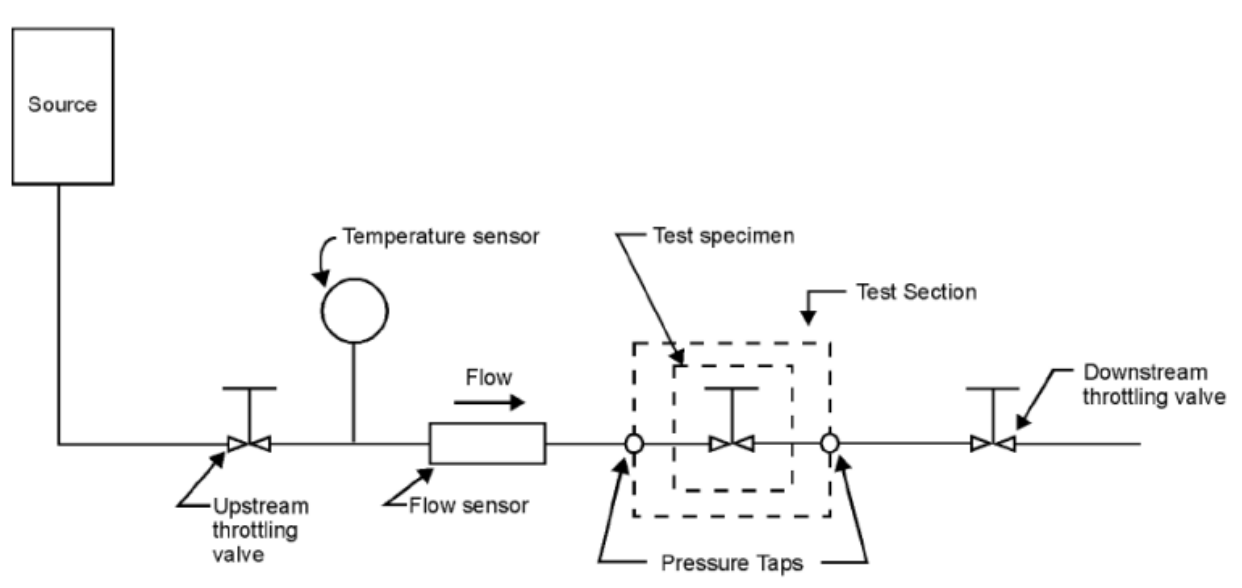

Fonte: ARAGÓN et al; 2007

Atualmente no laboratório não se tem a instrumentação necessária para realizar este teste, para realizá-lo é necessário ter medidores de pressão diferencial com os quais é possível medir a diferença de pressão causada ao mudar o valor de vazão, e desta forma, estimar o valor de $C v$ relativo das válvulas. Este procedimento é proposto como trabalho futuro, porque pode ser uma possível causa do problema, pois a válvula de teflon também esta apresentando um erro considerável.

Adicionalmente realizou-se uma parada na planta para realizar manutenção da placa de orifício (Figura 4-4) e calibração dos transmissores de vazão. A placa estava com ferrugem, mas o diâmetro dela e suas partes principais não apresentavam alterações, portanto não se considerou como uma possível causa dos erros no modelo. 
Figura 4-4 Placa de Orifício.

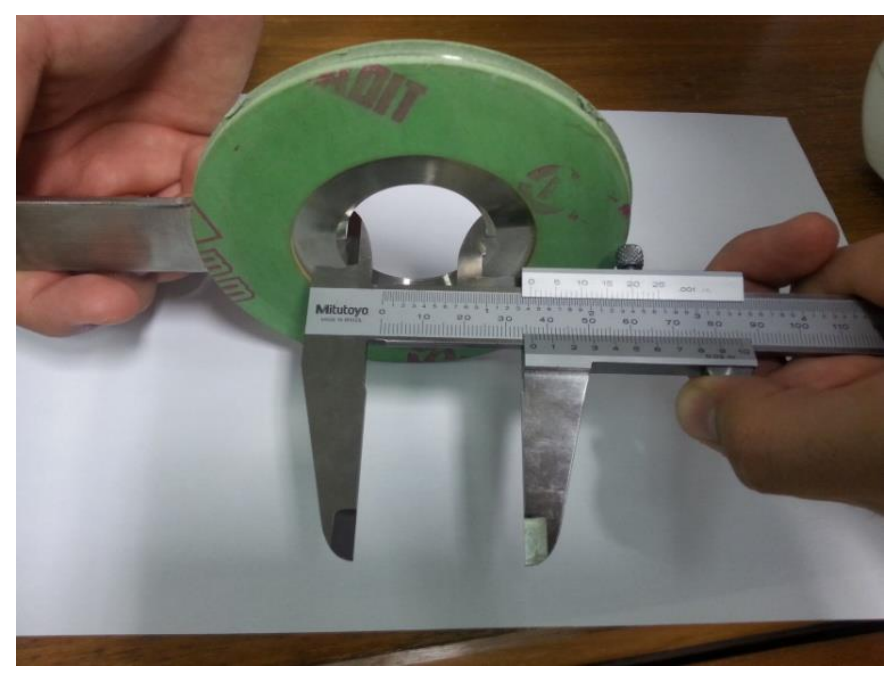

Fonte: Autor

Finalmente, visto que os valores de vazão medidos realizando variações na abertura da válvula não foram satisfatórios, estudou-se a possibilidade de que os transmissores estejam enviando um valor errado de vazão. Portanto, procurou-se uma segunda opção de medidor para realizar a medição de vazão. O medidor usado para realizar estes testes foi o Fluxus F601 fabricado pela FLEXIM (ver Figura 4-5). É um medidor de vazão portátil de ultrassom para todo tipo de líquidos, tem uma faixa de precisão de $\pm 0,5 \%$ de leitura.

O medidor trabalha com sinais de ultrassom, esses sinais são transmitidos por meio de um transdutor que é instalado na tubulação e são recebidos por um segundo transdutor, como se pode ver na Figura 4-6. A diferença de tempo $\Delta t$ que demora o sinal em ser recebido permite ao medidor determinar a velocidade do fluido. 
Figura 4-5 Medidor de Vazão Fluxus F601

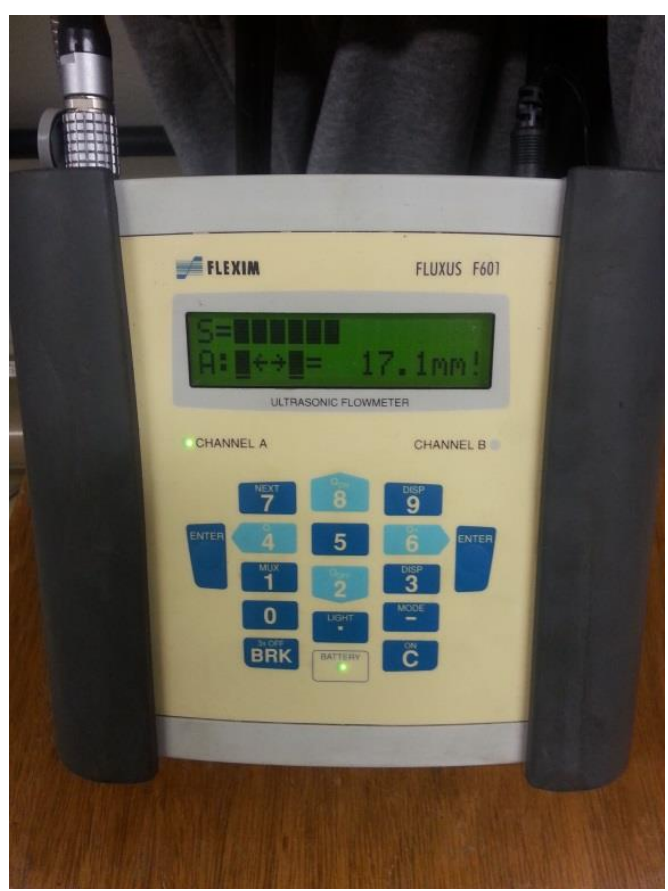

Fonte: Autor

Figura 4-6 Funcionamento do Medidor de Vazão Fluxus F601.
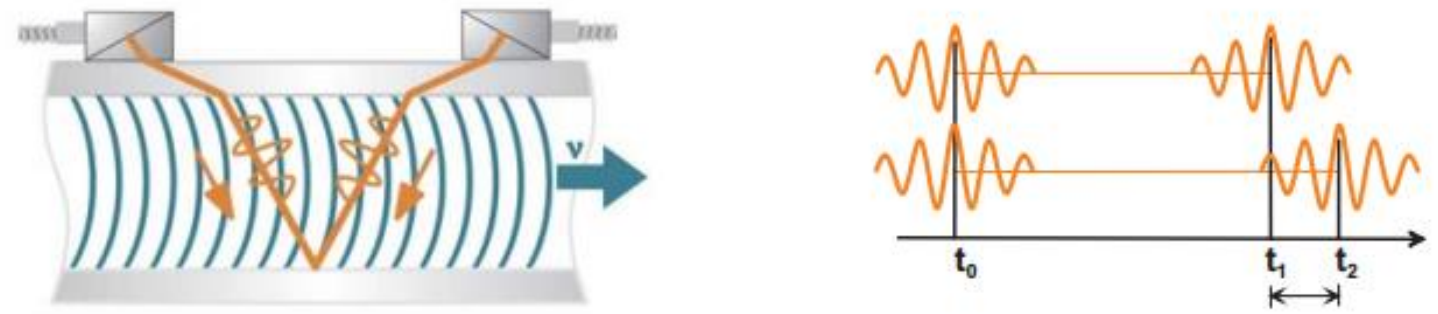

Fonte: (Fluxus, 2014)

Foram realizados testes variando a rotação da bomba para comparar os resultados obtidos com os transmissores de vazão e com o medidor de ultrassom. Para obter bons resultados é necessário configurar o medidor de ultrassom para ter uma boa qualidade de sinal, essa qualidade é determinada pela distância entre os transdutores. Na Figura 4-7 pode-se ver que os transdutores foram posicionados de forma tal que a qualidade seja a melhor possível para ter uma boa confiabilidade nas medições. 
Figura 4-7 Funcionamento do Medidor de Vazão Fluxus F601

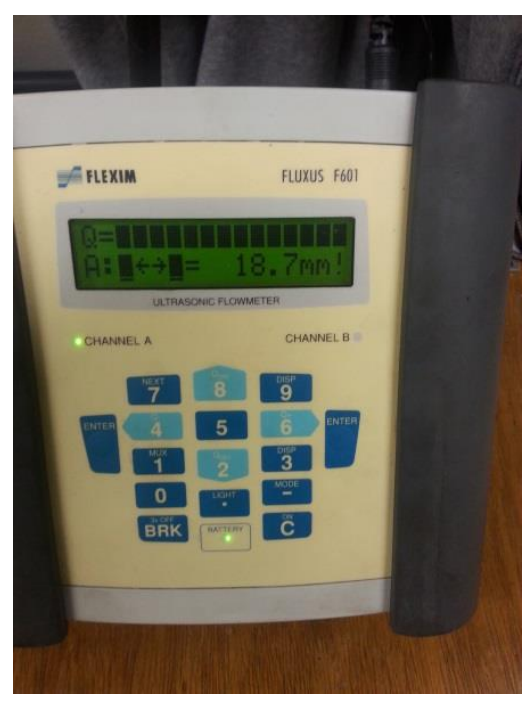

Fonte: Autor

Na Tabela 4-4 apresenta-se um dos resultados obtidos com o medidor e os dados obtidos com os transmissores instalados na planta.

Tabela 4-4 Resultados obtidos com o medidor de ultrassom.

\begin{tabular}{cccc}
\hline $\begin{array}{c}\text { Rotação da } \\
\text { bomba (\%) }\end{array}$ & $\begin{array}{c}\text { Placa de } \\
\text { Orificio } \\
\boldsymbol{Q}_{p}\left(\mathrm{~m}^{3} / \mathrm{h}\right)\end{array}$ & $\begin{array}{c}\text { Medidor de } \\
\text { Ultrassom } \\
\boldsymbol{Q}_{s}\left(\mathbf{m}^{3} / \mathrm{h}\right)\end{array}$ & $\begin{array}{c}\text { Diferença } \\
\text { (\%) }\end{array}$ \\
\hline $\mathbf{3 0}$ & 4,27 & 4,85 & 13,58 \\
\hline $\mathbf{4 0}$ & 6,36 & 6,69 & 5,188 \\
$\mathbf{5 0}$ & 8,01 & 8,76 & 9,363 \\
$\mathbf{6 0}$ & 9,70 & 10,56 & 8,86 \\
\hline $\mathbf{7 0}$ & 11,12 & 12,31 & 10,70 \\
$\mathbf{8 0}$ & 13,01 & 14,18 & 8,99 \\
$\mathbf{9 0}$ & 14,35 & 15,96 & 11,21 \\
$\mathbf{1 0 0}$ & 15,47 & 17,29 & 11,76 \\
\hline
\end{tabular}

Fonte: Autor 
Os resultados obtidos foram diferentes, além que dependendo do lugar onde o medidor de ultrassom foi instalado, ele apresentou medições diferentes, mas em nenhum dos casos os valores de vazão chegaram a ser parecidos aos valores obtidos com os transmissores instalados na planta. Chegou-se à conclusão que é preciso realizar uma terceira validação de medição para testar a validade dos dados obtidos com os transmissores, pois os dados obtidos com o medidor de ultrassom foram bem diferentes, mesmo que não sejam muito confiáveis.

Como não se tem disponível uma terceira opção para verificar os valores de vazão, passou-se a verificar a dinâmica da bomba e das válvulas ao aplicar sinais degrau em cada uma delas e não os valores de vazão obtidos. As ferramentas disponíveis no laboratório não permitem verificar se os valores medidos de vazão são 100\% confiáveis ou se o problema está em algum outro instrumento.

\subsection{Comportamento da vazão em regime transitório}

Para estudar o comportamento dinâmico da vazão, é importante verificar o instante em que ocorre uma variação em uma das entradas do processo, seja a abertura das válvulas ou uma variação na rotação da bomba, para estudar como é o comportamento da saída durante o tempo em que aconteceu a mudança na entrada. Neste caso, a variável de saída é a vazão.

Para o caso do modelo, foram aplicados sinais tipo degrau em cada uma das entradas e os resultados vão ser comparados com os resultados da planta, quando é aplicado o mesmo sinal tipo degrau.

\subsubsection{Comportamento da Bomba}

Nesta parte dos testes foram considerados diferentes sinais de tipo degrau como entrada na rotação da bomba $(N)$, levando-se em conta os fatores que influem na vazão volumétrica do processo $(Q)$, como a dinâmica da bomba e o atraso de transporte. Para este último analisou-se o comportamento da planta em malha aberta, introduzindo-se um sinal tipo 
degrau na rotação da bomba de $50 \%$ para $80 \%$ do valor nominal em $t=10$ s. A Figura $4-8$ mostra a saída da vazão para o sinal aplicado.

Figura 4-8 Resposta dinâmica da vazão para um sinal degrau de 50\% para $80 \%$

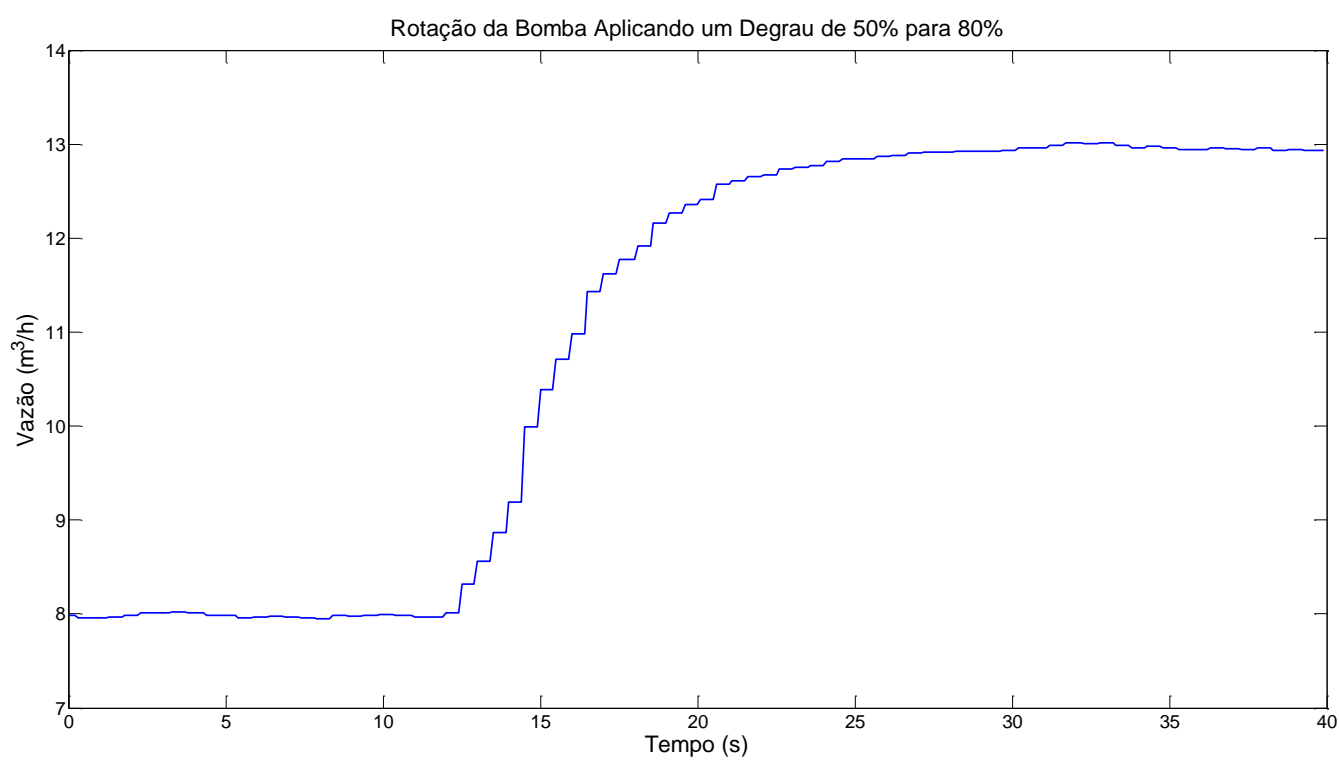

Fonte: Autor

Pode-se ver que para uma variação brusca na rotação da bomba, a vazão se comporta como um sistema de primeira ordem. A função de transferência para um sistema deste tipo é mostrada na Figura 4-9.

Figura 4-9 Função de transferência para sistemas de primeira ordem

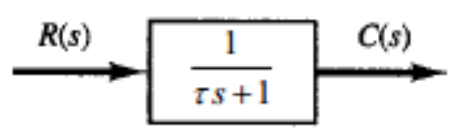

Fonte: (OGATA; 2003) 
A constante de tempo $(\tau)$ é obtida fazendo-se uma análise da curva do processo. É definida como o tempo que o processo demora em responder até alcançar 63,2\% da sua variação total. A constante de tempo pode ser calculada da seguinte forma (OGATA, 2003):

$Q_{\tau}=Q_{i}+0,632\left(Q_{f}-Q_{i}\right)$

onde se tem que $Q_{\tau}$ é a vazão do fluido no instante $t=\tau, Q_{f}$ é o valor de vazão final quando alcança um valor estável e $Q_{i}$ é o valor de vazão inicial. No caso da Figura 4-8, tem-se que $Q_{i}$ $=7,982 \mathrm{~m}^{3} / \mathrm{h}, Q_{f}=13,01 \mathrm{~m}^{3} / \mathrm{s}$, portanto, aplicando-se a equação (4-2), obtém-se que $Q_{\tau}=$ $11,1597 \mathrm{~m}^{3} / \mathrm{h}$. Finalmente, o tempo em que a vazão alcança este valor é de 3,6 s com um atraso puro de $2 \mathrm{~s}$ em relação ao instante em que foi aplicado o degrau, que foi em 10s. Devido ao tempo de amostragem dos gráficos obtidos e a testes adicionais feitos, se chegou à conclusão de considerar a constante de tempo da bomba de 1,1s e do transmissor de vazão de 2,5s, totalizando $3,6 \mathrm{~s}$.

O transmissor de vazão tem uma constante de tempo muito alta, isto é devido que o amortecimento do instrumento está configurado para ser alto para diminuir ruído de medição.

Os resultados dinâmicos da rotação da bomba, da mesma forma que nos testes estáticos, foram feitos com as válvulas totalmente abertas, somente aplicando degraus na rotação. Na Tabela 4-5 podem ser vistos os resultados obtidos.

Tabela 4-5 Comportamento dinâmico da vazão para um sinal em degrau na rotação da bomba.

\begin{tabular}{ccc}
\hline $\begin{array}{c}\text { Degrau na } \\
\text { rotação da } \\
\text { bomba }(\mathbf{\%})\end{array}$ & $\begin{array}{c}\text { Planta } \\
\boldsymbol{Q}_{p}\left(\mathbf{m}^{\mathbf{3}} / \mathbf{h}\right)\end{array}$ & $\begin{array}{c}\text { Simulink } \\
\boldsymbol{Q}_{s}\left(\mathbf{m}^{\mathbf{3}} \mathbf{h}\right)\end{array}$ \\
\hline $\mathbf{8 0}-\mathbf{9 0}$ & $13,00-14,34$ & $13,01-14,38$ \\
$\mathbf{9 0}-\mathbf{8 0}$ & $14,35-13,01$ & $14,38-13,01$ \\
$\mathbf{8 0}-\mathbf{7 0}$ & $13,01-11,09$ & $13,01-11,13$ \\
$\mathbf{7 0}-\mathbf{8 0}$ & $11,07-12,99$ & $11,13-13,01$ \\
$\mathbf{8 0}-\mathbf{6 0}$ & $12,99-9,69$ & $13,01-9,74$ \\
$\mathbf{6 0}-\mathbf{8 0}$ & $9,69-13$ & $9,74-13,01$ \\
$\mathbf{8 0}-\mathbf{5 0}$ & $13,02-7,98$ & $13,01-8,08$ \\
$\mathbf{5 0}-\mathbf{8 0}$ & $7,96-13,03$ & $8,08-13,01$ \\
$\mathbf{8 0}-\mathbf{4 0}$ & $13,01-6,4$ & $13,01-6,47$ \\
$\mathbf{4 0}-\mathbf{8 0}$ & $6,36-13,02$ & $6,47-13,01$ \\
\hline
\end{tabular}




\section{Fonte: Autor}

Na Figura 4-10 pode-se ver o resultado obtido ao comparar o comportamento dinâmico da planta com os valores obtidos em Simulink ${ }^{\circledR}$, aplicando-se um degrau positivo na rotação da bomba. Pode-se ver que a planta real e o modelo simulado tiveram um comportamento parecido.

Figura 4-10 Resultados da vazão aplicando-se um degrau de $80 \%$ para $90 \%$ na rotação da bomba.

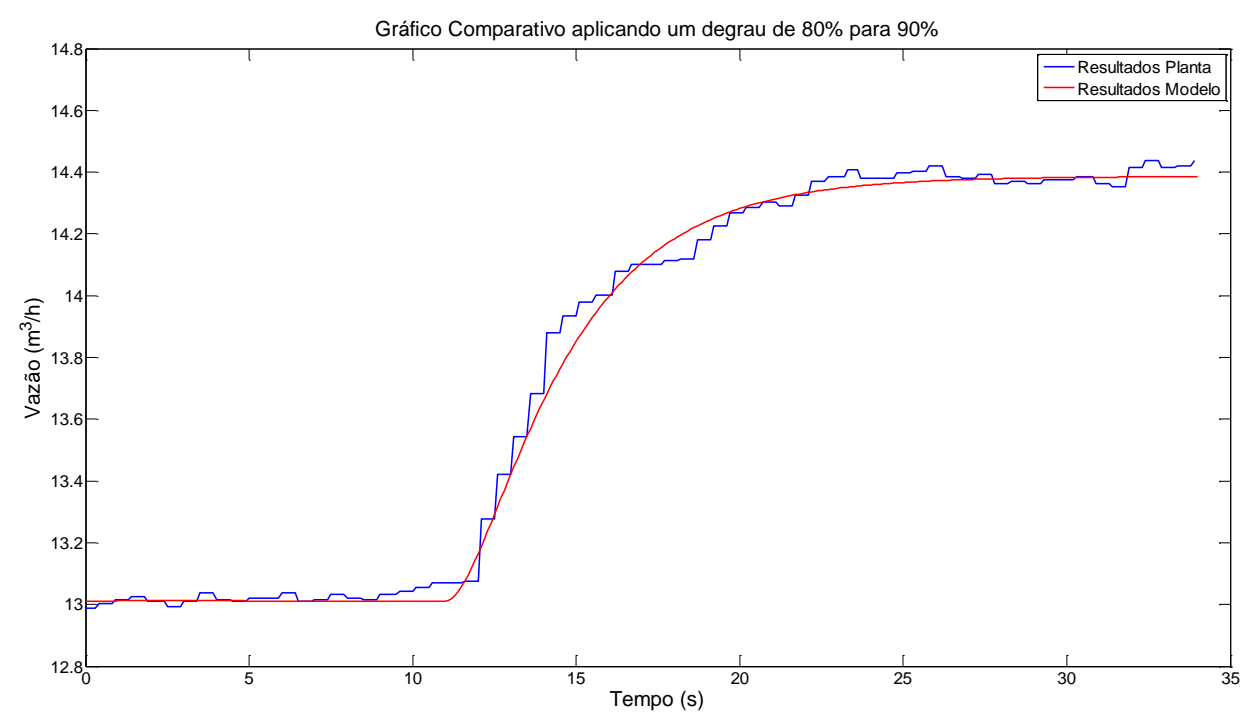

Fonte: Autor

Da mesma forma foi aplicado um degrau negativo para validar o modelo. Na Figura 411 se podem ver os resultados obtidos aplicando-se um degrau de $80 \%$ para $70 \%$ na rotação da bomba. 
Figura 4-11 Resultados da vazão aplicando-se um degrau de $80 \%$ para $70 \%$ na rotação da bomba.

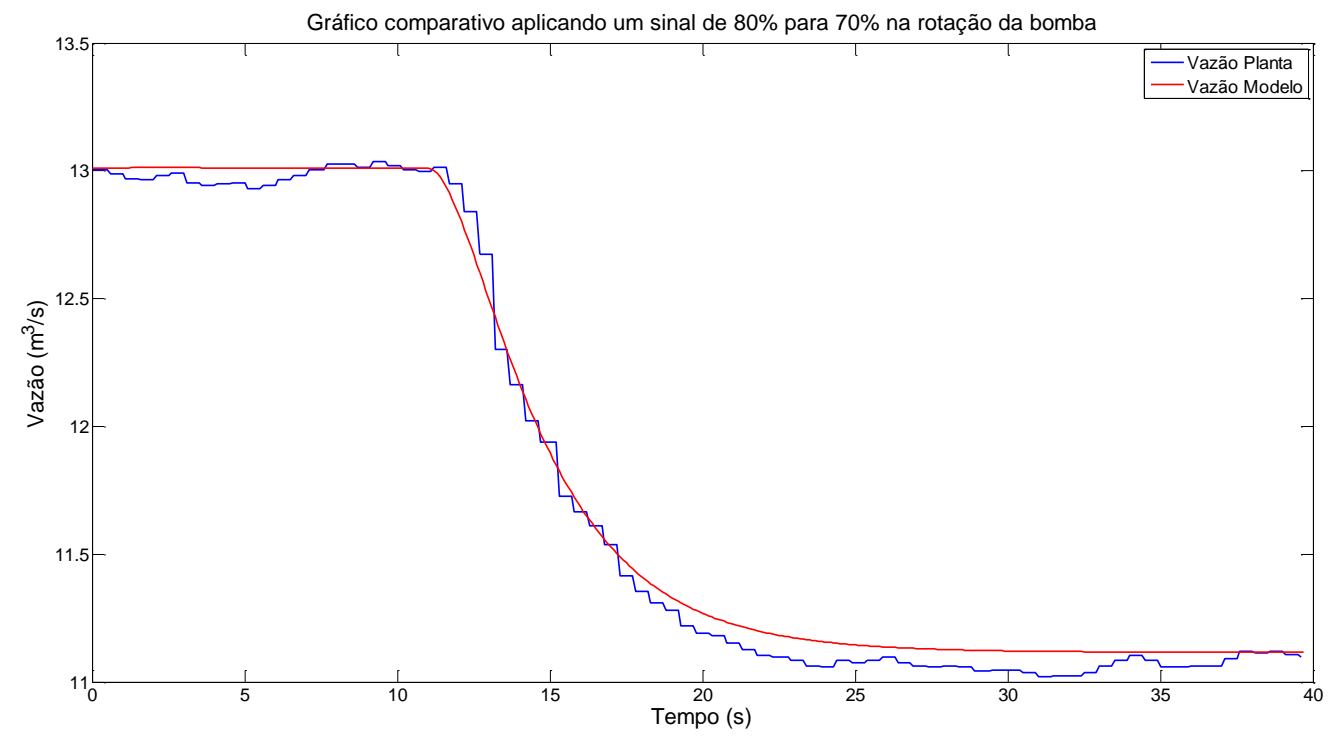

Fonte: Autor

Na Figura 4-11 se pode notar que a resposta dinâmica das duas curvas são parecidas.

\subsubsection{Comportamento dinâmico das válvulas de controle}

Para os estudos das válvulas de controle foram aplicados sinais tipo degrau na abertura da válvula. Esta se refere à posição da haste e não ao sinal de controle enviado diretamente pelo operador, os degraus foram aplicados em $t=10 \mathrm{~s}$.

Da mesma forma que nos testes da bomba, foram realizados vários testes e se tomou um valor médio. Na Tabela 4-6 são apresentados os resultados obtidos, tanto para abertura como para fechamento da válvula de controle. 
Tabela 4-6 Comportamento dinâmico da válvula com gaxetas de teflon aplicando um sinal degrau.

\begin{tabular}{|c|c|c|c|}
\hline \multicolumn{2}{|c|}{$\begin{array}{l}\text { Sinal da válvula de } \\
\text { controle }(\%)\end{array}$} & \multirow{2}{*}{$\begin{array}{c}\begin{array}{c}\text { Planta } \\
Q_{p}\left(\mathbf{m}^{3} / \mathbf{h}\right)\end{array} \\
8,41-10,98\end{array}$} & \multirow{2}{*}{$\begin{array}{c}\text { Simulink } \\
Q_{s}\left(\mathbf{m}^{3} / \mathbf{h}\right) \\
7,87-9,8\end{array}$} \\
\hline \multirow{5}{*}{ 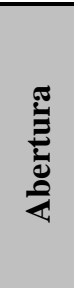 } & $50-40$ & & \\
\hline & $50-30$ & $8,44-12,21$ & $7,87-11,51$ \\
\hline & $50-20$ & $8,41-12,71$ & $7,87-12,68$ \\
\hline & $50-10$ & $8,41-12,91$ & $7,87-12,96$ \\
\hline & $50-0$ & $8,42-12,99$ & $7,87-13,01$ \\
\hline \multirow{5}{*}{ 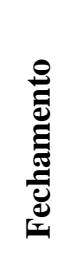 } & $0-50$ & $12,99-8,44$ & $13,01-7,87$ \\
\hline & $0-40$ & $13,01-10,97$ & $13,01-9,8$ \\
\hline & $0-30$ & $13,01-12,2$ & $13,01-11,51$ \\
\hline & $0-20$ & $13-12,72$ & $13,01-12,68$ \\
\hline & $0-10$ & $12,99-12,9$ & $13,01-12,97$ \\
\hline
\end{tabular}

Fonte: Autor

Da mesma forma que para os testes dinâmicos na bomba, foram comparados os resultados da curva dinâmica obtida da vazão. Na Figura 4-12 pode-se ver o resultado do teste aplicando um degrau negativo, de $50 \%$ para $0 \%$. É necessário lembrar que as válvulas presentes no laboratório são do tipo ar para fechar, portanto $0 \%$ corresponde a ter a válvula totalmente aberta.

Figura 4-12 Comportamento da vazão aplicando um degrau de 50\% para 0\% na válvula com gaxetas de teflon.

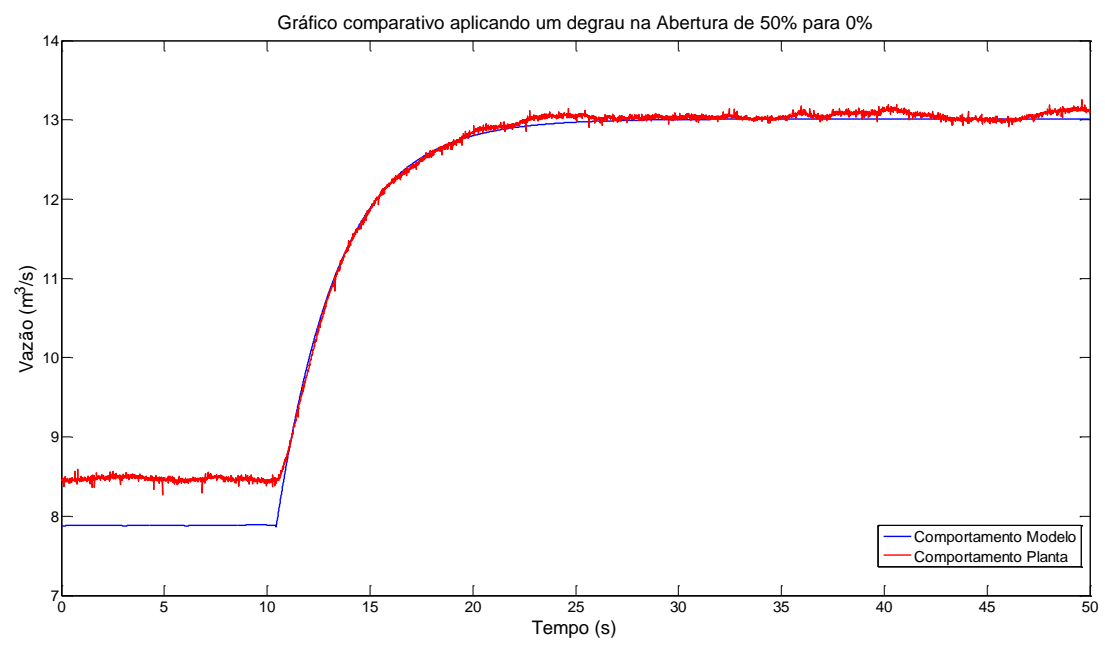

Fonte: Autor 
Foram feitos os mesmos testes aplicando-se degraus positivos na válvula para testar o comportamento quando a válvula está sendo fechada. Na Figura 4-13 se pode ver o comportamento que tem a vazão quando é aplicado um degrau de $0 \%$ para $50 \%$ na abertura da válvula.

Figura 4-13 Comportamento da vazão aplicando um degrau de $0 \%$ para $50 \%$ na válvula com gaxetas de teflon.

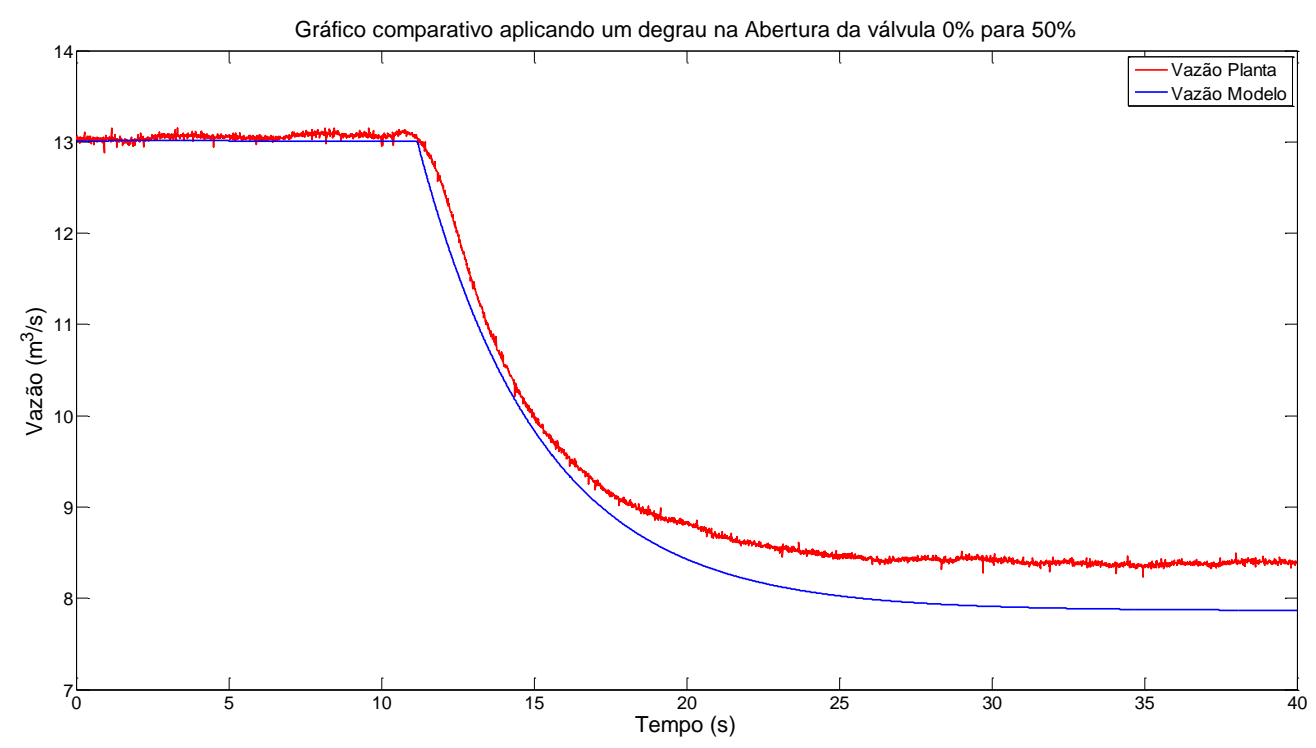

Fonte: Autor

Pode-se ver nos gráficos das Figuras 4-12 e 4-13 que a curva varia no instante da aplicação do degrau, portanto não foi considerado nenhum atraso de transporte. O erro nos valores que se apresentam nesta válvula é menor do que na válvula com gaxetas de grafite. 


\subsubsection{Comportamento dinâmico da válvula com gaxetas de grafite}

Foram feitos testes de abertura e fechamento da válvula e foram comparados com os resultados obtidos no modelo feito em Simulink ${ }^{\circledR}$, os resultados obtidos podem ser vistos na Tabela 4-7.

Tabela 4-7 Comportamento dinâmico da válvula com gaxetas de grafite aplicando sinais em degrau

\begin{tabular}{|c|c|c|c|}
\hline \multicolumn{2}{|c|}{$\begin{array}{c}\text { Sinal de da válvula } \\
\text { de controle }(\%)\end{array}$} & \multirow{2}{*}{$\begin{array}{c}\begin{array}{c}\text { Planta } \\
Q_{p}\left(\mathbf{m}^{3} / \mathbf{h}\right)\end{array} \\
9,9-11,59\end{array}$} & \multirow{2}{*}{$\begin{array}{l}\text { Simulink } \\
Q_{s}\left(\mathbf{m}^{3} / \mathbf{h}\right) \\
7,74-9,92\end{array}$} \\
\hline \multirow{5}{*}{ 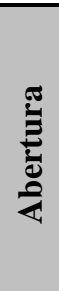 } & $50-40$ & & \\
\hline & $50-30$ & $9,87-12,65$ & $7,74-11,6$ \\
\hline & $50-20$ & $9,91-12,99$ & $7,74-12,73$ \\
\hline & $50-10$ & $9,9-12,99$ & $7,74-13,01$ \\
\hline & $50-0$ & $9,89-13,01$ & $7,74-13,01$ \\
\hline \multirow{5}{*}{ 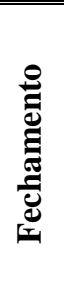 } & $0-50$ & $13,01-9,89$ & $13,01-7,74$ \\
\hline & $0-40$ & 13-11,6 & $13,01-9,92$ \\
\hline & $0-30$ & $13,01-12,63$ & $13,01-12,73$ \\
\hline & $0-20$ & $12,98-12,99$ & $13,01-13,01$ \\
\hline & $0-10$ & $13,01-13$ & $13,01-13,01$ \\
\hline
\end{tabular}

Fonte: Autor

Na Figura 4-14 se pode ver o comportamento dinâmico da válvula com gaxetas de grafite aplicando-se um degrau de $0 \%$ para $50 \%$. 
Figura 4-14 Comportamento da vazão aplicando um degrau de $0 \%$ para $50 \%$ na válvula com gaxetas de grafite

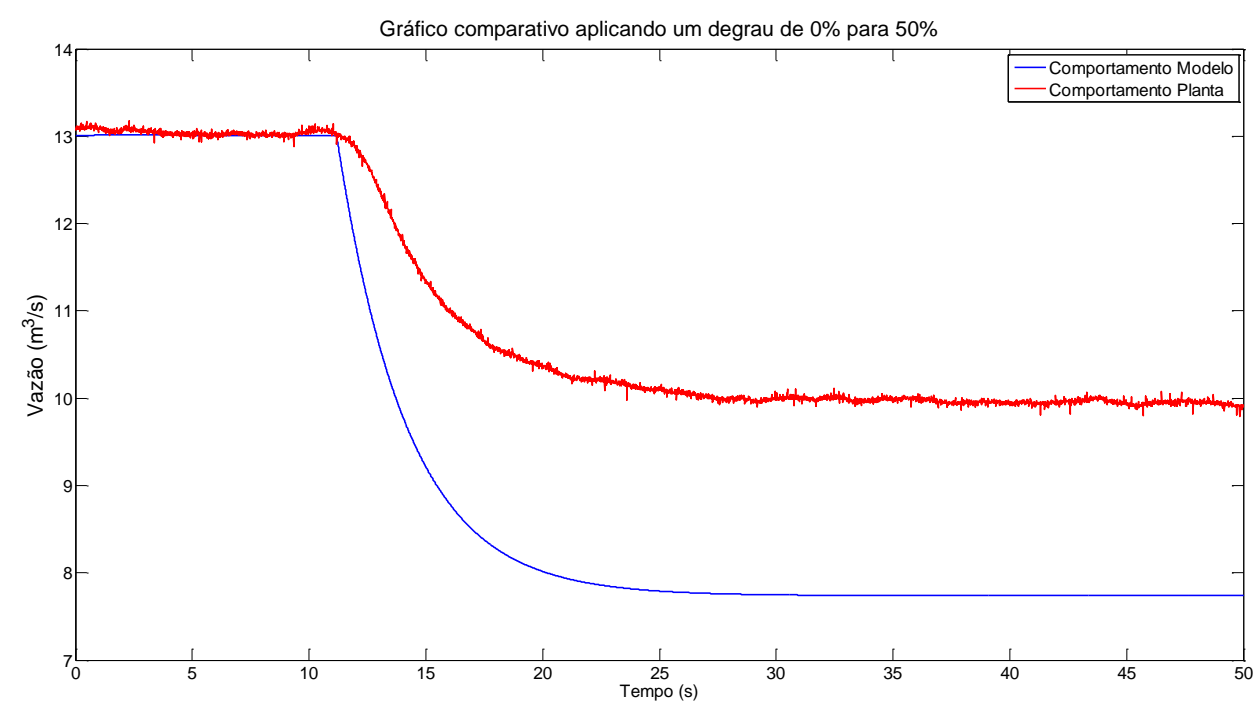

Fonte: Autor

O degrau foi aplicado em $t=10 \mathrm{~s}$. A resposta apresentou erros grandes, mas não apresentou um erro considerável na dinâmica, repetiu-se o teste aplicando-se um degrau negativo de $50 \%$ para $0 \%$, os resultados podem ser vistos na Figura 4-15.

Figura 4-15 Comportamento da vazão aplicando um degrau de 50\% para 0\% na válvula com gaxetas de grafite

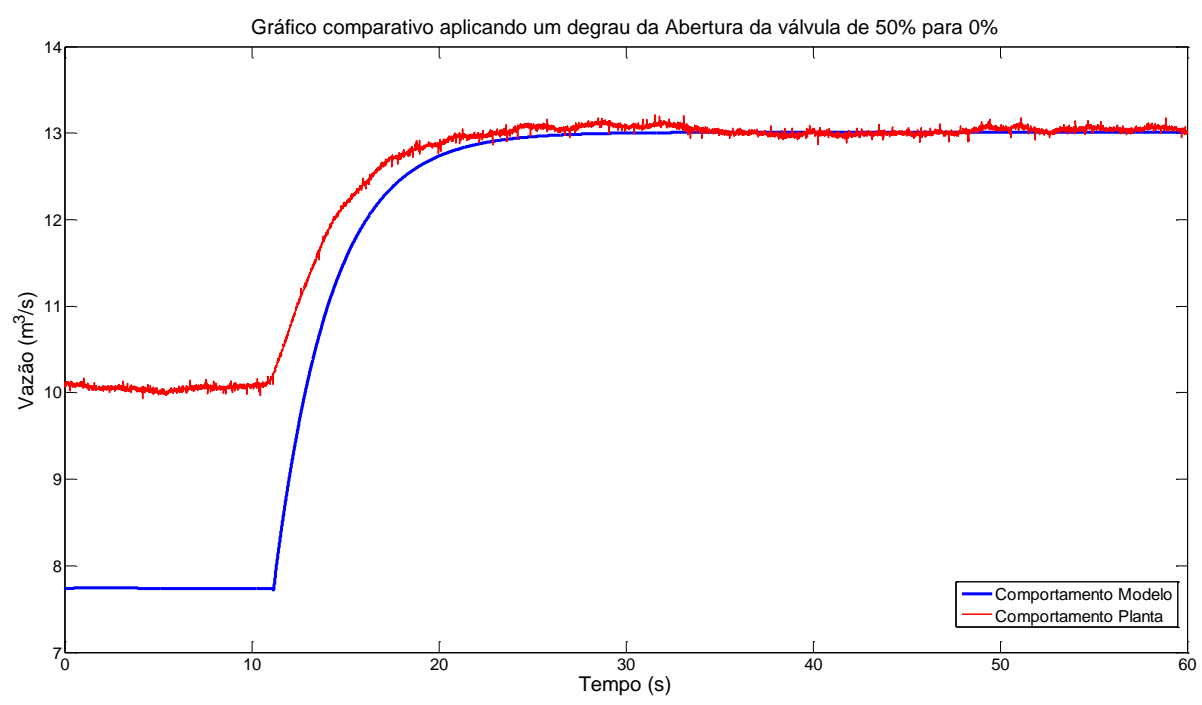

Fonte: Autor 
No teste da Figura 4-15 a dinâmica entre os dois gráficos foi parecida, para os primeiros valores de vazão o erro foi muito grande.

Em geral, os erros para todos os testes realizados na bomba foram pequenos, nas duas válvulas se apresentaram erros bem maiores. Com as manutenções realizadas não se encontrou a fonte do problema, ainda é necessário realizar manutenções adicionais, como nos atuadores I/P e na válvula com gaxetas de teflon. Como se falou anteriormente é necessário adicionar medidores de pressão diferencial nas válvulas para realizar a validação dos valores de $C v$ delas, pois de fato não se tem certeza onde está a fonte do problema.

\subsection{Validação do controle e variabilidade do processo}

Por causa do efeito do atrito, a variável controlada gera oscilações em torno do valor de set-point. No trabalho de (CASTRO, 2013) estudaram-se dois modelos de atrito para as válvulas de controle presentes no laboratório, estes modelos foram aplicados no modelo geral da planta e foram realizados testes para estudar a variabilidade que apresenta o modelo comparado com a planta real.

Foram aplicados valores de set-point na vazão iniciando em $55 \%$ da vazão, seguido de dois degraus positivos de $5 \%$ adicionais e terminando com dois degraus negativos para chegar de novo em 55\%, a duração de cada patamar foi de 1200s com o objetivo de observar as possíveis oscilações na vazão. Na Figura 4-16 se apresenta o resultado obtido aplicando o sinal de set-point na planta e no modelo de Kano para a válvula com gaxetas de teflon e na Figura 4-17 se apresenta o sinal de controle obtido no acompanhamento do set-point. A sintonia que se trabalhou foi a mesma que está na planta, para manter homogeneidade do modelo com a planta real.

A válvula com gaxetas de grafite está apresentando problemas de funcionamento e no momento de realizar testes comparativos não se obtiveram os resultados desejados, portanto não foi possível realizar testes da planta. Foram utilizados dados obtidos no trabalho de (CASTRO, 2013) para realizar as comparações com esta válvula. 
Figura 4-16 Acompanhamento do set-point da válvula com gaxetas de teflon

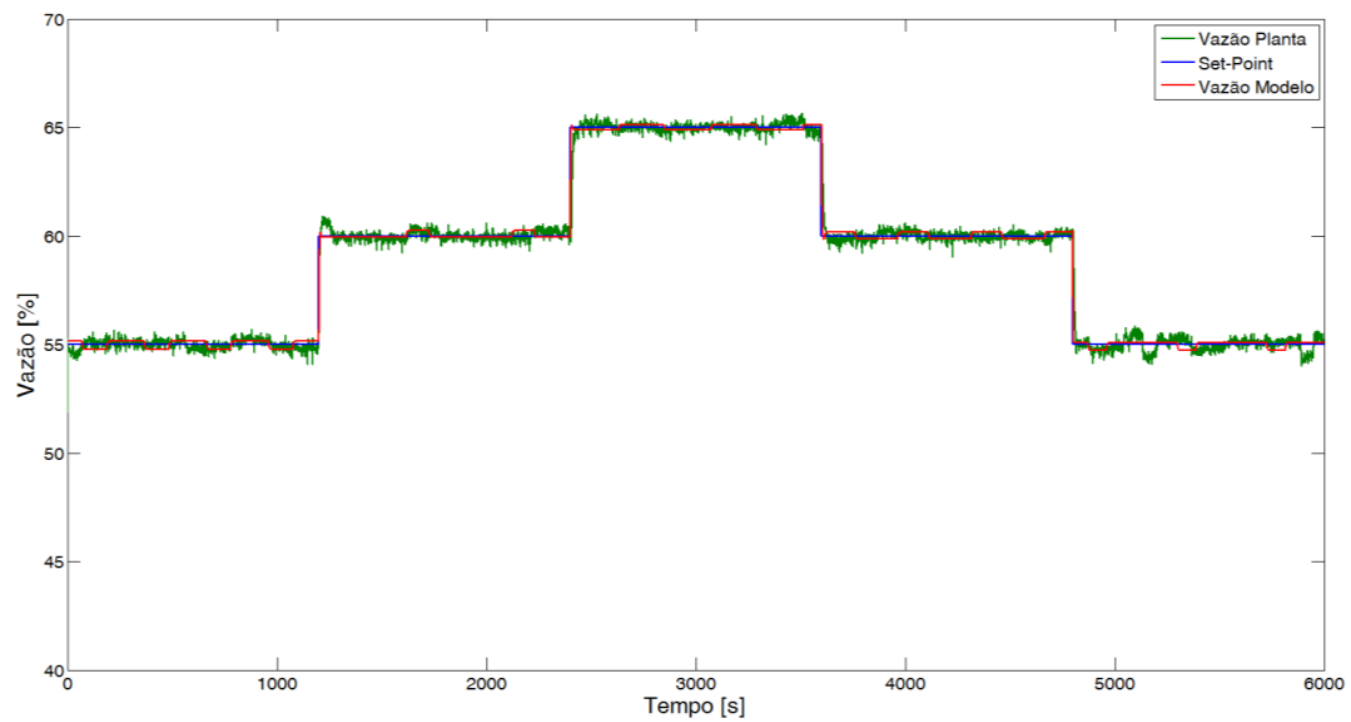

Fonte: Autor

Figura 4-17 Sinal de controle

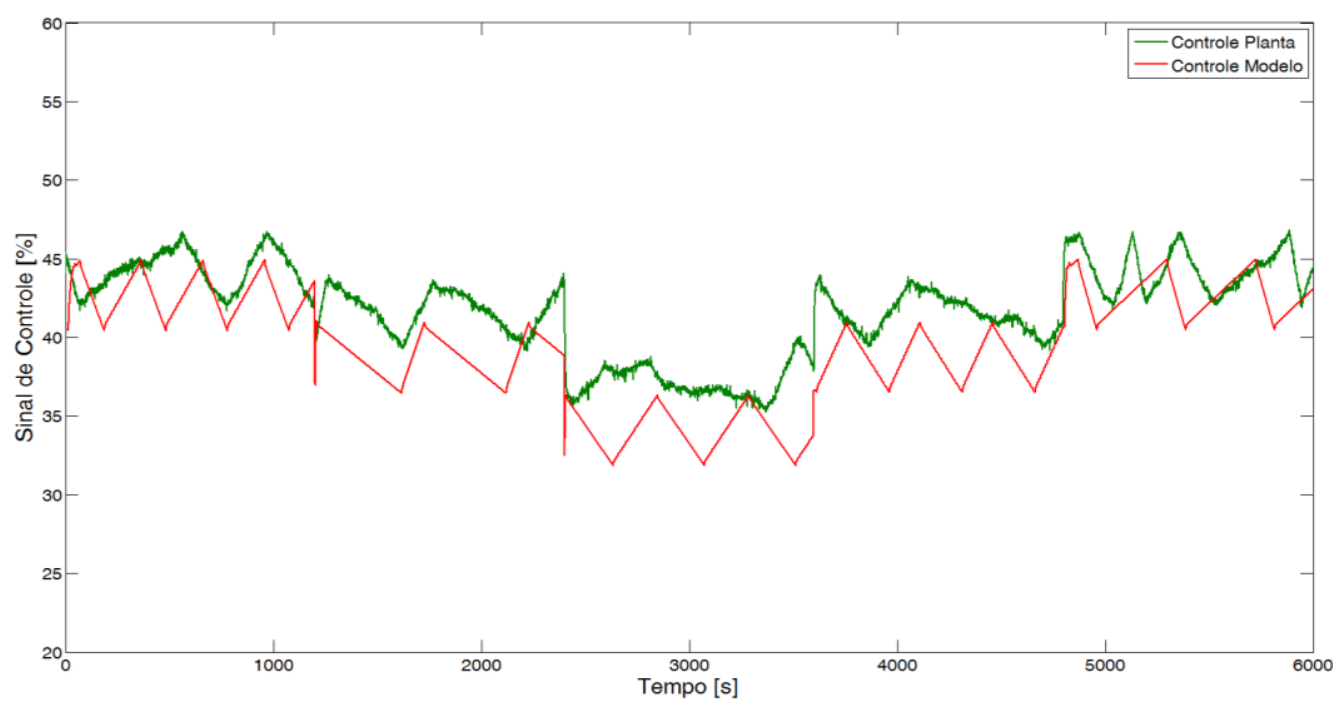

Fonte: Autor 
No sinal de vazão o modelo acompanhou o set-point e teve uma boa representação da variabilidade no processo. Houve um erro no sinal de controle, já era de se esperar devido ao fato nos testes dinâmicos se apresentarem erros na vazão.

Enviou-se o mesmo sinal de set-point com a válvula com gaxetas de grafite, os resultados se apresentam nas Figuras 4-18 e 4-19.

Figura 4-18 Acompanhamento do set-point da válvula com gaxetas de grafite

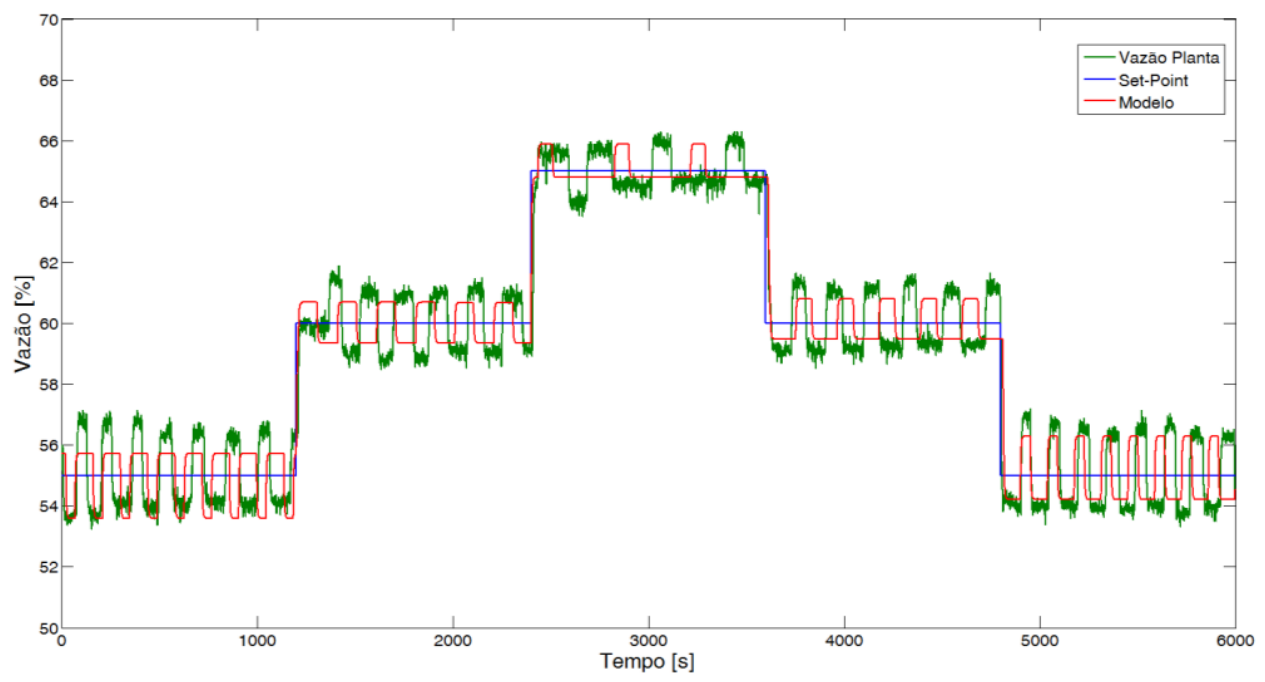

Fonte: Autor

Figura 4-19 Sinal de controle

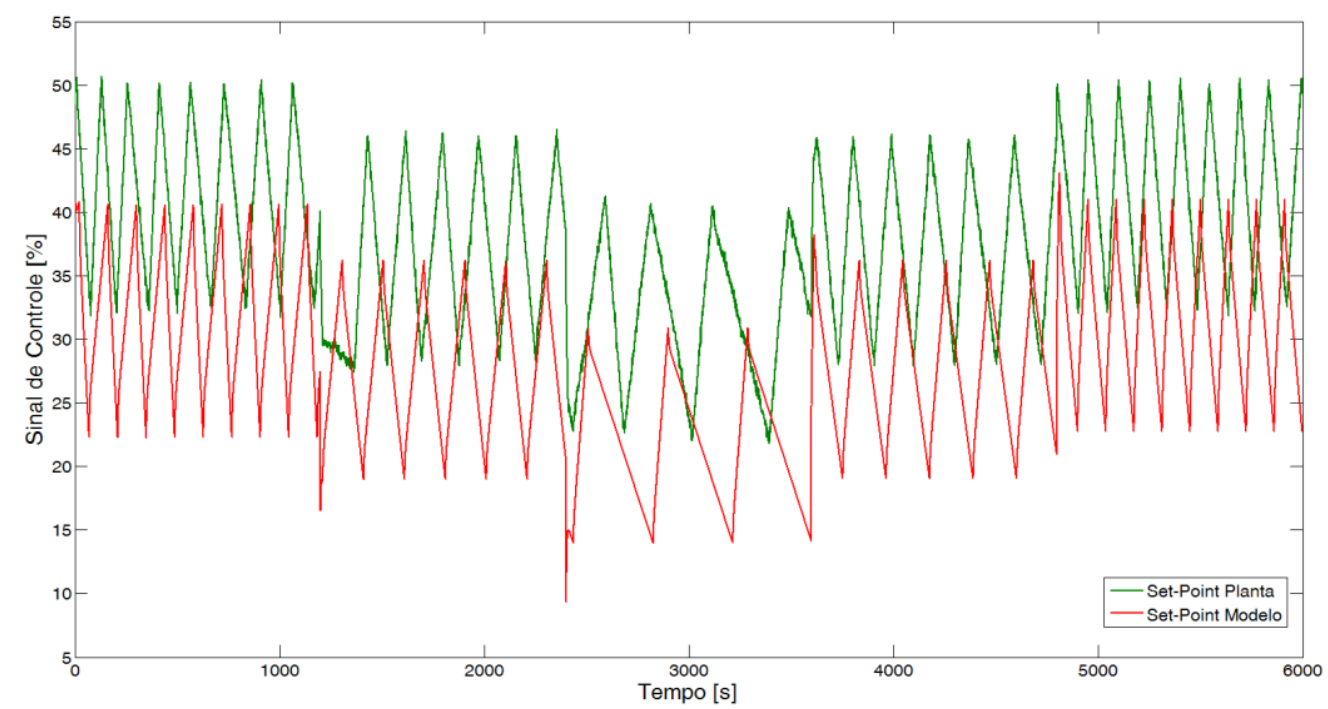

Fonte: Autor 
Da mesma forma que na válvula com gaxetas de teflon, apresentou-se um erro no sinal de controle. Neste caso foi maior comparado com a válvula com gaxetas de teflon como era de se esperar, o controle fez um bom acompanhamento do set-point e representou bem a variabilidade no processo, a variabilidade é maior neste caso, pois o $S$ nesta válvula é maior que da válvula com gaxetas de teflon.

Foi aplicado o mesmo sinal para o modelo de Karnopp, nas Figuras 4-20 e 4-21 podese ver a resposta obtida para o modelo da válvula com gaxetas de teflon.

Figura 4-20 Acompanhamento do set-point da válvula com gaxetas de Teflon

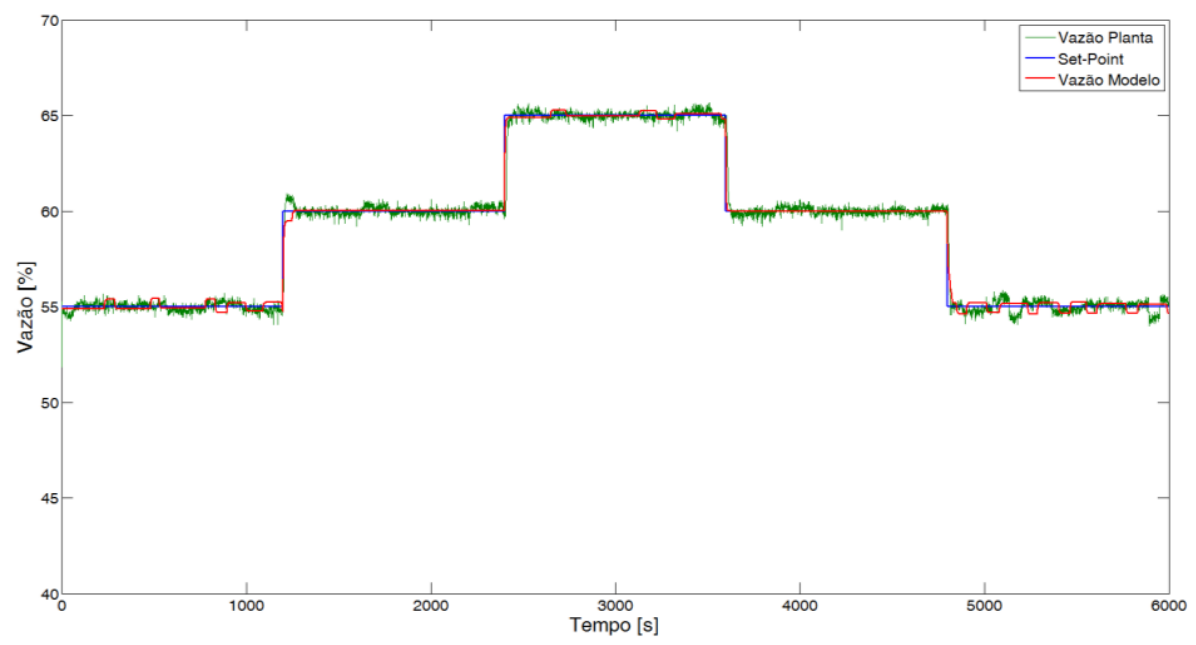

Fonte: Autor

Figura 21 Sinal de Controle

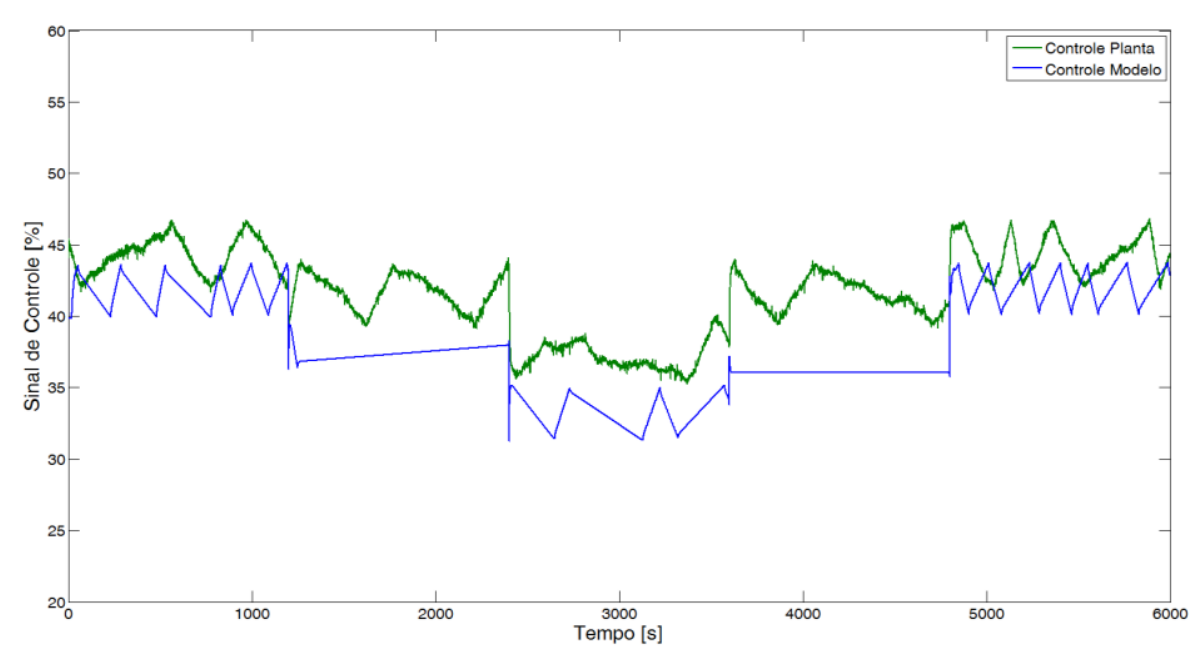

Fonte: Autor 
O modelo acompanhou bem o set-point e teve uma boa representação da variabilidade do processo. Da mesma forma que no modelo de Kano, observou-se um erro no sinal de controle. Além disso, para alguns trajetos parece que o modelo de Kano representou melhor o sinal de controle da planta.

Nas Figuras 4-22 e 4-23 se apresentam os gráficos correspondentes à válvula com gaxetas de grafite.

Figura 4-22 Acompanhamento do set-point da válvula com gaxetas de Grafite

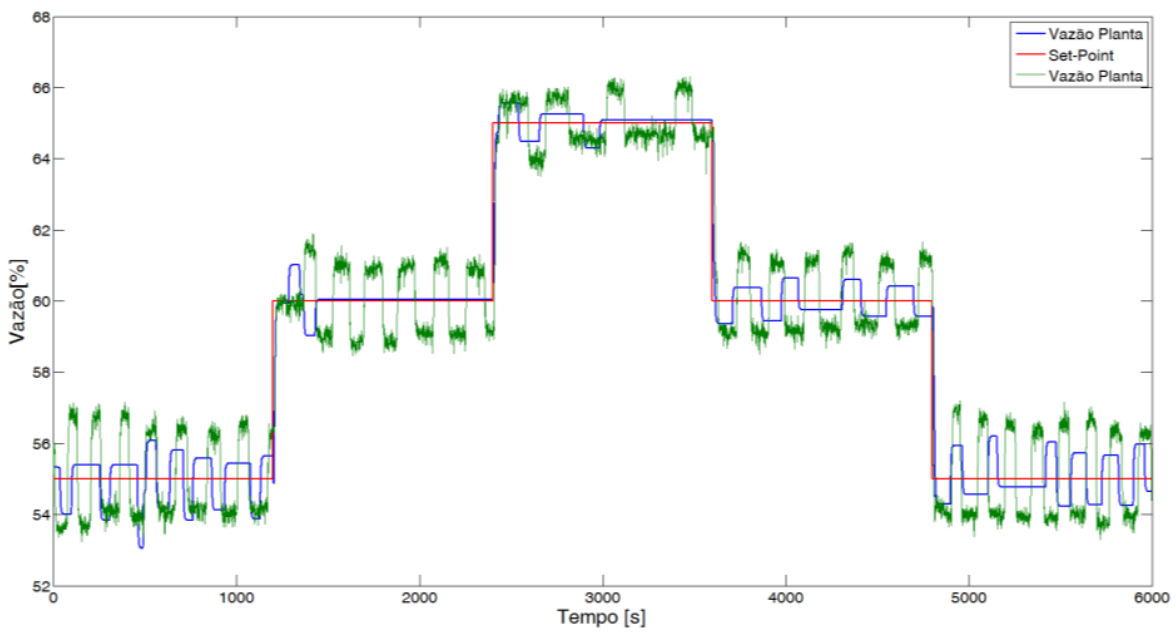

Fonte: Autor

Figura 4-23 Sinal de Controle

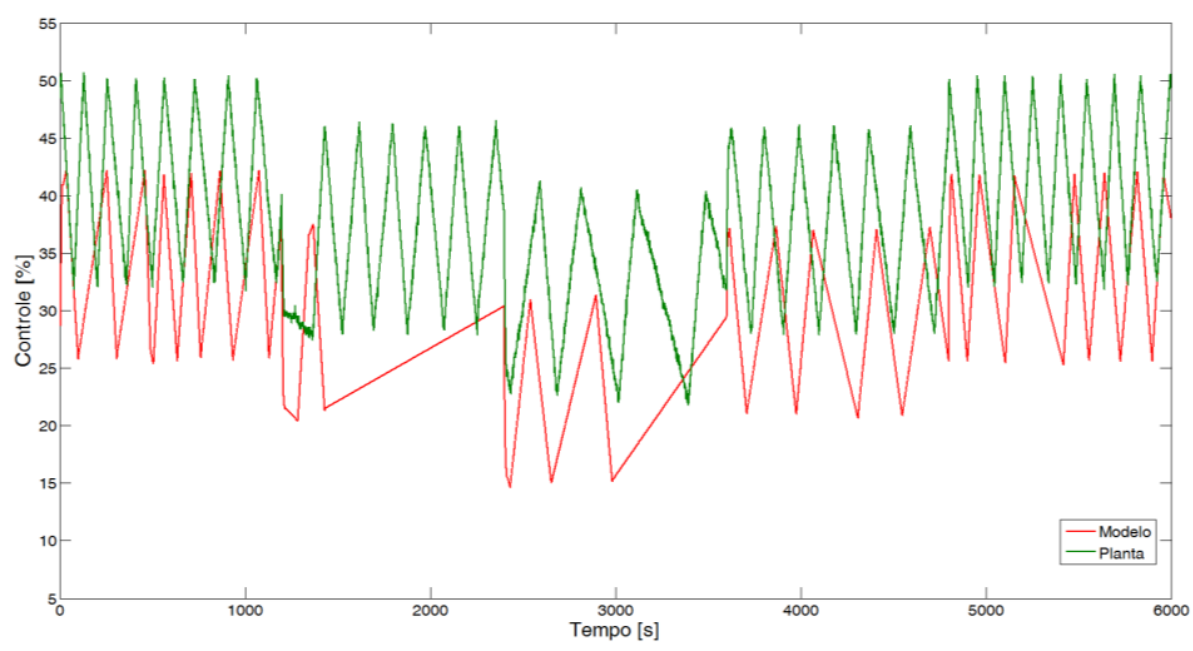

Fonte: Autor 
O modelo de Karnopp para a válvula com gaxetas de grafite acompanhou bem o setpoint e teve uma boa representação da variabilidade do processo. Teve alguns momentos onde não acompanhou bem a variabilidade do processo, mas em geral os resultados foram aceitáveis. O sinal de controle teve um erro como era de se esperar.

Em geral os dois modelos representaram bem a variabilidade do processo, que era um dos pontos mais importantes da modelagem, devido a que no modelo da planta vai poder ser possível aplicar técnicas de compensação de variabilidade na vazão. 


\section{Conclusões}

Neste capítulo são apresentadas as conclusões obtidas durante o processo de modelagem da planta. As primeiras são referentes à modelagem estática e dinâmica da planta. Em seguida se realiza uma análise dos resultados obtidos com os modelos de atrito das válvulas e finalmente se fala sobre algumas propostas de trabalhos futuros.

\subsection{Modelagem estática e dinâmica}

A modelagem realizada neste trabalho representou as perdas de carga para os instrumentos da planta e representou o valor de vazão dependendo da perda de carga no processo, porém, é necessário adicionar instrumentos adicionais na planta para validar o modelo. Somente realizando uma validação dos valores de vazão e posição não é suficiente, é necessário adicionar medidores de pressão diferencial nas válvulas de controle para validar a modelagem delas, já que o erro que se apresenta no modelo pode ser causado por problemas nas válvulas. Nos testes em regime estacionário e transitório na bomba não se apresentaram erros grandes, portanto é pouco provável que o problema esteja na bomba. Fontes de erro possíveis foram as válvulas de controle ou os transmissores de vazão, devido ao teste realizado com o medidor de ultrassom que apresentou erros muito grandes relativos aos transmissores de vazão instalados na planta.

\subsection{Modelos de atrito nas válvulas de controle}

Os modelos de atrito testados em (CASTRO, 2013) apresentaram bons resultados ao implementá-los no modelo geral da planta, porém, eles apresentaram algumas diferenças com as assinaturas atuais das válvulas, devido a que esses modelos estão definidos para válvulas que têm uma curva de assinatura uniforme, isto quer dizer, que o $S$ é o mesmo ao abrir ou ao fechar a válvula. As válvulas presentes no laboratório não estão apresentando este comportamento uniforme, a não uniformidade nas válvulas pode ser causada por falta de manutenção nelas ou em algum instrumento relacionado a elas. Já se realizou manutenção na válvula com gaxetas de grafite e não solucionou o problema, por tanto é necessário revisar os 
instrumentos ligados a elas. Em geral os modelos apresentaram resultados bons e é possível trabalhar com eles para realizar testes de compensação de atrito nas válvulas e testes de variabilidade.

\subsection{Propostas de trabalhos futuros.}

- Com relação ao modelo de perdas de carga, não foi possível validar a curva de $C v$ relativo das válvulas de controle, é necessário adicionar medidores de pressão diferencial nas válvulas e fazer uma validação da curva das válvulas.

- Os modelos de atrito apresentaram bons resultados. O modelo de Karnopp tem um passo de integração muito pequeno, portanto ele demora muito tempo para realizar os testes. Para realizar um teste de 60 segundos o modelo demora em torno de 25 minutos realizando a simulação. Seria muito importante implementar um algoritmo de otimização do modelo para torna-lo mais rápido.

- O modelo representou bem a variabilidade do processo. No trabalho de (CASTRO, 2013) e (BAEZA, 2013) foram aplicados compensadores de atrito para diminuir a variabilidade na vazão, é possível aplicar as técnicas aplicadas nesses trabalhos no modelo da planta e fazer comparações dos resultados obtidos. 


\section{REFERÊNCIAS}

AGUIRRE, L. A. Introdução à identificação de sistemas - técnicas lineares e não-lineares. 3. Ed. Belo Horizonte: Editora UFMG, 2007.

ALVARADO, M. C. Identificação e controle preditivo de uma planta-piloto de neutralização de pH. Tese (Mestrado) - Escola Politécnica da Universidade de São Paulo. Departamento de Telecomunicações e Controle, 2013.

ARAGÓN, C.; ARAGÓN, G.; CANALES, A.; Test Bench for Process Control Valves. Fourth Congress of Electronics, Robotics and Automotive Mechanics. [S L]. 2007.

ASCOVAL. Catálogo geral, linha controle de fluidos. [S.L.]: Catálogo 31B, 2011.

BAEZA, J. R. Controle Não Linear Aplicado a Malhas de Controle com Válvulas de Alto Atrito. Dissertação (Mestrado) - Escola Politécnica da USP. Departamento de Telecomunicações e Controle., 2013

CHOUDHURY, M. A. A. S; JAIN, M.; SHAH, S. L. Stiction - definition, modeling, detection and quantification. Journal of Process Control, v. 18, p. 232-243, 2008.

CUADROS, M. A. de S. L. Quantificação e Compensação de Atrito em Válvulas de Controle Pneumáticas. Tese (Doutorado) - Centro Tecnológico da Universidade Federal de Espírito Santo, 2011.

DELMÉE, G. J. Manual de medição de vazão. 3. ed. São Paulo: Edgard Blücher, 2003.

FISHER CONTROLS INTERNATIONAL. Control valve handbook. 4. ed. [S.L.]: Fisher Controls International LLC, 2005.

FLUXUS, Technical Specification, Fluxus ${ }^{\circledR}$ G601, 2014. Disponivel em: http://www.flexim.com/files/tsfluxus_g601v1-5-1en_leu.pdf Acceso em: Feb, 2014.

GARCIA, C. Friction model parameter estimation for control valves. 8th IFAC DYCOPS, 2007. 
GARCIA, C. Comparison of friction models applied to a control valves. Control Engineering Practice, v. 16, p. 1231-1243, 2008.

GARCIA, C. Modelagem e simulação. 2. ed. São Paulo: EDUSP, 2009.

HALLIDAY, D; RESNICK, R. Fundamentos de Física. ed. Rio de Janeiro: Livros Técnicos e Científicos, 1996.

KANO, M. et al. Practical model and detection algorithm for valve stiction. In: 7th IFAC DYCOPS. [S.1:s.n.], 2004.

KARNOPP, D. Computer simulation of stick-slip friction in mechanical dynamics system. Journal of Dynamic Systems, Measurement and Control, v. 107, p. 100-103, 1985.

KAYIHAN, A.; DOYLE III, F. J. Friction compensation for a process control valve. Control Engineering Practice, v. 8, p. 799-812, 2000.

KSB. Manual de curvas características, N A2740/42/44.1P/E/S/6, 2009.

LJUNG, L. System Identification: Theory for the user. Prentice Hall, Upper Saddle River, NJ, $2^{\text {nd }}$ edition, 1999.

LUYBEN, W. L. Process modeling, simulation and control for chemical engineers. 2.ed. New York: McGraw Hill, 1990.

MATTOS, E. E.; FALCO, R. Bombas industriais. Rio de Janeiro: JR Editora Técnica, 1989.

ANSI/ISA-5.1 2009. Instrumentation symbols and identification. North Carolina: ANSI/ISA, 2009.

OGATA, K. Engenharia de Controle Moderno. 4. ed. São Paulo: Pearson/Prentice Hall, 2003.

SILVA, B. C.; MORA, J. A. A. Manual de operação da planta de vazão. São Paulo: Escola Politécnica da Universidade de São Paulo, 2013. 
SILVA, B. C.; Avaliação da eficiência de compensadores de atrito aplicados a válvulas de controle. 2013. Dissertação (mestrado) - Escola Politécnica da Universidade de São Paulo, 2013.

TIGRE. Catálogo Técnico Agua Fria Predial. [S.L.]: Tigre, 2008.

TRUNG, N. T.; TRUONG D. T; AHN K. K.; Identification of a Pneumatic Actuator using Non-linear Black-Box Model, International Conference on Control, Automation and Systems, 2011.

VALTEK SURAMERICANA GLS, Manual Válvula de Controle Globo, 2007. Disponível em: http://www.valteksulamericana.com/editor/arquivo/catalogo/GLS_Catalogo_PT.pdf Acesso em: Nov. 2012. 
ANEXO 
ANEXO A - Loop Diagrams da Planta de Vazão (Silva; Mora, 2013)

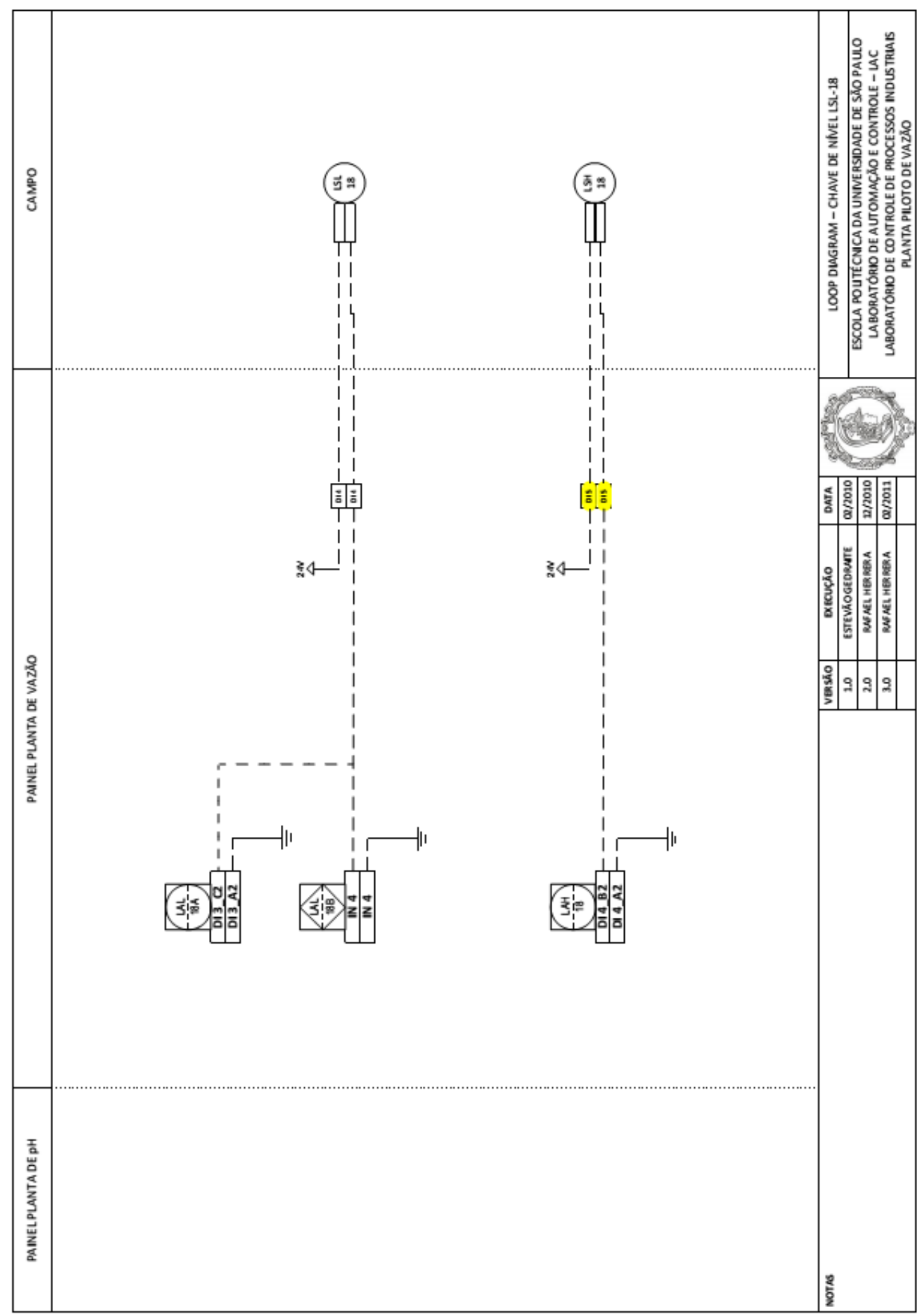




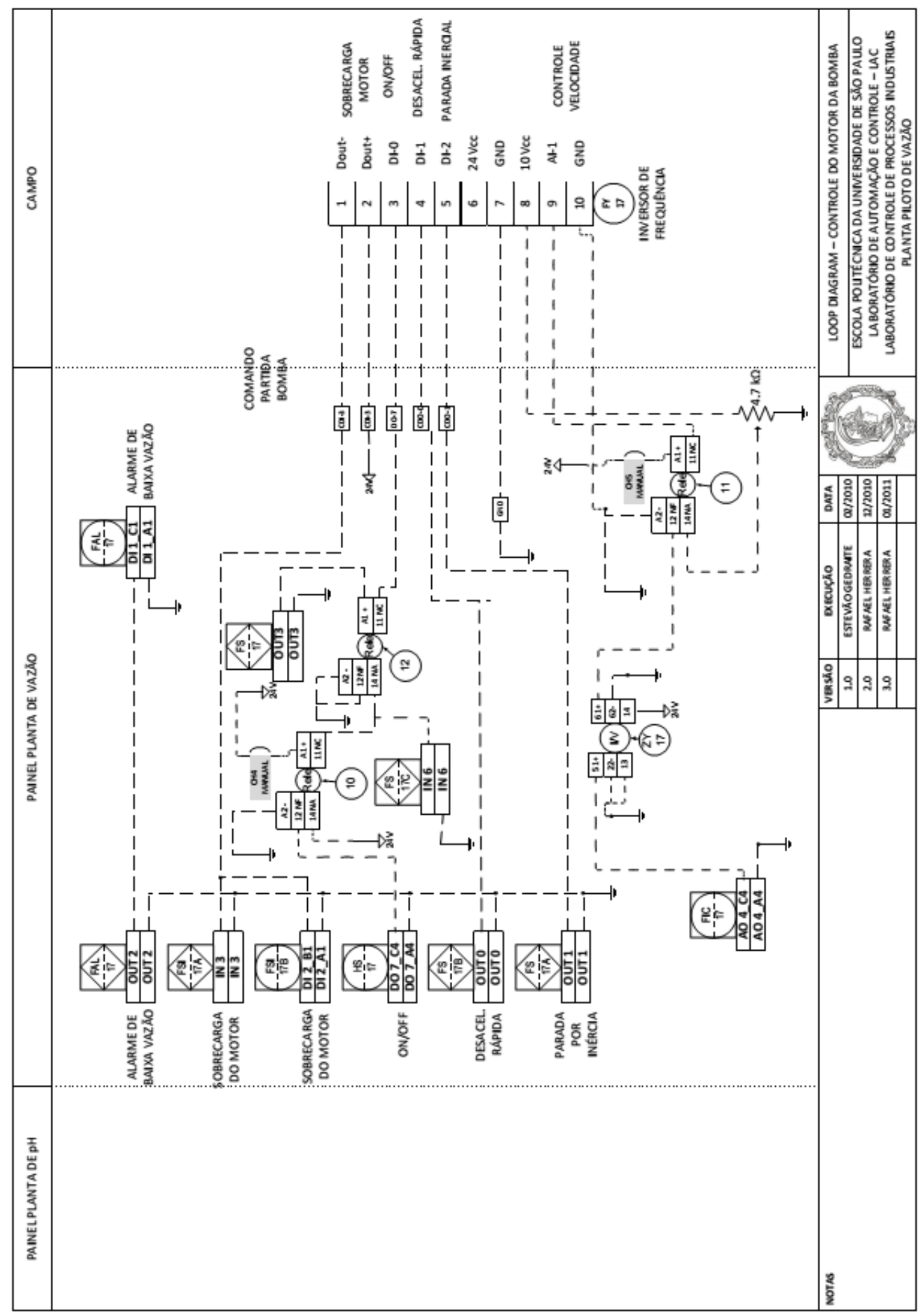




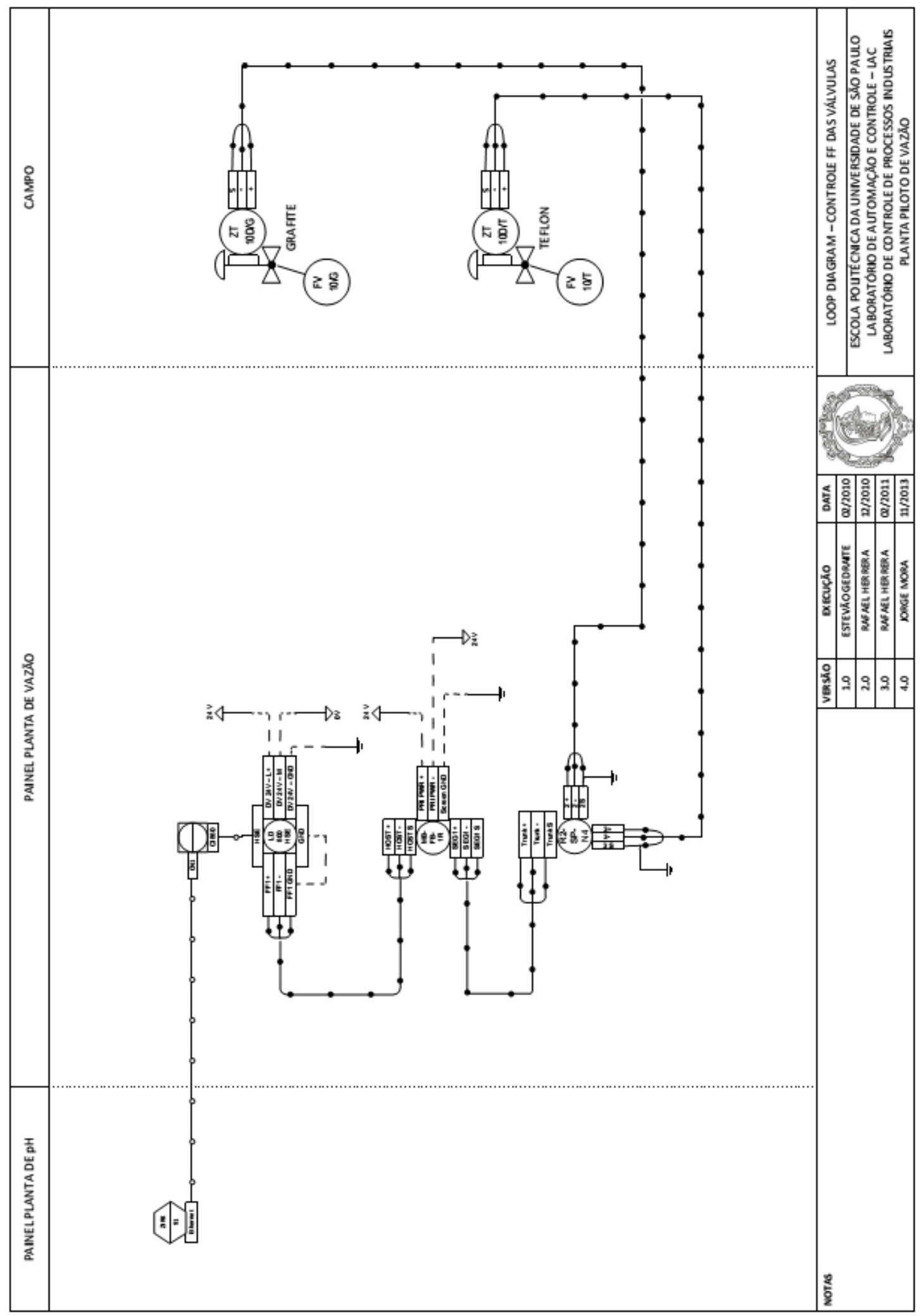




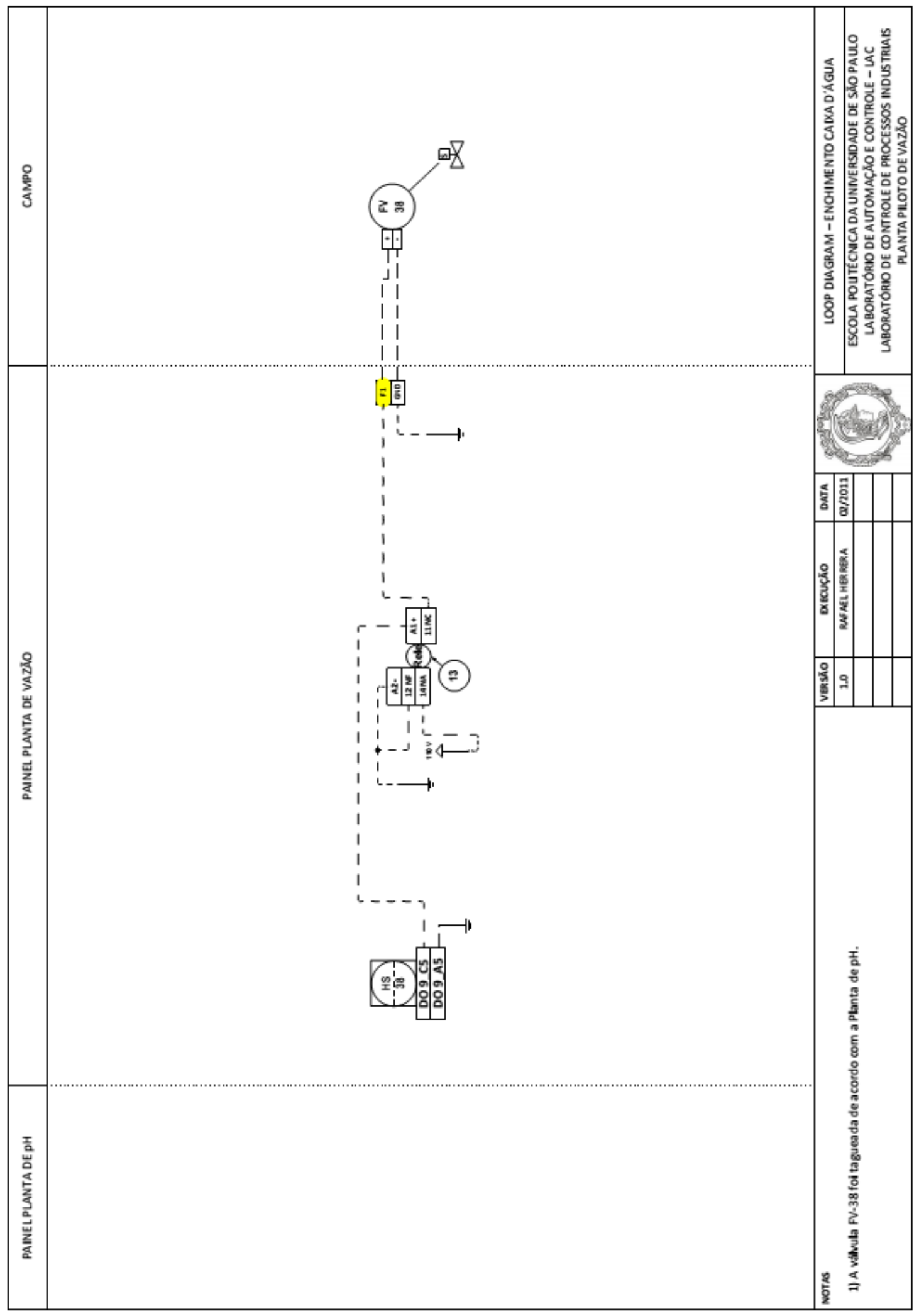




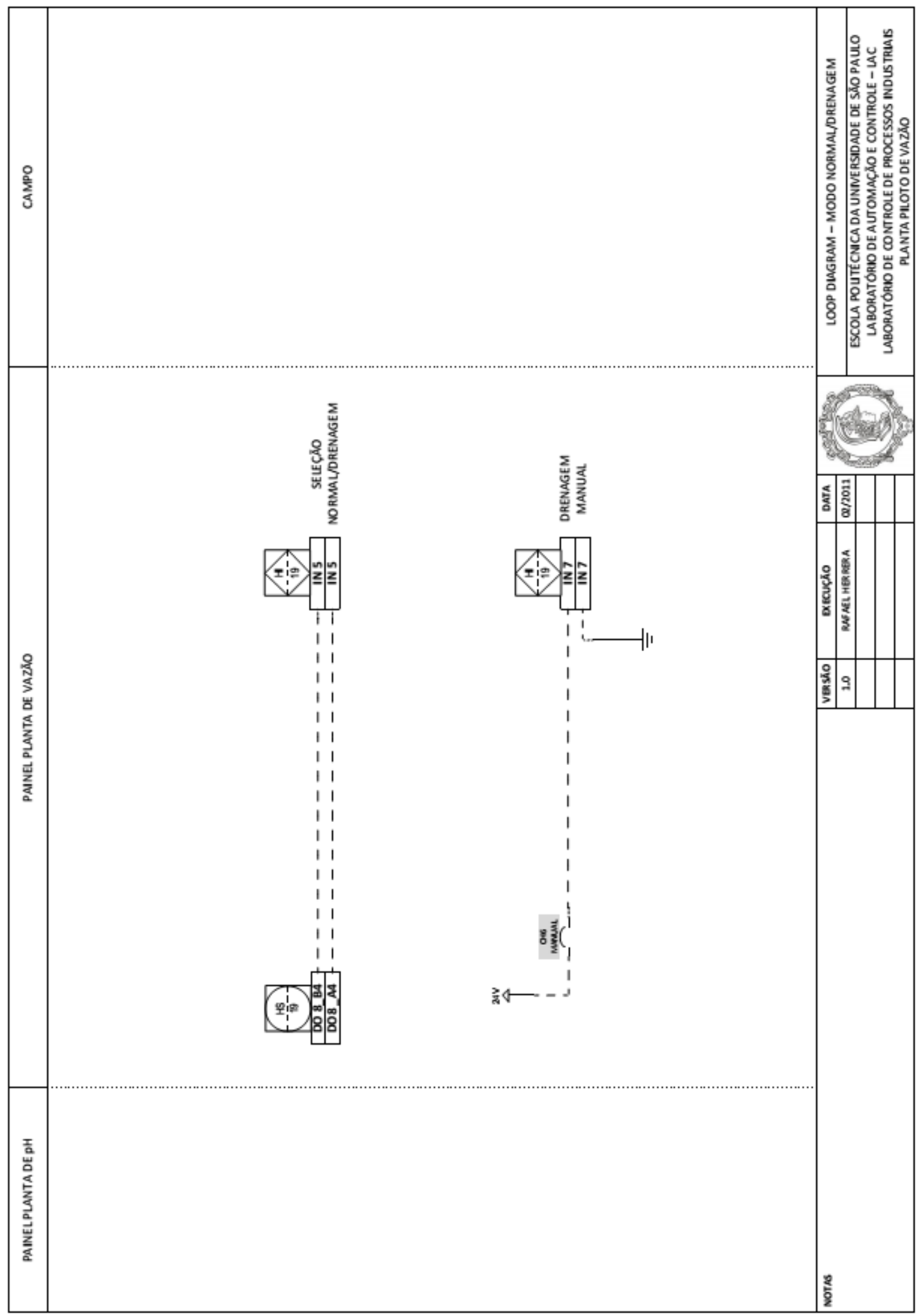




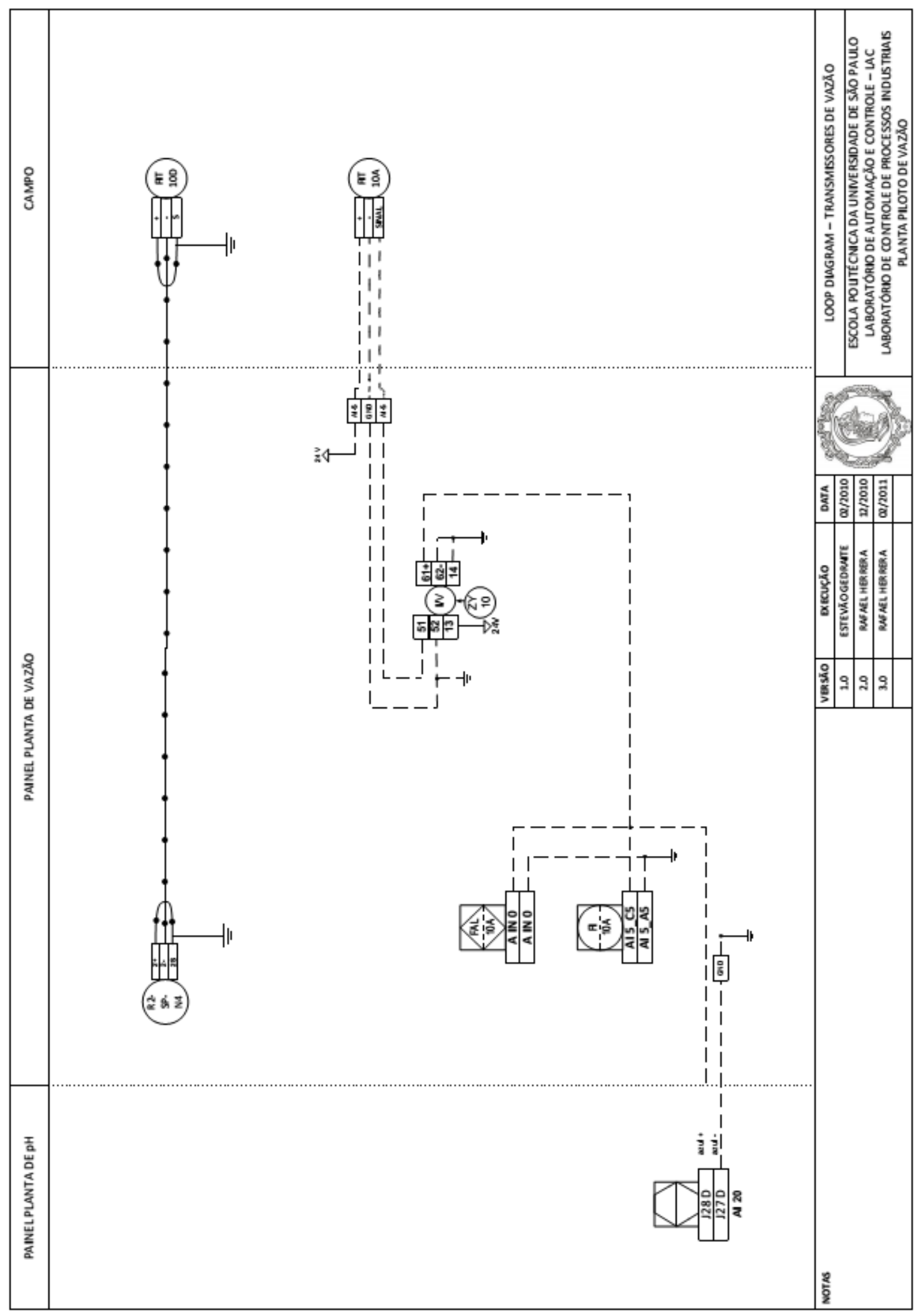




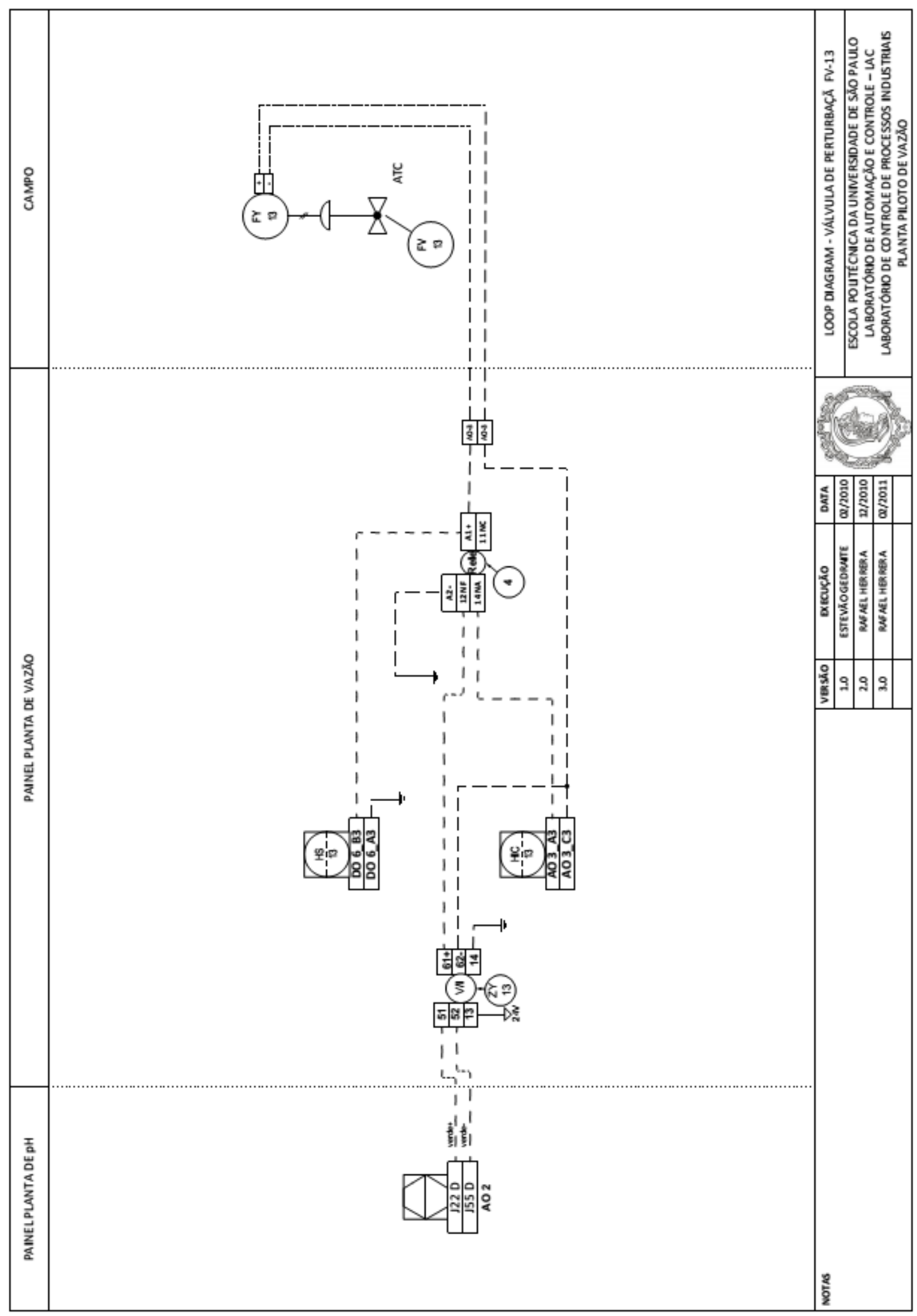




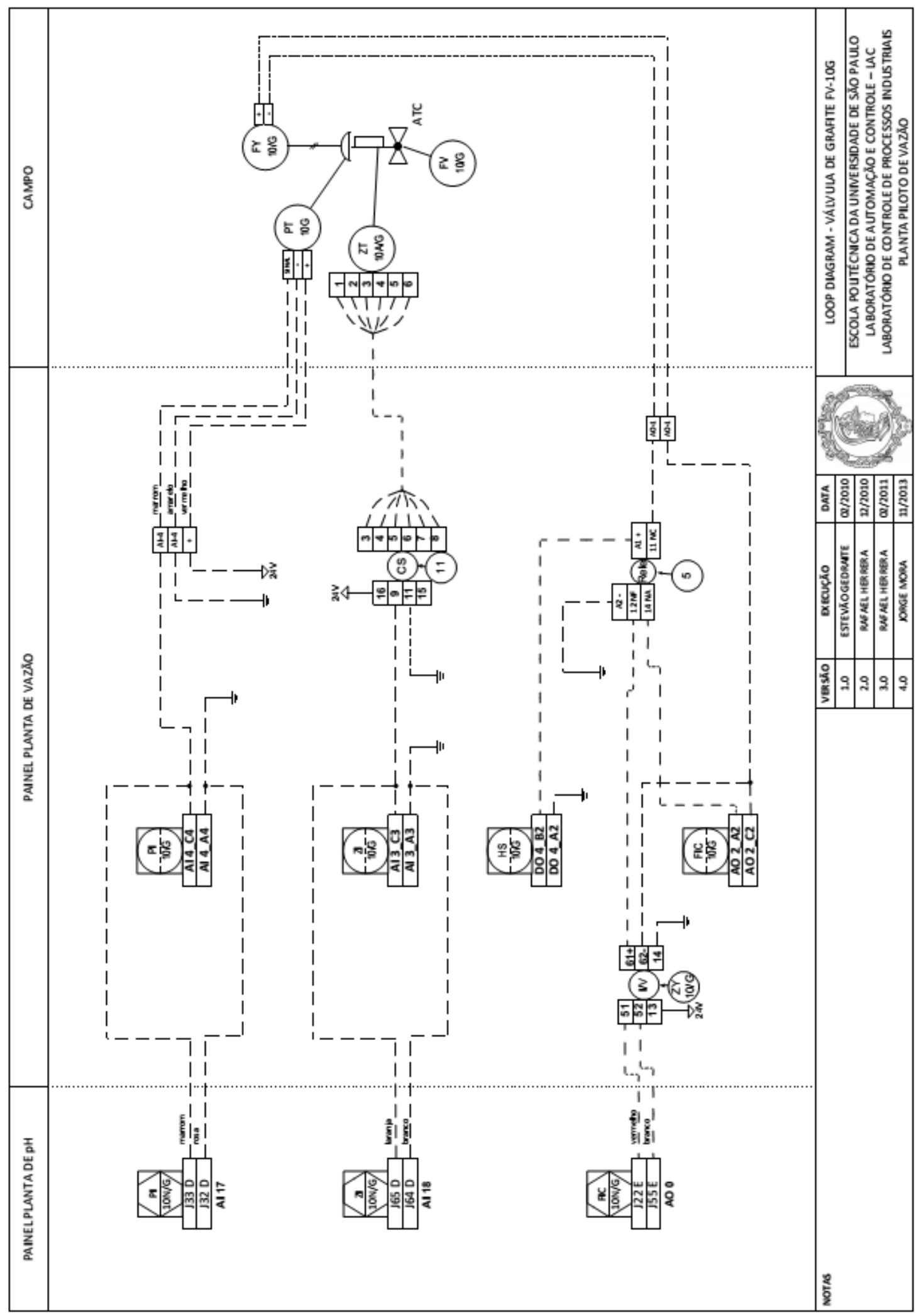




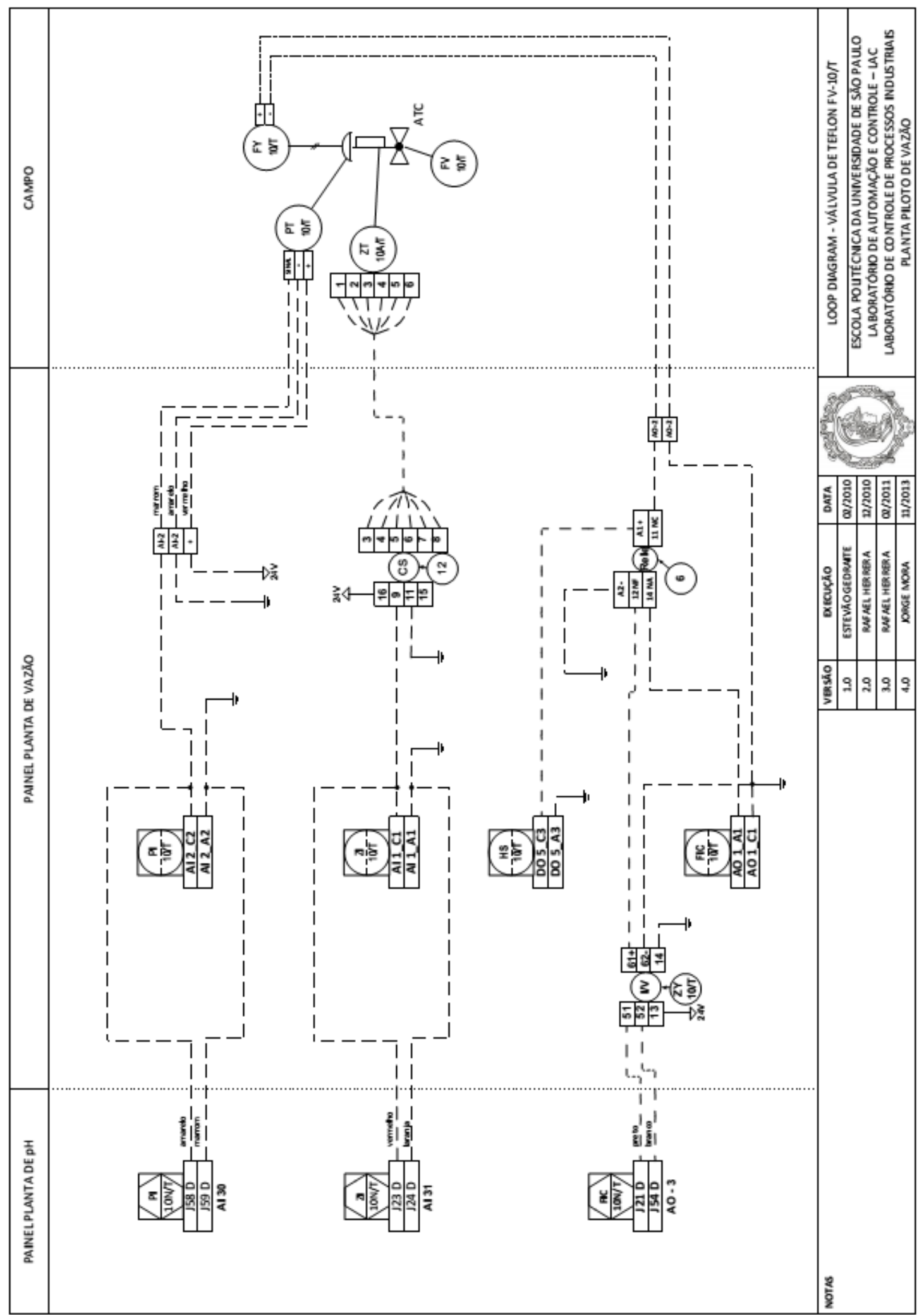




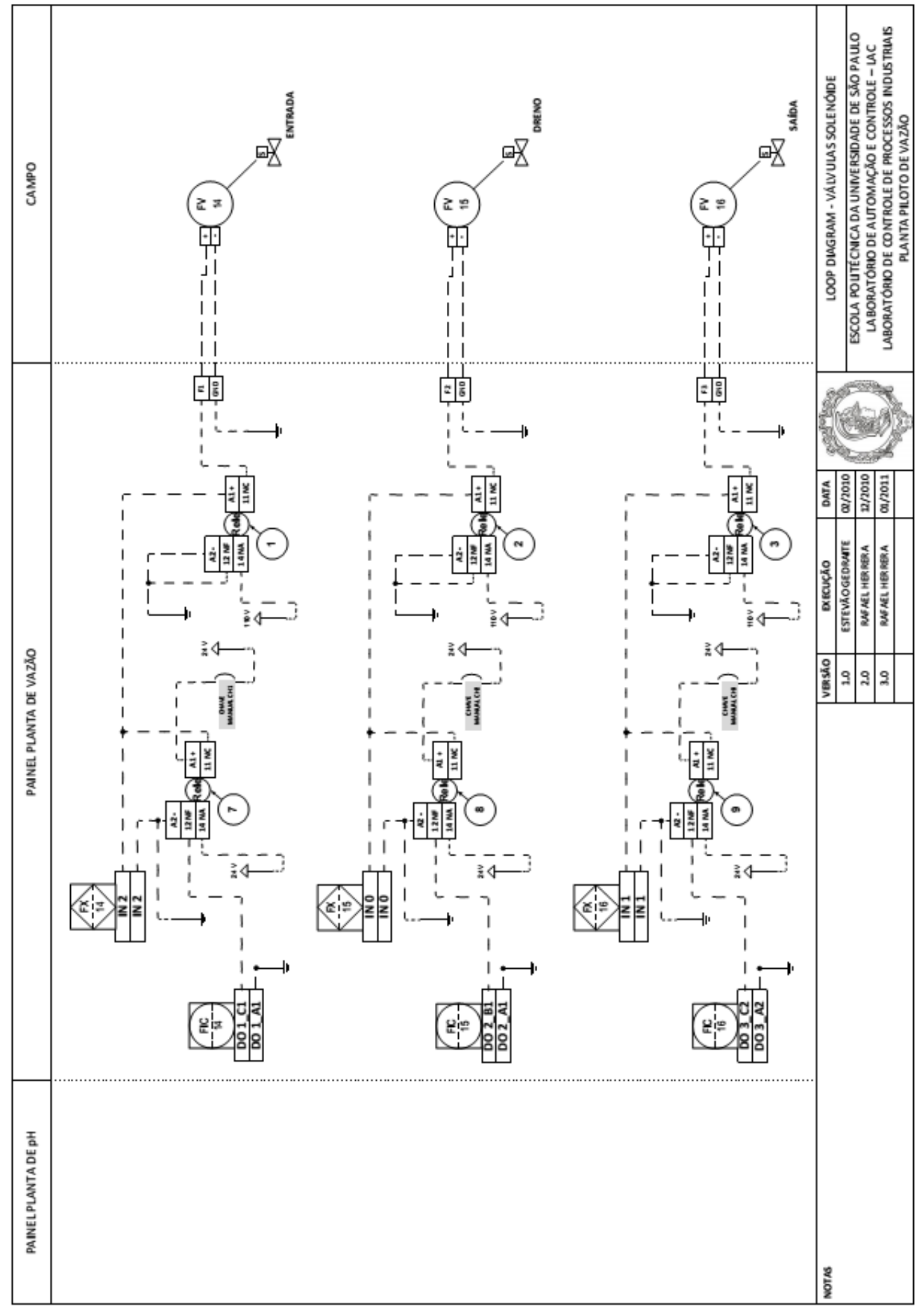




\section{ANEXO B - Ábaco para tubulações de PVC rígido}

(Tigre, 2008)

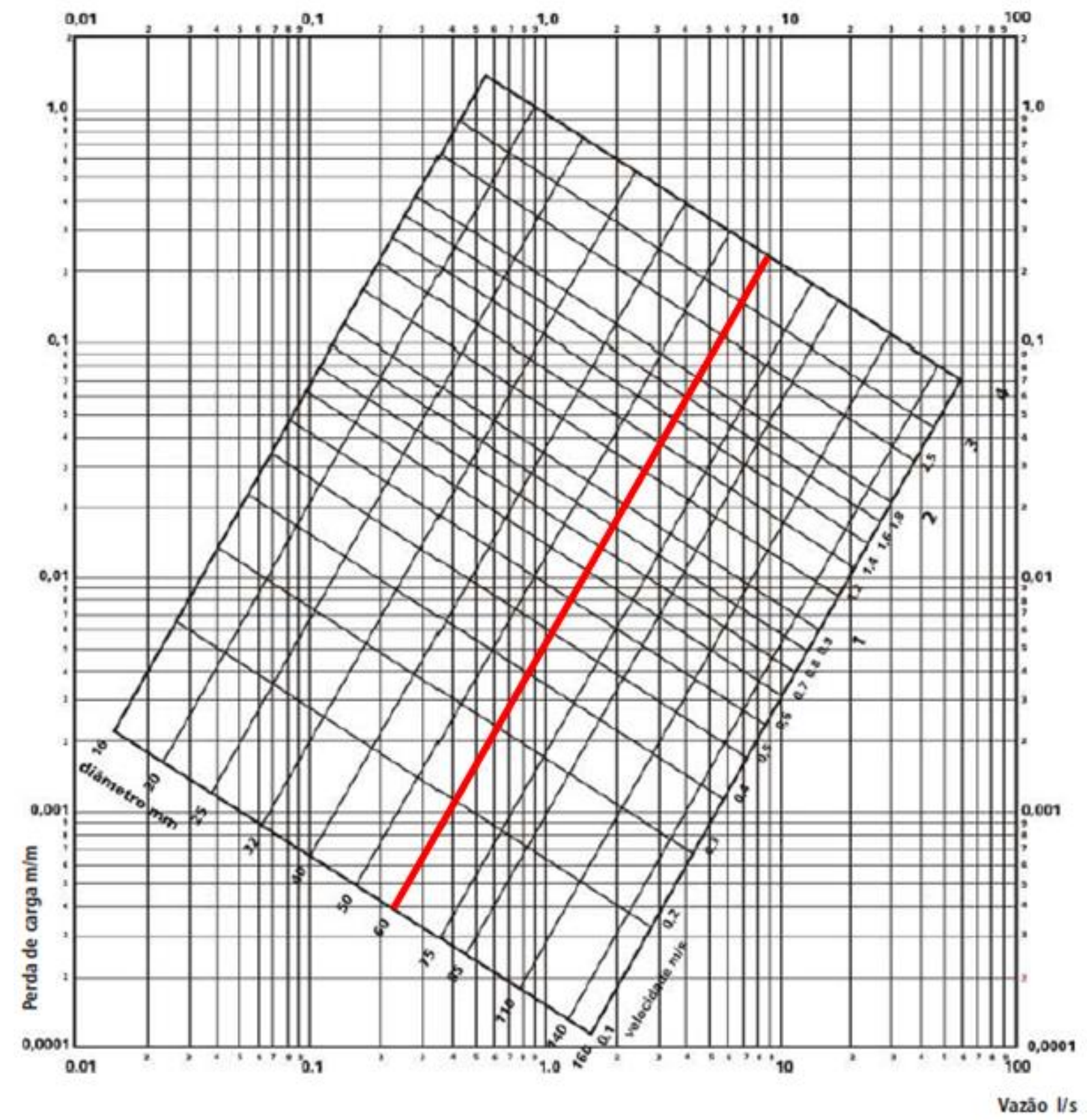


